Ph.D.

PSYCHOLOGY

SHORT TERM MEMORY AND CODING STRATEGIES OF THE DEAF

Graeme Wallace

Abstract

This thesis investigates short term memory processing in orally and manually trained deaf children, as well as in hearing controls. The first two experiments used visual presentation of four- and five-letter sequences. Results were analyzed in terms of the rehearsal strategies, encoding processes and confusions. The results showed not only that the deaf were inferior to the hearing, but that they encoded verbal material differently. Both deaf groups, in contrast to the hearing group who relied mainly on articulatory coding, made extensive use of visual coding with four-letter sequences. The evidence also suggested that with the fiveletter sequences, the orally-trained group used articulatory as well as visual coding, whereas the manual group utilized some other secondary code, which may have been based in part on kinaesthetic cues. The third and final experiment studied the comparative performance of deaf and hearing children on recognition of pictures of faces. For this task, the deaf were superior to the hearing controls. The implications of these findings for short term memory theorists and deaf educators are discussed. 
by

Graeme Wallace

A thesis submitted to the Faculty of Graduate Studies and Research in partial fulfillment of the requirements for the degree of Doctor of Philosophy.

Department of Psychology McGill University

March, 1972 Montreal.

(C) Graeme Wallace 1972 
The main contribution of this thesis is to show that, in short-term recall of visually presented letters, profoundly deaf children rely mainly on a visual shape code, unlike normal hearing children who rely primarily on an articulatory code. However the deaf do make some use of additional codes for longer sequences; those trained in oral communication methods show some evidence for articulatory coding, while those taught by manual methous seem to use a code based in part on finger-spelling movements. These findings have implications concerning both the nature and variety of coding processes in short-term memory, and the conceptual capacities of the profoundly deaf.

I wish to express my sincerest appreciation to my supervisor, Dr. Michael C. Corballis, who was a continual source of guidance, support and encouragement.

The research reported in this thesis was supported by a Defence Research Board Grant (9425-10) to Dr. Dalbir Bindra and Dr. Michael C. Corballis, and was undertaken while the writer held a National Research Council of Canada Postgraduate Scholarship. 
TABLE OF CONTENTS

Page

INTRODUCTION

1

Methods of Deaf Communication 2

Short-term Memory

Memory in the Deaf

EXPERTMENT 1

20

Introduction

20

Method

21

Results

25

Discussion

39

EXPERTMENT 2

43

Introduction

43

Method

44

Results

45

Discussion

EXPERTMENT 3

59

Introduction

59

Method

62

Results

63

Discussion

DISCUSSION

67

APPENDICES 


\section{INTRODUCTION}

This thesis is concerned with how the deaf encode items in short term memory. The topic combines at least two separate lines of research, that on cognitive processes and handicaps in the deaf, and that on encoding of items in short term memory in normal hearing subjects. Conrad (1962, 1964, 1970, 1971; Conrad \& Rush, 1965) foresaw that these apparently disparate areas of research could contribute to each other. The research presented in this thesis attempts to extend and refine his pioneering work. Early in the last decade, it was found that normal hearing subjects often made what appeared to be acoustic confusions in short term recall of verbal items, even if the items were presented visually (Conrad, 1964; Sperling, 1963). This suggested that short term memory may be mediated, at least initially, by some acoustic code. More recent studies suggested that the code may be articulatory (Hintzman, 1965, 1967) or some abstract verbal code (Wickelgren, 1966). They also raised the question of how the profoundly deaf would encode in short term memory, since presumably they are deprived of auditory encoding mechanisms. This question deals with issues both in deaf research and memory research. In deaf research, for example, among the most pervasive questions in the literature (Conrad, 1970; Furth, 1966) are: How do the deaf encode? How do they think? The technique of studying confusions in short term 
recall provides a potential way of approaching this problem, at least in the context of short term memory. Comparison of the coding processes in deaf and hearing subjects should provide information on the codes available, and how they differ from each other.

Conrad and Rush (1965) and Conrad (1970, 1971) have pioneered research on short term encoding in the deaf. Their data indicates that the deaf encode differently from normals, although they do not clearly indicate what characterizes the code or codes used by the deaf. This research attempts to extend and refine theirs, hoping to provide some more explicit answers. However, before introducing this research, it will be useful to review the relevant background, both in research with the deaf and in research on normal memory processes. In addition, the communication methods used in deaf instruction will be briefly described, since they could have some bearing on the manner in which the deaf encode items in memory.

Methods of Deaf Communication

The main purpose of this section is to describe the principal methods in communicating with the deaf. For a more extensive historical review the reader is referred to Bender (1960), Best (1943), Deland (1968), Merritt (1965) and Quigley (1969).

Basically, there are three different communication methods used in deaf education in North America; namely, the 
Oral method, the Rochester method, and what could be called the Total Communication method.

\section{The Oral Method}

Under this method the child is instructed through speech and written work. The deaf subject communicates through speech, speechreading, writing and reading. Speechreading (also known as lipreading) is the process of orally understanding another individual by observing only visual cues. These visual cues are mainly the movement of the lips, tongue and jaw, but also include the facial muscles. Davis and Silverman (1967) state that "At the present time $85 \%$ of children enrolled in schools for the deaf are reported to be instructed by the Oral method of communication at least in their early years...[p. 391]. Oralists assume that this method of instruction gives the child an easier adjustment to a normal hearing world. In practice, many schools which do have good oral programs permit, or at least do not restrict, the use of manual communication outside the classroom.

The Rochester Method

This method is similar to the above method in that it uses speech, speechreading, writing and reading as means of communication. The important difference is that finger spelling is used as an additional means of communication. In other words, both finger spelling and speech are combined simultaneously in instruction--finger spelling itself is not 
a language. It uses certain hand and finger positions to designate the various letters of the written alphabet of a language (see Appendix A). In the United States and Canada a one-handed system is used, while in England and Scotland two hands are used to designate the alphabet. The two handed system is supposedly a slower method. The American alphabet ( see Appendix A) is made up of nineteen distinct configurations. The seven remaining letters of the alphabet are formed either by different positioning or motion of an already existing configuration. In finger spelling, the words run together without any pause or other indication for punctuation or capitalization. The general rule in manual spelling is to hold the hand with the palm toward the person or persons being addressed.

This method was introduced into the Rochester school in 1878 by Zenos Westervelt, and was used in all grades at that school until the $1940^{\prime} \mathrm{s}$. It was then abandoned in the primary grades, or until the child reached twelve to thirteen years of age, because it was thought that wartime improvements in amplification techniques would enable teachers to develop whatever hearing capacity a child might have, especially in the early stages of development. However, no substantial evidence was ever presented to support the view that this revised program was effective.

Hence, the Rochester method now rarely exists in a total school environment in pure form. In fact, it is often 
integrated into the method discussed below. The Total Communication Method

This method is like the Rochester method, except that manual signs are added as well. The language of signs is often abstract (Boese, 1968). It makes use of manual gestures or signs, to convey concepts rather than words. Best (1943) argued that although sign language is referred to as "manual," it actually involves movement and interpretation of body, face, head, arms and hands.

Sign language has become universally accepted as a language for the deaf. As in verbally expressed languages, there are dialects. For example, the same concept in sign language may be represented differently from deaf community to deaf community. However, while sign language may contain the essential elements of a language, it does differ from the English language, at least in symbolic and syntactic structure (Stokoe, 1960, 1965).

Recent Developments

Much of the literature on the different communication methods has been merely polemical, advocating one or other method without any attempt at objective evaluation. Recently, however, there have been some comparative studies (e.g., Meadows, 1967; Quigley, 1969; Quigley \& Frisina, 1961; Stevenson, 1961; Stuckless \& Birch, 1966). All showed the overall superiority of manually trained deaf children on such tasks as reading and written language. However, univer- 
sal acceptance of even these results has not been attained. This stalemate will remain true so long as educators of the deaf see the issue as purely an oral versus manual controversy. Until educators examine the issue as a combined oral and manual approach in contrast to only oral techniques, the controversy will not be dealt with rationally.

Perhaps the strongest claim for a particular method has come from Morkovin (1968) who argued that the use of "dactylic" (i.e., manual) language from preschool level aids oral skills. He claimed that deaf children in the U.S.S.R., when trained by his method, attain a level of vocabulary which far exceeds the vocabulary of a typical deaf child trained by other methods. However, as Quigley suggests (1969, p. 9), the vocabulary counts reported by Morkovin may not be reliable. Also, considering the fact that many changes took place in the curriculum of the deaf in the U.S.S.R. at this time, it is hard to ascertain exactly how much was due to finger spelling and how much to curriculum changes. Hence, the controversy about methods still remains unsettled. In fact, many schools use a combination of methods, which is partially caused by the lack of any conclusive research regarding the best method to use in deaf instruction.

\section{Short-term Memory}

The experimental investigation of short-term memory (STM) is a relatively recent phenomenon which probably owes 
its origins chiefly to Broadbent (1958) and Hebb (1949).

Both authors have argued that STM and long-term memory (LTM) depended upon fundamentally different processes. STM supposedly depended upon active processes that were subject to rapid decay if rehearsal did not occur. By comparison, LTM was thought to be structurally encoded, associative and more susceptible to interference than decay.

Although some authors, such as Melton (1963) opposed the distinction between STM and LTM, it became generally accepted. Further, intensive research within the area of STM also indicated the need for a distinction between sensory storage (called "pre-perceptual" by Broadbent, 1963; or "precategorical" by Crowder $\&$ Morton, 1969) and memory for items that have been categorized. The term STM is now most commonly applied to the latter and excludes sensory storage.

Most recent models of human memory thus suggest three different modes of storage: sensory storage, STM and LTM (e.g., Atkinson \& Shiffrin, 1968; Crowder \& Morton, 1969; Neisser, 1967; Sper1ing, 1963, 1967). One of the exceptions to this tripartite division is Wickelgren's (1970) model which postulates an intermediate term storage between STM and LTM, making four different modes of storage. Sperling's (1969) work perhaps did most to establish the concept of sensory storage in the visual modality. Sperling advocated a visual information storage of very brief duration (1ess than 500 msec.). Neisser (1967) termed this 
"iconic" memory. Although there are indications that an auditory equivalent exists (Sperling, 1963), it is not so wel1 documented. Neisser distinguishes between the two modalities by calling auditory memory "echoic。"

Much of the early work on STM was concerned with whether or not it is subject to spontaneous decay over time, or whether it obeys the laws of interference (cf. Melton, 1963). However, since sensory memory was isolated as a distinct component of memory, separate from STM, the research emphasis has changed. One main area of interest concerns the nature of the coding processes in STM. Early evidence suggested that STM was mediated by an acoustic code, even if the items to be recalled were presented visually (Conrad, 1964; Sperling, 1963). This point is of major importance to this thesis, and will be discussed in detail later in this section.

The current views on ITM will not be discussed in detail here, since they are of little relevance to this thesis. Suffice it to say that Atkinson and Shiffrin (1968) have argued that with long-term storage the major problem is that of retrieval since material in this storage system is essentially permanent. Other researchers have argued for the role of semantic coding in LTM, in contrast to acoustic coding in STM (Baddeley, 1966; Dale \& Gregory, 1966; Kintsch \& Buschke, 1969; Neisser, 1967; Norman, 1969). 
Two further issues of central relevance to this thesis need also to be considered in this section. They are first, what is the nature of visual storage? and second, what is the nature of the nediating code in STM? What is the Nature of Visual Storage?

Most models of human memory imply that visual memory only exists at the level of sensory memory. This appears to be too simple an assumption to make as several widely varying values of the duration of visual storage have been given (Averbach \& Coriel1, 1961; Mackworth, 1963; Posner \& Keele, 1967; Posner, Boies, Eichelman, \& Taylor, 1969; Sperling, 1960, 1963). The duration of the visual image may vary with the conditions of exposure, between individuals and with appropriate variations of the post-exposure conditions.

While not all visual information is subject to the same decay (Dick, 1967), it is conceivable that both different materials and different tasks (for example, search or recall) require different encoding strategies but similar processing mechanisms (Clark, 1969; Standing \& Haber, 1968). As recent evidence has suggested that storage of visual attributes may last longer than pure iconic storage (Clark, 1969; Cohen, 1969; Dick, 1969), it seems appropriate to make a theoretical distinction between a visual image (of very brief duration) and storage of visual attributes. It is not clear whether this storage of visual attributes is pre-attentive or whether it represents storage at the level of STM. There 
is evidence for a purely visual component in STM (Cermak, 1971; Hiles, 1971) and the results of this thesis will also suggest that the deaf rely extensively on this component. Haber (1965) and Standing, Haber, Cataldo, and Sales (1969) have bot? emphasized that visual storage was certainly affected by such factors as knowledge of the stimulus and past experience with the stimulus conditions. Recent evidence (Bahrick \& Boucher, 1968; Kro11, Parks, Parkinson, Bieber, \& Johnson, 1970; Shepard, 1967) has shown that visual storage can be retained for longer durations than previously acknowledged, if recognition measures of retention or shadowing tasks are used. For example, Shepard (1967) asked Ss to look through a series of approximately 600 stimuli. The stimuli used were either words, sentences or pictures. The median Ss were able to recognize the initial stimulus presented with $90 \%, 88 \%$, or $98 \%$ accuracy for the respective test series. This informational and temporal capacity for visual memory considerably exceeds previous estimates for storage in this modality. What is the Nature of Encoding of Items in STM?

Conrad (1962, 1964) observed an acoustic dimension in confusion errors in short term recall. This was supported by Baddeley $(1964,1966,1970)$, Conrad and Hull (1967), Dale (1964) and Wickelgren (1965a). While an acoustic coding system was used under these experimental conditions, it is conceivable that other codes may be used under other conditions. 
From a long series of studies, Wickelgren (1965a, 1965b, 1965c, 1965d, 1966a) argued that a distinctive features system with three dimensions, nàmely, nasality, voicing and openness of the vocal tract, could predict the phonemic errors in immediate memory. However, regarding the nature of the actual code used in STM (whether it was acoustic or not) Wickelgren could not be specific. Another series of studies (Cole, Haber, \& Sales, 1968; Cole, Sales, \& Haber, 1969; Sales, Haber, \& Cole, 1968; Sales, Haber, \& Cole, 1969; Sales, Cole, $\&$ Haber, 1969) replicated and extended Wickelgren's findings. The overall results showed that Wickelgren's distinctive feature system was inadequate to predict how vowels were encoded under many conditions. These findings substantiated earlier criticisms of Wickelgren's work by Liberman, Cooper, and Shankweiler, and Studdert-Kennedy (1967).

Hintzman (1965, 1967) observed when Ss were presented with phonemically similar lists that they subvocally named the visual stimulus, which produced small movements and tensions in the vocal apparatus. According to Hintzmar, this produces kinaesthetic feedback which is monitored for retrieval processes. Furthermore, Hintzman argued that $\underline{S} s$ remember whether a consonant was voiced or unvoiced, and also the place of articulation. Hence, Hintzman argued for an articulatory, rather than an acoustic coding mechanism in STM. 
Wickelgren (1969) seriously questioned certain of Hintzman's conclusions. Wickelgren questioned Hintzman's exclusive use of Miller and Nicely's (1955) data, and moreover Hintzman's assumption that auditory confusion matrices reflect only auditory coding. In conclusion, Wickelgren argued that the nature of the code used for items in STM could be some "abstract verbal code" just as easily as it could be either acoustic or articulatory.

Recently, researchers have emphasized the temporal characteristics of the auditory components of storage, decay and retrieval in STM (Adams, Thorsheim, \& McIntyre, 1969a, 1969b; Baddeley, 1968; Johnson \& Chamberlain, 1970; Sperling, 1.968). Adams et al. challenged the effects of acoustic confusability when they found that acoustic confusability only occurred if sequential presentation was used, if the retention interval was short (less than $5 \mathrm{sec}$. ), and if some proactive inhibition was present.

Other research has questioned whether auditory coding exists at all. Kaplan, Yonas, and Schurcliff (1966) found no effect of acoustic confusability and this was substantiated by Chase and Posner (1965), Dainoff and Haber (1967), Glucksberg, Fisher, and Monty (1967), Hershenson (1969), and Keele and Chase (1967). However, Dainoff (1970) argues that these particular experiments may not have been sufficiently powerful to demonstrate whether or not acoustic coding need exist. 
At the present moment, many questions remain unanswered. It seems quite plausible that verbal and non-verbal storage are quite different. Neither verbal nor acoustic encoding may be necessary under all experimental conditions, but under certain conditions verbal may be more efficient, particularly where verbal recall is required.

\section{Memory in the Deaf}

\section{Generalized Deficits}

As research on the deaf has been extensively reviewed elsewhere (Furth, 1964, 1966, 1971; Myklebust, 1964; Pinter, Eisenson \& Stanton, 1941; Vernon, 1968, 1969), on1y aspects related to the experiments reported later will be reviewed here.

Naturally, severe hearing loss from an early stage results in language deficiencies (Pintner, 1917, Pintner $\varepsilon$ Paterson, 1916; Reamer, 1921). In fact, there was a tendency to regard language impairment as the only respect in which deaf and hearing differed cognitively, although it is now clear that this was an oversimplification. Deficits in language are not the result of deafness per se, but a lack of appropriate verbal stimulation, since marked improvements in 1 anguage tasks have been observed when special efforts have been made to overcome the communication problem (Ewing, 1957; Fry, 1966; Whetnall \& Fry, 1966). However, if the deaf do not receive early experience with language, they may develop their own systems of symbolic 
representation which may actually impede later development of speech (Boese \& Cicourcel, 1971). Thus Blanton (1965), studying early communication patterns in the deaf, has drawn a parallel between the learning of a first language by the deaf and learning of a second language by the hearing. According to Blanton's hypothesis, the deaf individual learns language essentially by a process in which he translates his own symbolic representations into the oral language of the community .

The limited communication systems used by the deaf may also hinder their level of thinking. 01eron (1953) suggested that the deaf operate predominantly on a perceptual level. When tasks become more "abstract," the deaf may be unabie to conceptualize the problem. McAndrew (1948) hypothesized that the mental and social isolation of a deaf environment causes greater rigidity in their observed behavior. Even in object sorting tasks the deaf (when compared to blind and normal) needed more instruction before changing their ways of sorting. These results have been supported by 01eron (1953), who proposed that the deaf cannot change categorizing behavior because operating on a perceptual. level, they do not perceive the distinct attributes necessary for shifting criteria for grouping. However, the question of the rigidity of deaf categorization is not settled, as Heider and Heider (1940) found that the deaf change categories as readily as hearing subjects. 


\section{Specific Deficits}

It has been clearly established that the deaf have a shorter memory span than normals (Pintner \& Paterson, 1917). However, they are not necessarily poorer in all memory tasks. For example, Blair (1957) compared carefully selected samples of deaf and hearing $\underline{S} s$ on a variety of tasks, and found the deaf to be superior on the Knox cube test (Knox, 1914) and on a test of immediate pattern recognition (Graham $\varepsilon$ Kendal1, 1946). However, they were inferior on memory span tasks. One interesting finding was that the deaf compared to hearing children, were better on reverse digit span than on forward digit span.

The difficulty that the deaf experience in memory tasks may be due to their inability to rehearse effectively, which in turn seems to be related to their linguistic deficiencies, which have been summarized above. For example, Goetzinger and Huber (1964) found that deaf and hearing adolescents performed similarly in recall of geometric figures, but that the deaf were worse in delayed recall. Again, Withrow (1968) found no difference between various groups of deaf $\underline{S} s$, and a hearing group in recall of silhouettes or geometric and random forms presented simultaneously, but the hearing Ss were superior when the stimuli were presented sequentially. The deaf appear not to possess, or at least not to utilize, the types of rehearsal mechanisms necessary to take advantage of serial presentation. 
Other evidence has suggested that the deaf encode differently from hearing Sss. This qualitative difference sometimes places the deaf at a disadvantage. For example, Blanton and Nunnally (1967) compared deaf and hearing SSs on a recognition task. They used CVC trigrams of high and low pronounceability (Pr). For high $\mathrm{Pr}$ items there was no difference between groups. With low Pr items the deaf were superior. Blanton and Nunnally argued that later recall for the hearing SS, was hindered by their attempts to pronounce the low Pr items.

This brings us to the work of Conrad. This research has examined the coding processes employed by both deaf and hearing Ss (Conrad, 1963, 1964, 1970, 1971; Conrad \& Hul1, 1964; Conrad \& Rush, 1965). Conrad (1964), as reported earlier, showed a significant association between immediate recall errors for six-letter sequences and listening errors. Conrad argued that the most acoustically confusable letters were most likely to be confused in memory. The acoustic nature of memory was investigated and confirmed by Conrad and Hull (1968). Hence, the early experiments by Conrad (using normal hearing Ss) established that even with simple verbal material, the predominant mode of storage depends upon acoustic coding, even if the items are presented visually. Conrad and Rush (1965) used letters as stimuli with established acoustic and visual confusability (Conrad, 1964; Tinker, 1928). Combinations of these stimuli were presented 
to deaf and hearing subjects. The control group confirmed Conrad's (1964) findings when they showed high frequency occurrence of acoustic but no more than chance visual confusions. By comparison, the deaf did not make acoustic or spatially related errors in recall. Although the mode of encoding for the deaf was not clarified by this experiment, Conrad and Rush felt that the errors were consistent and specific to the group.

Conrad (1970) extended the earlier study. Variable sequence length (both five- and six-letter sequences) and serial position data were studied. Samples were taken from the following population of letters, B C H K L T X Y Z. According to Conrad (1970) "the selected letters rather weakly anticipated both articulatory and shape confusions [p. 182]." Two test conditions were used. In one, subjects were instructed to read the letters silently. The other conditions specified that the stimuli were read aloud. Conditions were alternated every nine trials. Results showed both specific and what appeared to be random confusions. Within the deaf group used in this experiment two mutually exclusive codes were used. One group showed articulatory confusions, while the other group did not. Ratings of speech quality correlated highly with the above classification. In other words, the teacher's rating of these $\underline{S} s$ who could speak well, correlated highly with whether or not the $\underline{S}$ made articulatory confusions. In a further experiment 
with these same Ss Conrad compared their serial learning on lists of homophone word pairs, and word pairs of similar shape. The articulatory group had more difficulty with both lists, although procedural weaknesses (cited by Conrad, 1970, p. 179) hinders any clear interpretation of the data. The Present Study

Conrad's data (1970) provide some interesting speculations on the possible encoding processes of deaf children. The following experiments attempt to extend and refine Conrad's research.

The first experiment compares groups of normal hearing, manally and orally trained deaf on a short-term memory task. The digits were visually presented in sequential manner and inmediate recall was tested. The second experiment compared the encoding processes of both deaf groups when a delay was introduced. Presentation and stimuli were otherwise the same as in the first experiment. The final experiment compared the three groups (deaf groups and hearing controls) on a non-verbal recognition task. The stimuli used were human faces.

The topic of this thesis encompases both the general area of human experimental psychology and the specific area of deaf education. The main emphasis of this thesis is on the former. While much research has been generated in the area of STM since Broadbent (1958) and Sperling (1960), many questions have remained unanswered. Some of the most elusive questions in the area have been concerned with coding 
in STM. For example, how do individuals encode? Do encoding strategies vary between individuals? What effect does the deprivation of one sensory modality have on encoding? This thesis is directed towards a more precise understanding of these types of questions, and it is hoped that the utilization of deaf $\underline{S}$ sill provide some valuable insights into them. 


\section{EXPERTMENT 1}

\section{Introduction}

In this experiment, both deaf and hearing children were tested for immediate recall of letters presented visually and sequentially. The main objective was to discover any significant patterns of confusions made in recall, in an attempt to discern the basis for the memory code utilized by the deaf. The present experiment incorporates a number of refinements on the earlier studies of Conrad (1970) and Conrad and Rush (1965).

Conrad and Rush (1965) did not control the communication method used by the S.s. For example, both orally trained and finger-spelling $\underline{S}$ s were used without any breakdown according to method. This may have been an important variable which was overlooked. In Conrad's (1970) experiment al1 subjects were orally trained. In the present experiment two groups of deaf $\underline{S} s$ from two different teaching methods were used. One group was purely orally trained and the other group trained under the Rochester Method.

Another innovation in this study was in the choice of stimuli. Previously, with normal hearing subjects the material used was acoustically or visually confusable. Conrad and Rush reported that the deaf did not make acoustic errors in recall. While they could not identify the coding method used, they believed the errors were both consistent and specific to the deaf. They hypothesized that the deaf 
subjects may have been using shape cues. The present experiment investigates the role of shape cues by comparing the pattern of errors among upper case letters with that of errors among the same letters in lower case. The actual letters chosen were those judged to differ most in shape between cases (see below, under Test Materials). Any marked differences in the patterns in the two cases would suggest shape coding, since it is only with respect to shape that the cases differ. On the other hand, similarities in the patterns could result from either acoustic, articulatory, or finger-spelling codes, in which the difference between cases is not represented.

Finally, the present experiment used two groups of deaf Ss, one chronologically older than the other. This was to establish whether or not the older deaf group would perform at a level of younger hearing controls--a common conclusion when quantitative comparisons are reported in the literature (e.g., Kates, Kates, \& Michae1, 1962).

\section{Method}

\section{Subjects}

There were three groups, two deaf and one hearing, each consisting of four boys and four girls.

1. Oral Deaf Group. This group of deaf children were aged between 11 years 2 months and 14 years 1 month at the time of testing. Over the speech range of frequency all subjects had a hearing loss greater than 75 d.B. in the 
better ear. This group had been taught solely by the oral method.

2. Manual Deaf Group. This was an older deaf group whose age range was 14 years 8 months to 27 years 2 months (although all but one was under 20) at the time of testing. The hearing loss of this group satisfied the same criterion as that of the Oral Deaf Group. This group had been taught by manual methods although the use of the Rochester Method had recently been encouraged in the school.

3. Normal Hearing Group. This was a group of normal hearing children within the same age range as the Oral Deaf Group. The I.Q. range of this group was 100 to 122 .

\section{Test Materials}

The stimuli used for this experiment were the ten letters of the alphabet whose representation in upper and lower case were judged most different. The letters chosen were taken from Letraset No. 207, and included: $A, B, D$, $E, G, H, N, Q, R, T$; and $a, b, d, e, g, h, n, q, r, t$. Note that the lower-case letter " $q$ " was written without a tail, which may explain why, as we shall see, many Ss confused the lower case "q" with the "g".

Sequences were constructed so that no letter occurred twice in any sequence and in such a way that each letter occurred equally often in each serial position. Four series of 60 trials were conducted for each group. Two of the series consisted of four-letter sequences, one in upper and 
the other in lower case. The other two series consisted of five-letter sequences, also in upper and lower case. The order of presentation of the series was counterbalanced within each group with respect to both case and sequence size.

\section{Test Procedure}

The instructions were typed and handed to each student individually. The class teacher of the respective deaf groups also communicated the instructions either orally or in manual language, as appropriate. Furthermore, each subject received four practice trials in which he wrote down and named the letters recalled. Each subject was pretested to ensure that he could name and distinguish each letter.

The stimuli were projected from a Carousel projector at the rate of one slide every $1.1 \mathrm{sec}$. The ten letters from which the sequences were drawn were displayed throughout in the appropriate case, under the projector screen. The purpose of this was to ensure, as far as possible, that any confusions made were restricted to the letters used in the experiment. Subjects were encouraged to guess when not sure of any particular letter.

Subjects wrote their recall on prepared answer sheets. There was a separate box for each serial position. They were instructed to wait until the final letter had been presented before beginning to write. 


\section{Scoring}

The raw data were scored for number correct and for confusions. Both were tabulated according to two different criteria, an ordered-recall and free-recall criterion.

1. Ordered Recall. According to this criterion, a letter was only scored correct if it was in the appropriate serial position. Each incorrectly recorded letter was scored as a confusion with the letter that should have been written in the box in which it appeared. For example: If the actual sequence presented was $D G R T$ and the subject responded $D Q T R$ only the $D$ was scored correct, while $Q T R$ were tabulated as confusions with $G R T$ respectively. Note that order errors are tabulated as confusions, which is a possible weakness of this scoring procedure.

\section{Free Recal1. Under this scoring method order} errors did not register as confusions. A reported letter was only labelled incorrect if it had not appeared somewhere in the stimulus sequence. If only one letter was incorrect, it was said to be confused with the missing letter from the report. If several letters were incorrect, they were matched first on the basis of serial position, then on the basis of order. For example, if $S$ was presented with a sequence A $B$ D $G$ and wrote down $G B R N$, both the $R$ and the $N$ would be judged incorrect. On the basis of serial position, the $\mathbb{R}$ would be scored as confused with the $D$, and the $N$ would be scored as confused with $A$. If $\underline{S}$ saw $G H A R$ and wrote $R N$ $H$ T then $N$ and $T$ are incorrect. However, they are matched 
according to serial position with letters which were correctly recorded. On the basis of serial order then, the $N$ would be judged as confused with $G$ and the $T$ with $A$. This scoring method is inevitably somewhat arbitrary. For instance, in the example just given, it might plausibly be argued that the $N$ was actually confused with the $H$, not with the $G$. However, there were in fact very few instances which involved any ambiguity in scoring.

\section{Results}

\section{Number Correct}

Analyses of variance were carried out separately for four- and five-letter sequences under each scoring.criterion. The independent variables were groups, case and serial position. The raw data were obtained simply by summing the number correct over each sequence of trials for each serial position. The analyses of variance are summarized in Appen$\operatorname{dix} C$.

In this experiment, both scoring criteria gave essentially similar results. Therefore, statements about results and significance apply to both criterion measures, unless there is cause to differentiate between them. When the significance levels differ, the higher probability value is given.

For four-letter sequences, there were significant differences between groups $(p<.001)$ and between serial positions ( $p<.001$, see Fig. 1). There was also a significant 


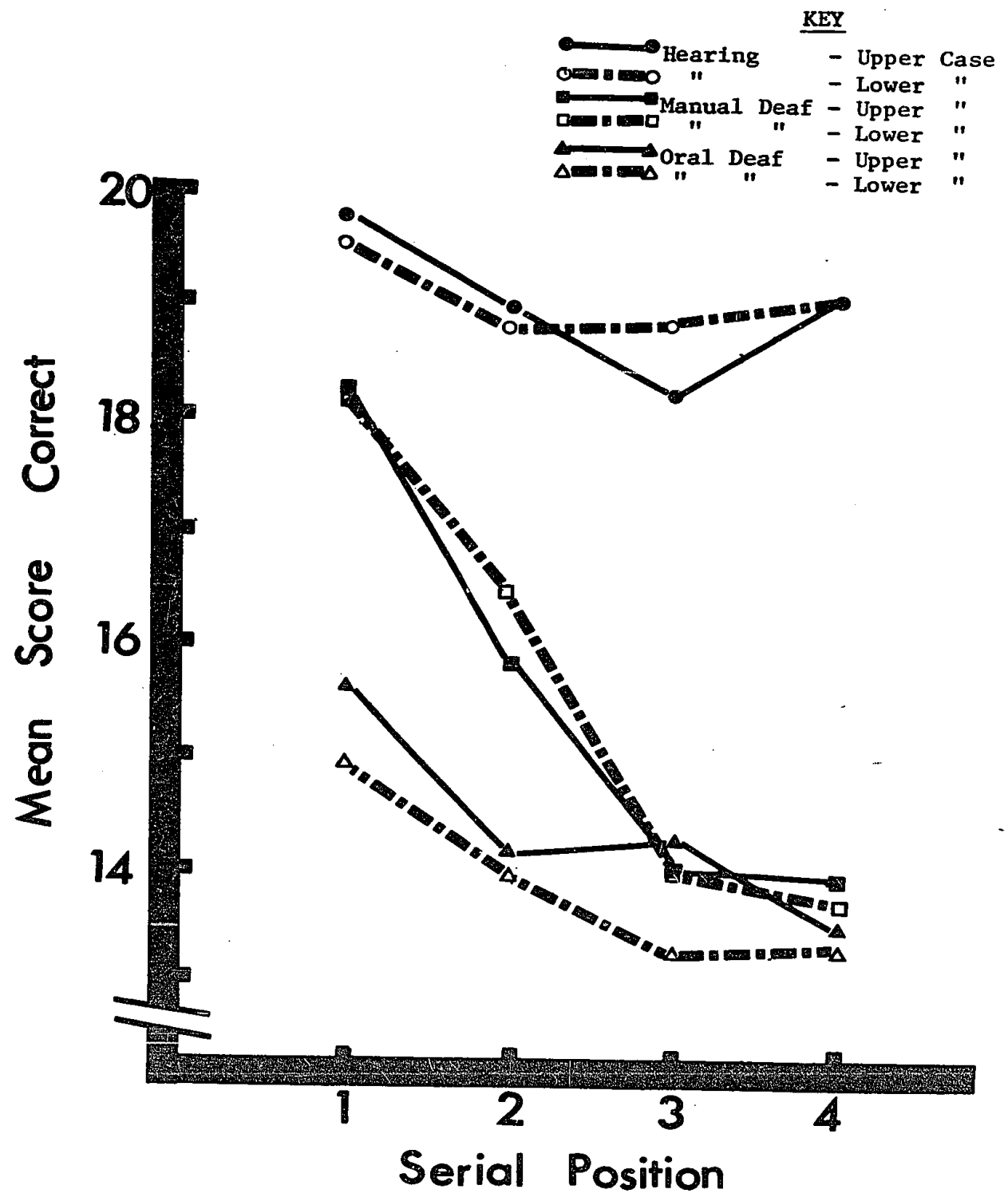

Fig: 1 Ordered Recall Criterion (Experiment 1) 


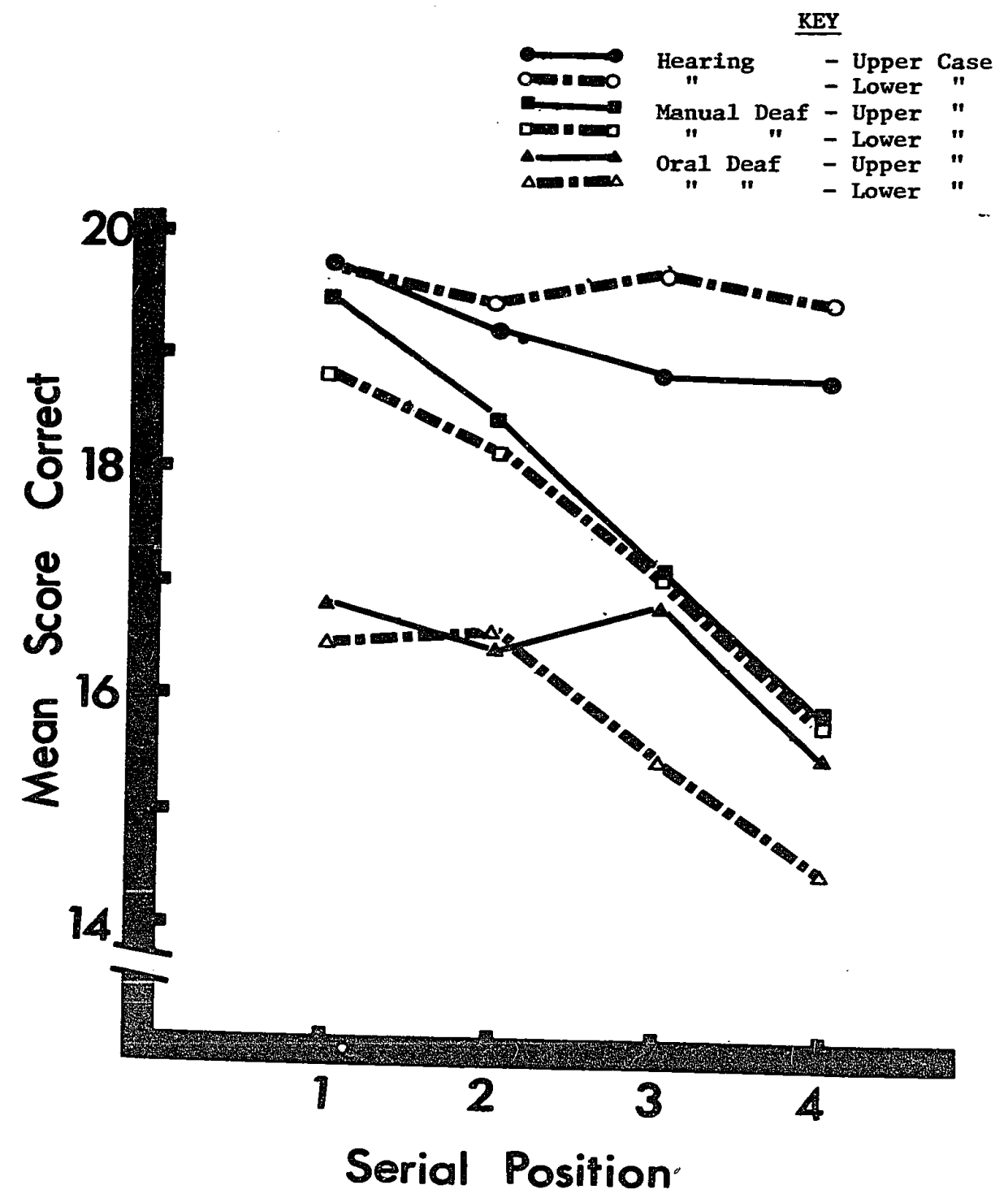

Fig: 2 Free Recall Criterion (Experiment 1) 
interaction between groups and position $(p<.01)$. A significant difference was observed when a multiple comparison was performed between deaf and hearing groups, but significance was not achieved for a comparison between the Oral and Manual deaf groups. An analysis of covariance using age as the covariate again revealed significant differences between the groups, even when the oldest $\underline{S}$ in the Manual group was removed* $(p<.01)$.

The serial position curves for four-letter sequences are shown in Figures 1 and 2. The Normal Hearing group and the Oral Deaf group showed flatter serial position curves than the Manual Deaf group, which exhibits a sharp primacy effect. This comparison between the groups could be contaminated by a ceiling effect which may have flattened the curve for the Normal Hearing group. The differences among the groups appear to be less for free than ordered recall, suggesting that the deaf groups may have experienced a sequential ordering problem, although this comparison is possibly contaminated by a ceiling effect too.

For five-letter sequences, there were also differences between groups $(p<.001)$ and serial position $(p<.001)$. A significant interaction occurred between groups and positions $(p<.01)$. An analysis of coveriance, with age as the covariate once more revealed significant differences between the groups $(p<.01)$, even when the oldest deaf $\underline{S}$ was removed from the analysis.*

*This $\underline{S}$ performed especially poorly, which created a nonhomogeneity of regression between groups. He was therefore removed from the analyses of covariance. 
The serial position curves for five-letter sequences, under the different criteria are shown below in Figures 3 and 4. The general shape of the serial position curves for the Normal Hearing and Manual Deaf groups are not dissimilar for this type of task. However, the shape of the serial position curve for the Oral Deaf differs markedly. This was probably due to the order in which this group wrote down the sequences in written recall. Almost without exception, Ss in this group were observed to write down the last one or two letters first, then the initial letter presented, followed by the others in variable order. The consistency of this strategy with the orally trained deaf, and the fact that it was apparently restricted to this group, suggests that this group may have been coding the material in a different manner.

\section{Confusions}

Confusions were tabulated in a $10 \times 10$ matrix, in which the rows corresponded to the letters recorded by the subjects, and the columns to the letters presented. The frequencies of confusions were added over $\underline{S} s$ in each group. Separate matrices were constructed for each group, sequence length (4 or 5), case (upper or lower) and scoring criterion. The 24 matrices are reproduced in Appendix B.

It was of interest to compare the pattern of confusions between different conditions. As a measure of similarity between a pair of matrices, product moment correlations were 


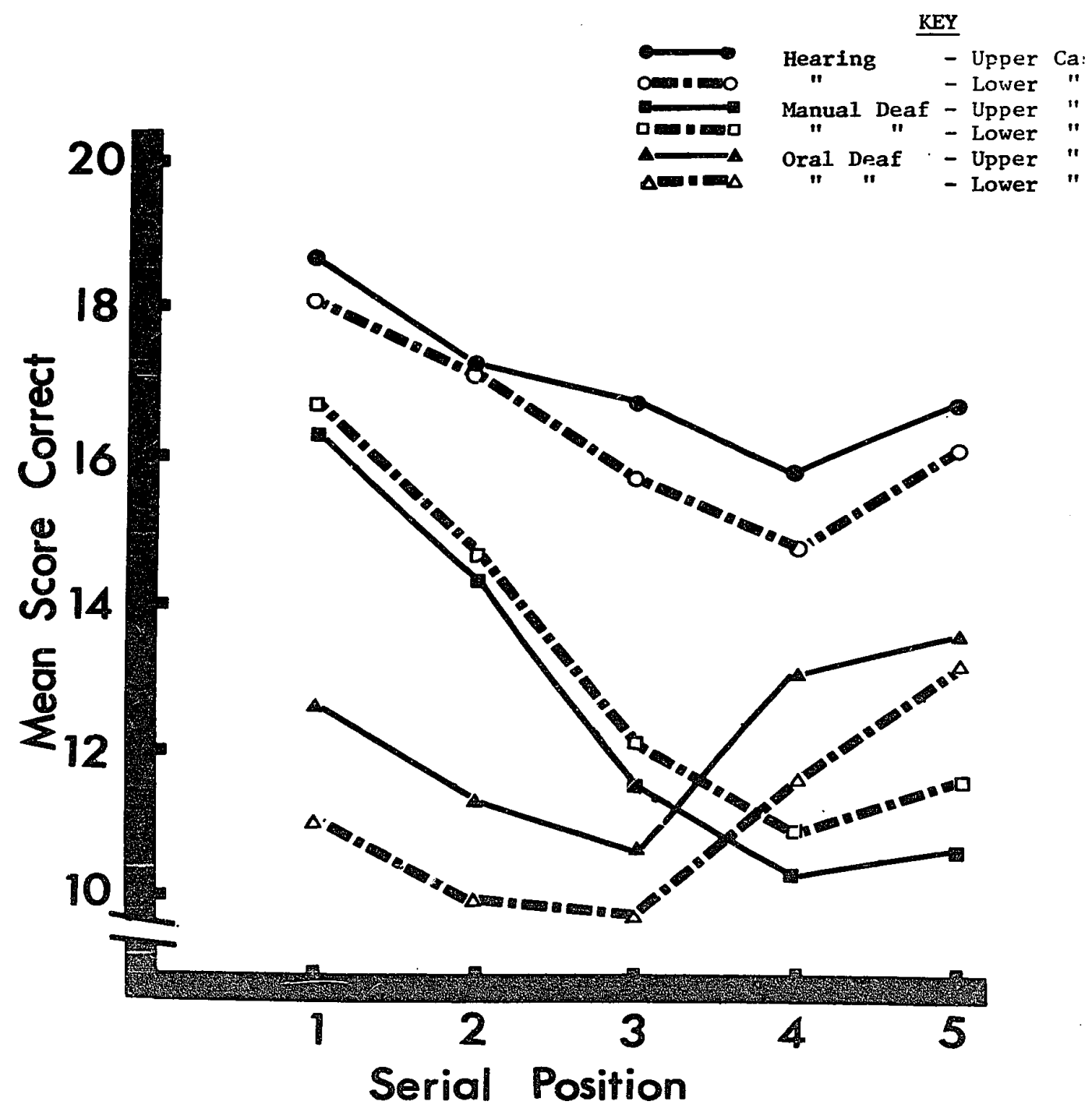

Fig: 3 Ordered Recall Criterion (Experiment 1) 


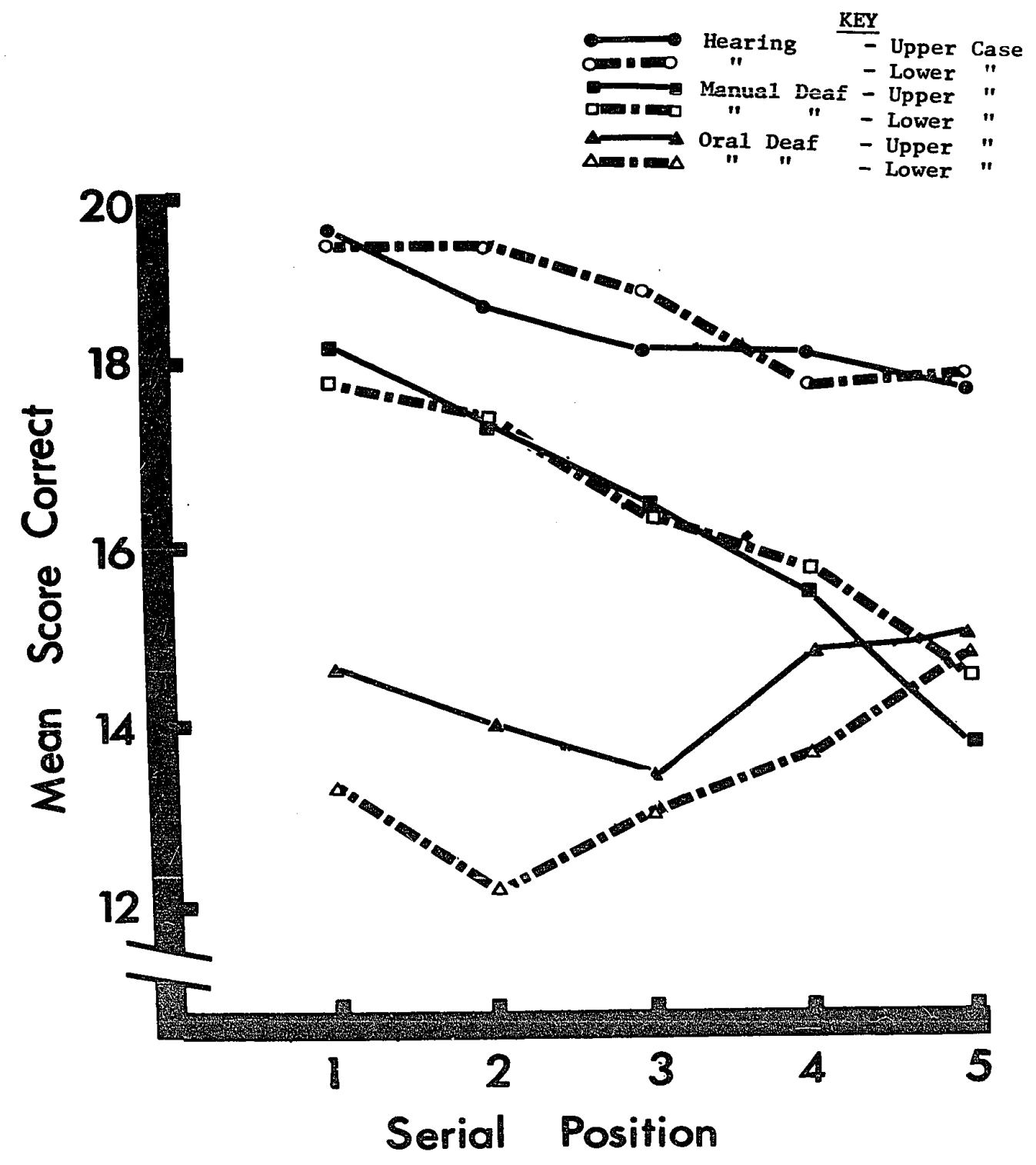

Fig: 4 Free Recall Criterion (Experiment 1) 
computed between them by regarding each matrix simply as a vector of $90^{\circ}$ scores (diagonal values were omitted). The following comparisons were of special theoretical interest. Upper vs, lower case comparisons. Table $1: 1$ shows the correlations between upper and lower case matrices for each group.

Correlation between cases indicate the extent to which they share a common code in written recall. If the material was coded visually, then one would expect a negligible correlation since the letters of the population were chosen on the basis of greatest differentiation between upper and lower case. If the method of encoding depended upon articulatory, acoustic or perhaps manual features, then one would expect similar confusions (i.e., high correlations) between cases.

Group comparison. Table 1:2 shows the extent to which different groups shared a common code. For example, if the deaf groups shared a common code with each other, one would expect high correlations between them. The table indicates that this was generally the case.

Comparison of data with those of Conrad (1964) and Kuennapas and Janson (1969). Conrad (1964) produced a matrix of listening confusions observed in his experiment using upper case letters of the English alphabet. Product moment correlations were made between the confusions in upper case in the present experiment and the corresponding 
Table 1:1

Summary of Correlations Between Cases and

Sequence Lengths, for each Group (Expt. 1)

\section{Group}

Oral

12

"

n

Manual

n

"

"

Normal Hearing

$\begin{array}{ll}n & n \\ n & n\end{array}$

\section{Recall Recall}

4 Upper - 4 Lower

.01

.04

5 n

5 n

.38

.38

4 "

5 Upper

.07

.13

4 Lower

5 Lower

.56

.55

4 Upper - 4 Lower

.11

. 29

5 "

$5 \quad 1$

$4 \quad 11$

5 Upper

4 Lower

5 Lower

.66

.50

.33

.41

.50

.56

4 Upper - 4 Lower

.52

.41

5

5 "

5 Upper

.43

.18

4 Lower

5 Lower

.57

.25 
Table 1:2

Summary of Correlations Between Groups

for Criteria, Case and Sequence Length

\begin{tabular}{|c|c|c|c|c|}
\hline Group & & Material Correlated & $\begin{array}{l}\text { Ordered } \\
\text { Recal1 } \\
\end{array}$ & $\begin{array}{c}\text { Free } \\
\text { Recall } \\
\end{array}$ \\
\hline Oral - & Manual & 4 Upper & .23 & .36 \\
\hline$n$ & $n$ & 4 Lower & .85 & .87 \\
\hline " & $n$ & 5 Upper & .25 & .17 \\
\hline$n$ & n & 5 Lower & .47 & .48 \\
\hline Oral - & $\begin{array}{l}\text { Normal } \\
\text { Hearing }\end{array}$ & 4 Upper & .06 & .03 \\
\hline$"$ & $n$ & 4 Lower & .13 & .12 \\
\hline$"$ & $n$ & 5 Upper & .14 & .12 \\
\hline$n$ & $"$ & 5 Lower & .34 & .27 \\
\hline Manual & $\begin{array}{l}\text { - Normal } \\
\text { Hearing }\end{array}$ & 4 Upper & .05 & .12 \\
\hline$"$ & $n$ & 4 Lower & .04 & .13 \\
\hline$"$ & $n$ & 5 Upper & .16 & .28 \\
\hline n & $"$ & 5 Lower & .23 & .16 \\
\hline
\end{tabular}


letters in Conrad's experiment. The results are shown in Table 1:3 below.

Kuennapas and Janson (1969) studied the Swedish alphabet and built up a similarity matrix in lower case. The Swedish alphabet includes all of the English alphabet, so provides appropriate comparison. However, minor variations due to differences in typescript and to different letter populations can be expected. Product moment correlations were performed on the letters of the population in the experiment reported above and Kuennapas and $J$ anson's study. Let us now consider the implications of these data for each group in turn.

Normal Hearing Group. This group showed the strongest evidence for acoustic encoding. For example, analysis of the confusion matrices shows that this group frequently confused T-B, B-E, B-D, D-B, G-D, D-G, D-T, $t-b, b-e, b-d, d-b$, $g-d, d-g, d-t$.

While the importance of acoustic or articulatory coding for normal hearing subjects has been established both in the present experiment, and in the literature (see Introduction), analysis of the confusion matrices also reveals evidence of visual coding. For example, this group frequently confused $r-t, H-N, q-g$. The $q-g$ confusion is particularly interesting because as we shall see, this was the confusion which dominated the confusion matrices for the deaf groups, particularly with four-letter sequences. However, the normal hearing 
Tab1e 1:3

Correlation with Conrad's (1964) in Upper Case

\begin{tabular}{cccccc} 
Group & Material Correlated & & $\begin{array}{c}\text { Ordered } \\
\text { Recall }\end{array}$ & $\begin{array}{c}\text { Free } \\
\text { Recall }\end{array}$ \\
\cline { 3 - 5 } Oral & 4 & Upper & & 0.18 & 0.07 \\
" & 5 & $"$ & & 0.12 & 0.16 \\
Manual & 4 & $"$ & -0.04 & -0.14 \\
" & 5 & $"$ & -0.06 & -0.14 \\
Normal Hearing & 4 & $n$ & 0.48 & 0.17 \\
" & 5 & & & 0.55 & 0.51
\end{tabular}

Table 1:4

Correlations with Kuennapas and Janson (1969)

for Both Criteria in Lower Case

\begin{tabular}{|c|c|c|c|}
\hline Group & Material Correlated & $\begin{array}{l}\text { Ordered } \\
\text { Recall } \\
\end{array}$ & $\begin{array}{c}\text { Free } \\
\text { Recal1 } \\
\end{array}$ \\
\hline Oral & 4 Lower & 0.48 & 0.39 \\
\hline$"$ & 8 & 0.36 & 0.29 \\
\hline Manual & 4 & 0.26 & 0.26 \\
\hline$n$ & " & 0.22 & 0.22 \\
\hline Normal Hearing & $"$ & 0.24 & 0.16 \\
\hline$"$ & 5 & 0.39 & 0.33 \\
\hline
\end{tabular}


group only made the confusion with five-letter sequences. It seems that this group used visual coding more with fiveletter sequences than four. Further support for this hypothesis can be seen from the higher correlations of this group with Kuennapas and $J$ anson is data for five-letter sequences (see Table 1:4) and the lower correlations between cases for five-letter sequence lengths (see Table 1:1)。 Closer analysis of $T a b l e ~ 1: 1$ reveals that the correlations between cases decreased for the hearing controls when sequence length was increased. By comparison, the deaf groups showed a higher correlation between cases, with increased sequence length.

Deaf Groups. Analysis of the data for both groups reveal that the deaf made extensive use of visual coding, especially with four-letter sequences. Although q-g was the most striking example (probably influenced by the fact that $q$ was represented without a tail), there were other instances of visual confusions. For example, $h-n, n-h, n-r$, $t-r, b-h, R-B, H-E, N-A, A-H$, could all be classed as visual shape confusions. It is also interesting, and perhaps worthy of noce, that the Oral Deaf group made relatively more shape confusions involving orientation (for example, $q-b, b-d)$.

Analysis of Table 1:1 provides some further evidence for visual shape encoding. With four-letter sequences, the correlations between cases were negligible for the 0ral 
group and only slightly higher for the Manual group. Furthermore, correlations between the deaf groups were generally higher than when either deaf group was compared with the hearing controls (see Table 1:2). The exceptionally high correlation for four-letter sequences in lower case were largely due to the frequent $q-g$ confusions.

The correlations with Kuennapas' visual similarity data were positive, but small. However, given that these correlations were probably attenuated not only by differences in typescript, but also by differences in the population of the letters selected, they can perhaps be taken as further evidence for visual encoding. Hence, with four-letter sequences, it appears from the evidence that the deaf groups shared a common code, and that the basis of this code was mainly visual shape.

Analysis of the data with recall of five-letter sequences seems to indicate that there is a second code. For example, the correlations between cases for both deaf groups are no longer negligible for five-letter sequences (see Table 1:1). The Oral Deaf group frequently confused the following: D-G, D-E, B-E, G-D, E-B, d-e, g-e, d-t. This second code appears to have involved an acoustic, or possibly, articulatory component. However, it should be noted that correlations with the Normal Hearing gioup, and Conrad's listening matrix are quite small. 
By comparison, the second code used by the Manual Deaf group is much more difficult to identify. Analysis of Table 1:1 reveals that the correlations between cases with five-letter sequences, for both criteria, is indeed consistent (.66 and .50 respectively). The confusions made by this group included d-n, n-e, E-R, H-G, N-E. The confusions between N-E (and n-e) and H-G could reasonably be explained in terms of similar finger-spelling positions (see Appendix A). However, the other confusions are not so readily explained; for example, the d-n confusion has no obvious basis in either visual, articulatory, acoustic or finger-spelling codes. This group also had lower correlations with both Conrad and Kuennapas' data than the Oral Deaf group. Component Analysis

Finally, component analyses were carried out on the correlations between the confusion matrices under each criterion. The correlation matrices are summarized in Appendix F. The aim of the component analyses was to identify the sources of similarity underlying the correlations. It should be noted however, that the results could be contaminated by distributional differences and by the fact that the withingroup and between-group correlations are mixed. Interpretation should be cautious, therefore. The approach was to extract several principal components and rotate them according to the varimax criterion (Kaiser, 1958 ).

On a priori grounds, one might anticipate four possible 
dimensione: a visual shape component for lower-case letters, a second visual shape component for upper-case letters, a component representing acoustic (or articulatory) coding, and possibly a component relevant to a finger-spelling or manual code. In retrospect, the most coherent results were obtained from three component solutions, and these are summarized in Tables $1: 5$ and 1:6. Both criteria revealed similar solutions. The components may be identified as follows.

Component A. This seoms to represent the visual encoding of lower-case letters. The deaf groups showed the highest loadings, particularly with four-letter sequences. This high loading was probably due to the high frequency of the "q-g" confusion. Unlike the deaf groups, the hearing group loaded only on five-letter sequences. This again confirms that the normal subjects only made use of visual storage with the longer sequences.

Component B. This component represents acoustic or articulatory storage and is dominated by the normal hearing group. But, it should be pointed out that the Oral Deaf group showed moderate loadings for five-letter sequences, although only for the free recall criterion. It seems reasonable to assume that this group does make use of acoustic or articulatory coding, at least to some extent.

Component $C$. This represents visual encoding of uppercase letters and is again restricted to the deaf groups. 
Table 1:5

\begin{abstract}
Summary of Principal Component Analysis Using Ordered Recall Criterion
\end{abstract}

\begin{tabular}{|c|c|c|c|c|}
\hline Group & & Component A & Component B & Component C \\
\hline Oral & 4 Upper & -0.091 & 0.169 & 0.700 \\
\hline Manual & n $\quad$ n & -0.031 & 0.077 & 0.580 \\
\hline Hearing & $n \quad n$ & -0.045 & 0.749 & -0.050 \\
\hline Oral & 4 Lower & 0.908 & 0.059 & 0.073 \\
\hline Manual & $n$ & 0.883 & -0.073 & 0.017 \\
\hline Hearing & $\eta$ & 0.113 & 0.873 & -0.004 \\
\hline Oral & 5 Upper & 0.330 & 0.170 & 0.244 \\
\hline Manual & $n$ & 0.327 & -0.170 & 0.802 \\
\hline Hearing & $n$ & 0.012 & 0.760 & 0.307 \\
\hline Oral & 5 Lower & 0.743 & 0.127 & 0.187 \\
\hline Manual & $"$ & 0.535 & -0.027 & 0.656 \\
\hline Hearing & $n$ & 0.516 & 0.629 & -0.054 \\
\hline
\end{tabular}


Table $1: 6$

\section{Summary of Principal Component Analysis \\ Using Free Recall Criterion}

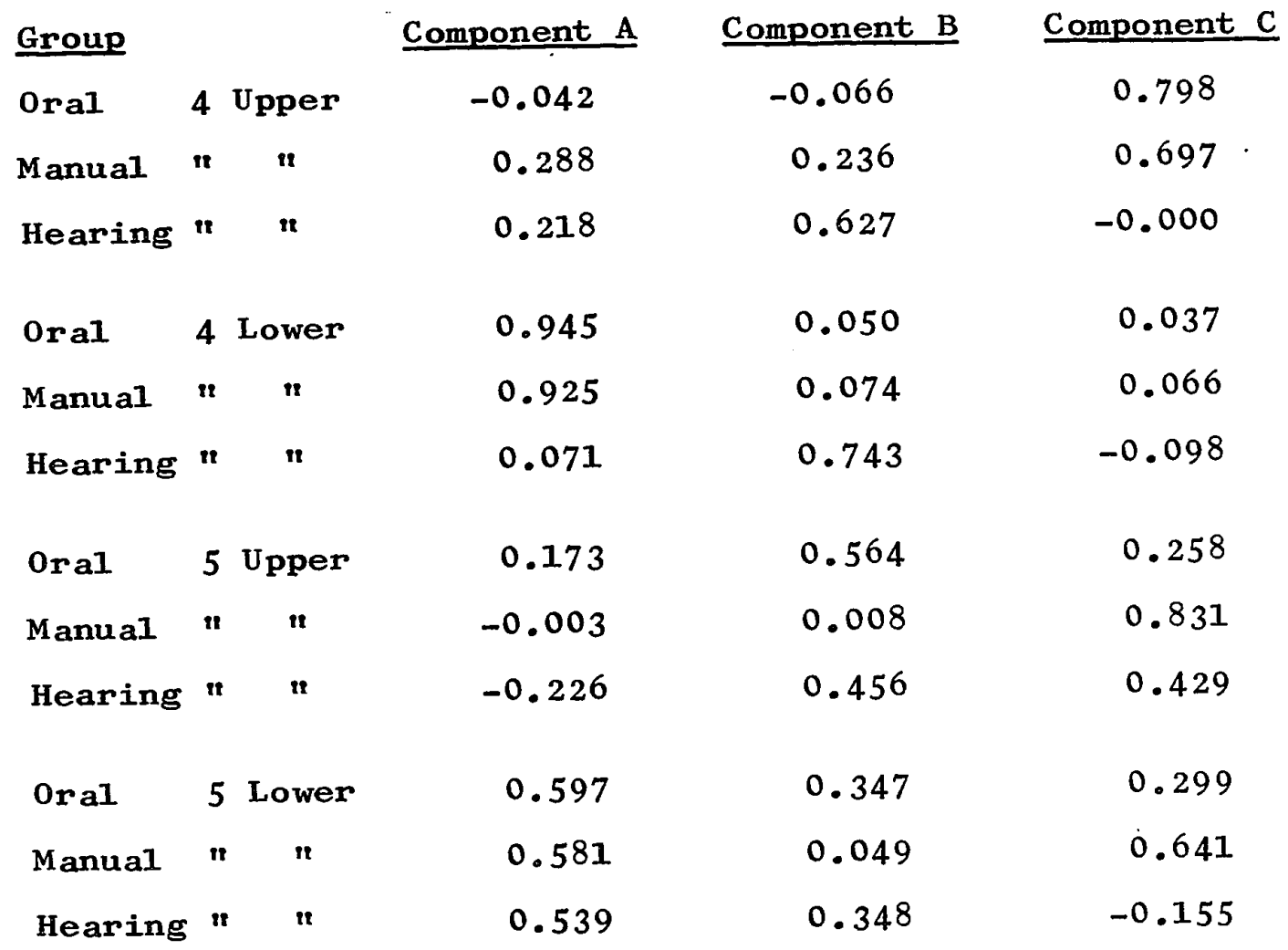


This component is contaminated by high loadings for the Manual Deaf group in recall of five-letter sequences in lower case. Analysis of the raw data showed that the Manual Deaf frequently recoded the visually presented items from one case to another. For example, all members of the Manual Deaf group except one, often wrote the letters down in upper case when lower case was actually presented, and visible under the projection screen. Perhaps it is coincidence, but the exception to this recoding procedure was a girl who had received many years of her training at an Oral school. By comparison, two members of the Oral group showed evidence of this with four-letter sequences, and only one with five-1etter sequences. Any attempt to extract a fourth component under either criterion failed to achieve a more satisfactory solution.

In summary, the component analysis essentially confirms the earlier conclusions, namely, that the hearing essentially use an articulatory or acoustic code, while the deaf use predominantly visual coding. No convincing evidence was found that established any uniform code related to manual communication techniques.

\section{Discussion}

The results substantiated earlier evidence that the deaf and hearing children encode verbal information different1y (McLinden, 1959; Odom \& Blanton, 1967; Allen, 1969, 
1970, 1971). It appears that the deaf make much more extensive use of visual shape encoding. The overall recall of both deaf groups was clearly worse than that of hearing children (cf. Kates et al., 1962). If one can equate the visual code used by the deaf with sensory visual storage (or "iconic" storage, in Neisser's [1967] terminology), these results are not surprising, in view of the evidence, reviewed earlier, that such storage dissipates rapidly. However, this may be an oversimplification. The deaf certainly showed much better recall than one would expect on the basis of decay rates reported by Averbach and Coriell (1961); Posner et al. (1969), and Sperling (1960). Furthermore, an analysis of the serial positions under the various criteria and sequence length reveals a strong primacy effect in most cases, which suggests retrieval from STM rather than from sensory storage (cf. Crowder \& Morton, 1969).

An interesting finding was the reverse ordering in recall that was observed in the Oral Deaf group with fiveletter sequences. The practice of reporting the final letters initially has been noted elsewhere with normal hearing subjects (Glanzer, 1966; Posner, 1964). A possible explanation for it is that the $\underline{S}$ can process only the first few letters, so that the last one or two are retained in sensory storage. The best strategy is then to report these last letters first, before they decay. Posner and Keele (1967) have estimated a decay time of about 1.5 seconds for 
secondary visual storage of single letters, which would possibly give $\underline{S}$ time to write down the last one or two letters. On the other hand, such strong recency effects are nore typical of acoustic (or echoic) storage than of visual (or iconic) storage (Crowder \& Morton, 1969). An examination of confusions in the final serial position showed no basic difference from those in earlier positions; that is there was evidence for both visual and acoustic (or articulatory) confusions.

The two deaf groups (oral and manual) appeared to differ in their encoding techniques beyond their visual memory span. The Oral group made many more articulatory errors. This supports Conrad's (1970) study where he found articulatory errors in recall using an Oral Deaf group. However, when Conrad analyzed his data separately for each individual, he found that not all oral deaf individuals made articulatory confusions. (The $\mathrm{N}$ in Conrad's experiment was 36 . Of these, 21 showed articulatory confusions.) By comparison, the Manual Deaf group made confusions which are obviously not articulatory, but confusions which are much more difficult to identify. If these two deaf groups do encode differently this would explain the low correlations found by Locke (1970, using finger-spelling subjects), when he correlated his data with those of Conrad and Rush (1965, where a certain unidentified number of finger-spelling and orally trained deaf students were used). 
Finally, while it was clearly established that all $\underline{S}$ used in the experiment could easily identify the letters of the population, it is possible that due to linguistic deficiencies they cannot perceive them correctly during sequential presentation. Withrow (1968) addressed himself to the relation between sequence learning and linguistic deficiency. He found that deaf Ss did not perform as well as hearing children on recall of letter sequences; although the presentation rates that he used were much faster (up to four items per sec.) than those used in this present experiment. Nevertheless, there remains the possibility that at least some of the visual confusions observed in the experiment were perceptual, rather than memory ones. The next experiment attempts to investigate this. 


\section{EXPERIMENT 2}

\section{Introduction}

The previous experiment has shown that deaf children are more likely than hearing children to confuse letters in immediate recall on the basis of physical shape. While the hearing showed evidence of recoding the items into an articulatory or acoustic code, the deaf appeared to make much more use of visual memory coding. The next experiment attempts to investigate the nature of the visual code more closely.

Firstly, as cited earlier, the previous experiment could not clearly distinguish between memory and perceptual errors. In the present experiment, $\underline{S} s$ were instructed to write down the letters as they were presented. Any errors written during presentation could be classed as perceptual, whereas, in later recall if any different errors occurred, they could be attributed to memory errors.

Secondly, a ten-second interval was interposed between presentation and recall. If visual confusions still dominated in recall, it would be difficult to argue that these Ss were relying on iconic memory, which decays much faster than this, at least in normal hearing Ss (Neisser, 1967). Rather, it would suggest that the deaf were relying on a longer lasting, more abstract code than iconic memory. 


\section{Method}

\section{Subjects}

There were two groups of nine Ss each, drawn from the same deaf populations (oral and manual) as in the previous experiment. Age ranges of the two groups also closely approximated those of the deaf $\underline{S} s$ in the previous experiment. None of the Ss had served in Experiment 1.

\section{Test Materials}

The test materials were made up in the same way and with the same constraints as those of the last experiment.

\section{Procedure}

The instructions were typed and handed to the subjects, and also given by the class teacher in the appropriate communication mode.

Each subject was presented with a writing block and a prepared answer sheet for each set of twenty trials. The stimuli were once again projected from a Carousel projector. For this experiment one stimulus was presented every two

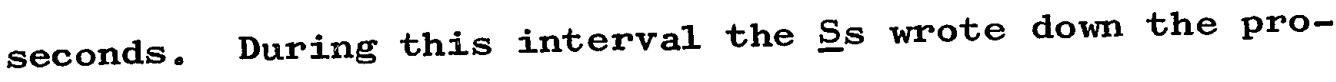
jected letter on the writing tablet. With very little practice, all Ss experienced little or no difficulty with this. This allowed the experimenter to check for perceptual confusions. As soon as the four- or five-letter sequence had been completed the subject immediately turned over the sheet of the tablet and waited. After a ten-second delay a Carousel slide projected a blue patch onto the projection 
screen. This was the signal to the subject to write the material that he still recalled onto the prepared answer sheet.

Under the projection screen were the letters of the population from which each sample was taken. Ss were encouraged to guess when not sure of the letters.

\section{Scoring}

The raw data was scored under the same criteria and conditions as reported in the previous experiment.

\section{Results}

As in the previous experiment, analyses were carried out on accuracy of recall and on the types of errors. Number Correct

The independent variables were again groups, case and serial position. The analyses of variance are summarized in Appendix E.

For four-1etter sequences, there was a significant difference between cases for the ordered recall criterion only $(p<.05)$. There were, however, significant differences between groups on both criteria $(p<.01)$. Differences in serial position were significant for ordered but not free recall $(p<.01)$. An analysis of covariance using age as the covariate showed the Manual group to be significantly better than the Oral group $(p<.05)$.

The serial position curves for four-letter sequences are shown in Figures 5 and 6 . The ceiling effect for the Manual group under the Free Recall criterion hampered any 


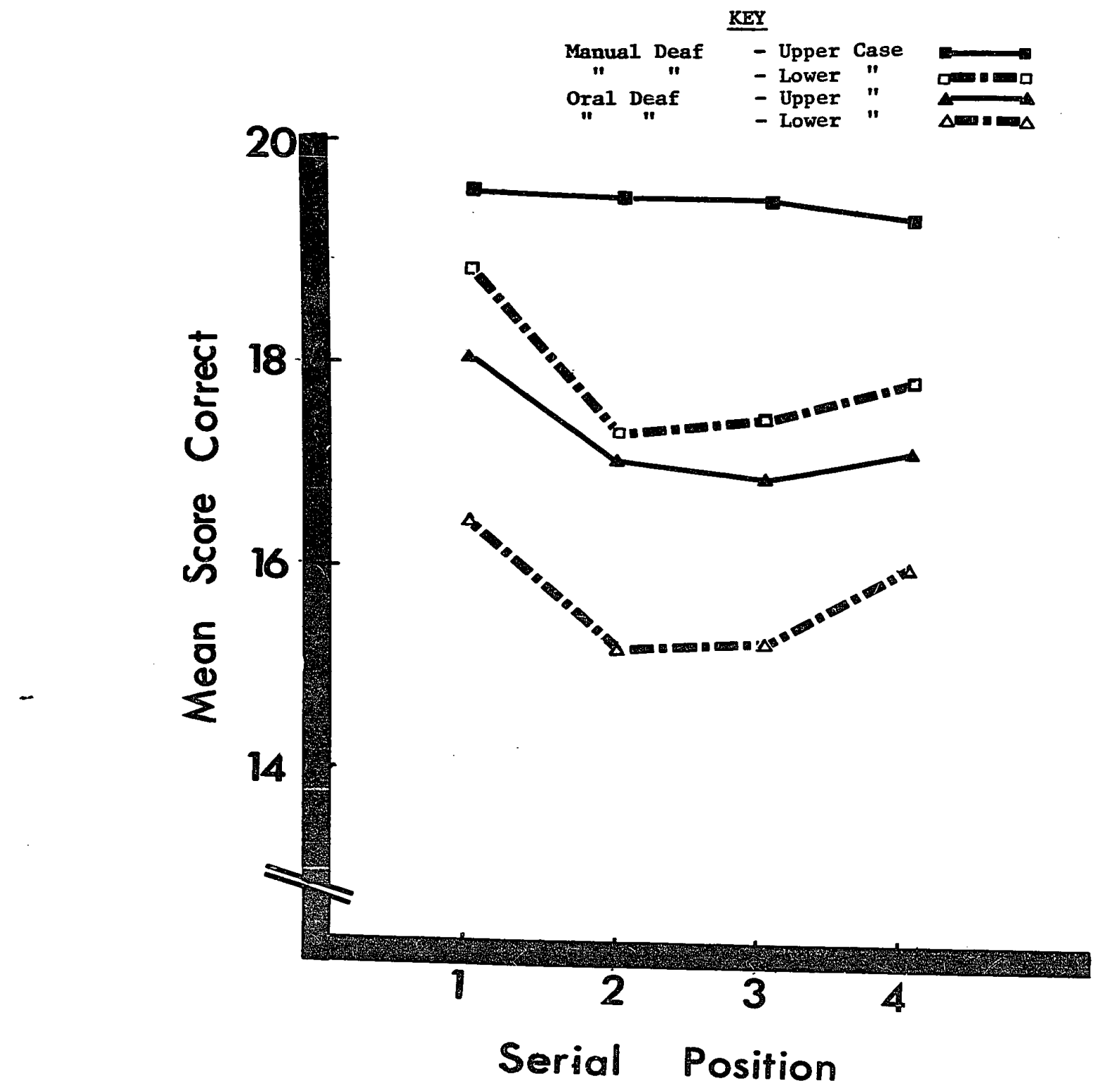

Fig: 5 Ordered Recall Criterion (Experiment 2) 


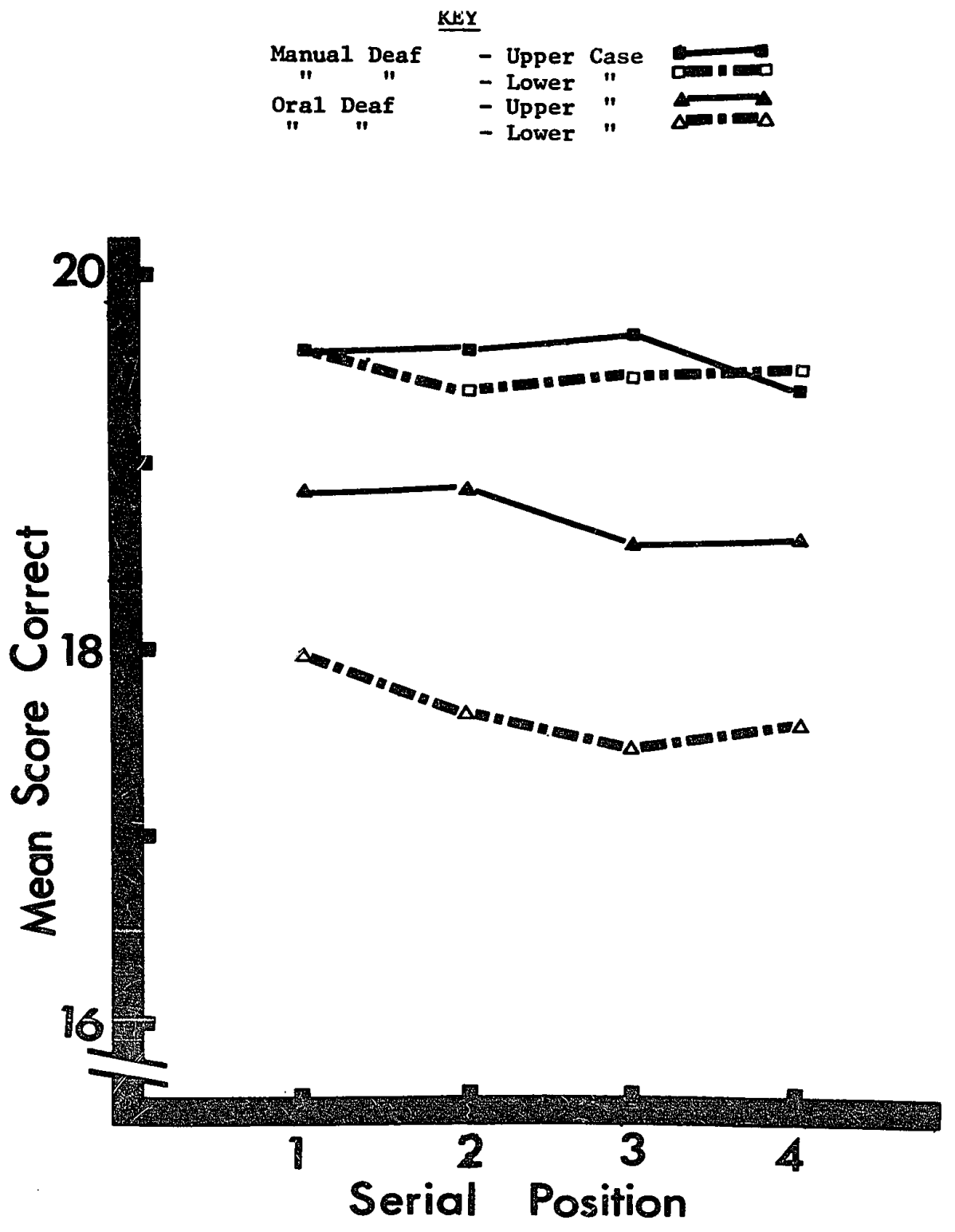

Fig: 6 Free Recall Criterion (Experiment 2) 


\begin{abstract}
firm conclusions.
With five-letter sequences, there were significant
\end{abstract} differences between groups $(p<.001)$. Also, a significant difference for serial position under ordered recall $(p<.01)$, but not free recall. This latter effect was probably affected by the ceiling effect of the Manual group. An analysis of covariance using age as the covariate still showed the Manual Group to be significantly better than the Oral Group $(p<.01)$.

The serial position curves for five-letter sequences are shown in Figures 7 and 8 below. Case was no longer significant, which suggests a different method of encoding with five letters. The differences between the groups was much larger with the longer sequence length.

The strategy of writing down the last letters first, which had been observed with the Oral Deaf Group in Experiment 1 , did not occur in this experiment. Different $\underline{S} s$ used different ordering strategies, although individual S appeared to maintain a fairly consistent strategy. It was also clear that the two groups behaved very differently during the test itself. The manually trained group often encoded in finger spelling during both presentation and retention interval . Any oral rehearsal of this group was certainly sub-vocal, if verbal at all. By comparison, all members of the orally trained groups verbalized. With help from the class teacher it was interesting to note strategy 


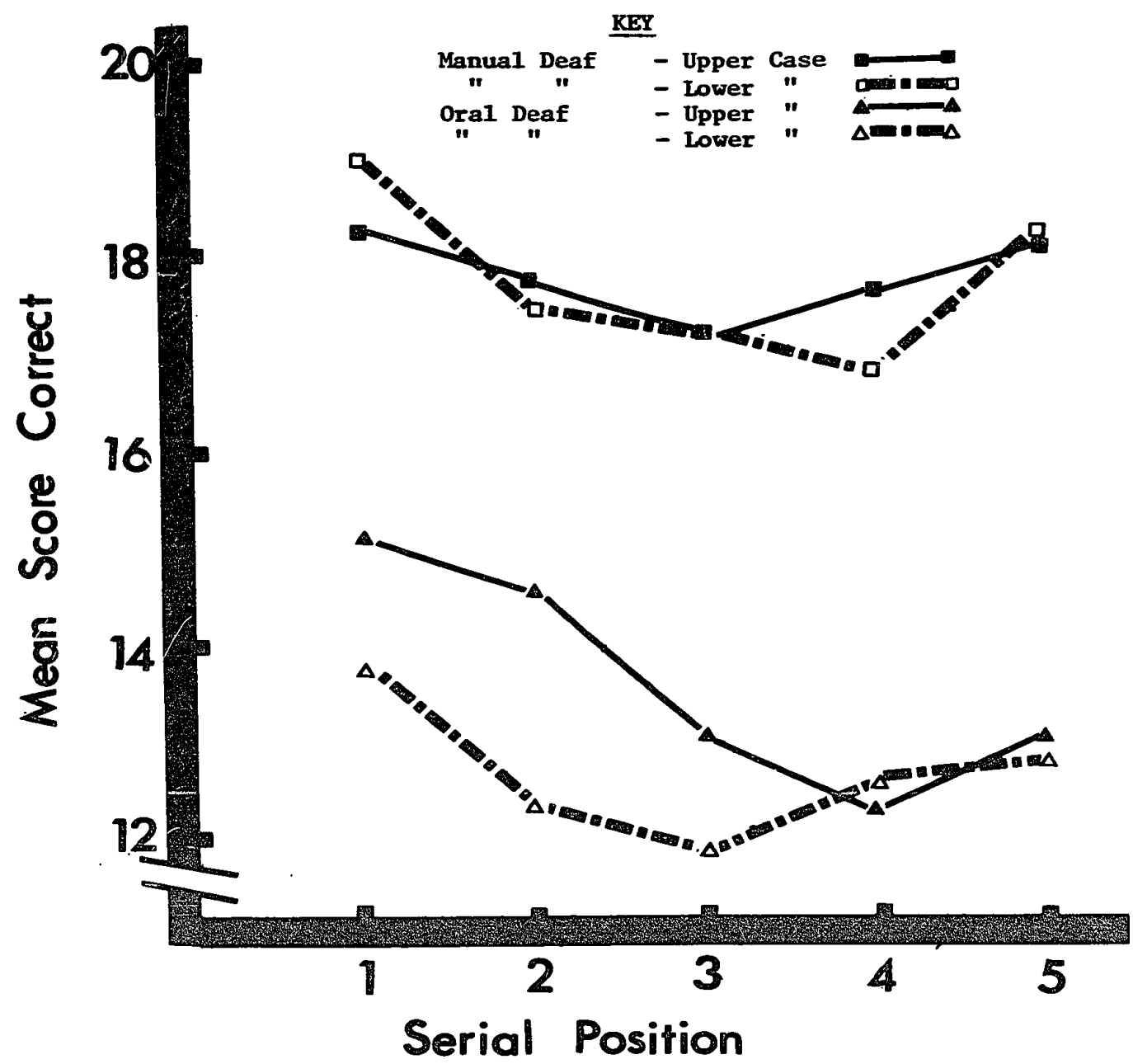

F1g: 7 Ordered Recall Criterion (Experiment 2) 


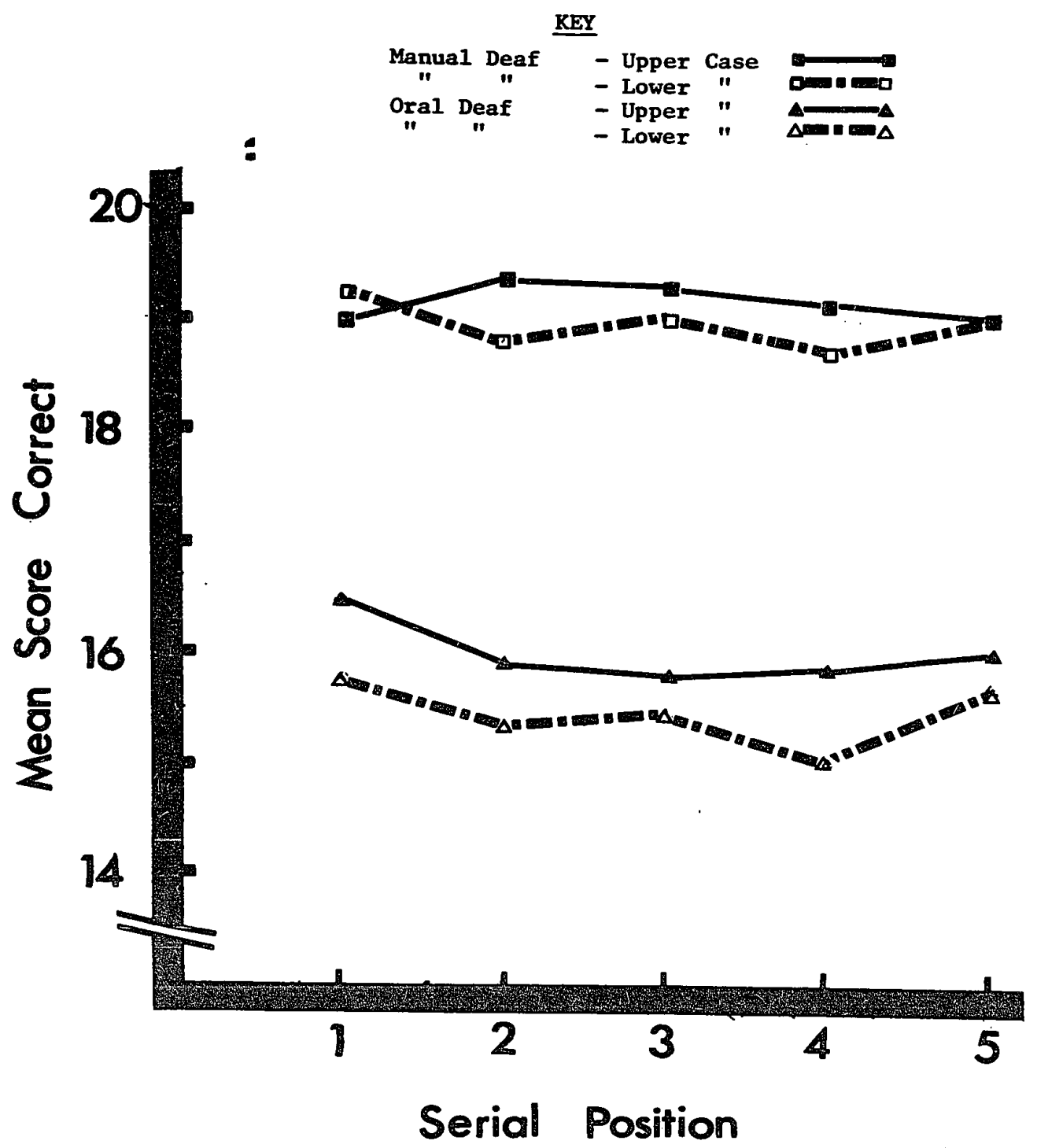

FIg: 8 Free Recall Criterion (Experiment 2) 
differences in rehearsal within this small group. For example, assume that the experimenter presented a sequence of $A, B, D, G$. Some subjects rehearsed the sequence $A, A B$, $A B D, A B D G$, and continued throughout the interval. Some rehearsed the sequence as $A, A B, D, D G$. During the delay period this type of strategy met with sequential ordering problems, e.g., DGBA, GDAB, BADG, BAGD, which persisted in written recall.

Analysis of the writing blocks showed that all subjects correctly recorded the letters during presentation. However, two subjects of the Manual group and one of the Oral group, on one occasion each, wrote only four letters of a five-letter sequence during presentation and written recall. It appeared that these $\underline{S}$ simply allowed their attention to wander, and thus missed a letter.

\section{Confusions}

Confusions were once again tabulated in a $10 \times 10$ matrix, in precisely the same manner as reported in the previous experiment. The sixteen matrices are shown in Appendix $D$.

Product moment correlations were computed between each pair of matrices for each criterion (as in Experiment 1). Tables 2.1 and 2.2 show the correlations between upper and lower case matrices for each group and the major correlations between groups respectively. Table 2.3 shows the product moment correlations between Kuennapas and Janson's 
Ieaf 48 omitted in page numbering. 
Table 2:1

\section{Summary of Upper vs Lower Case Correlations Under Both Criteria (Experiment 2)}

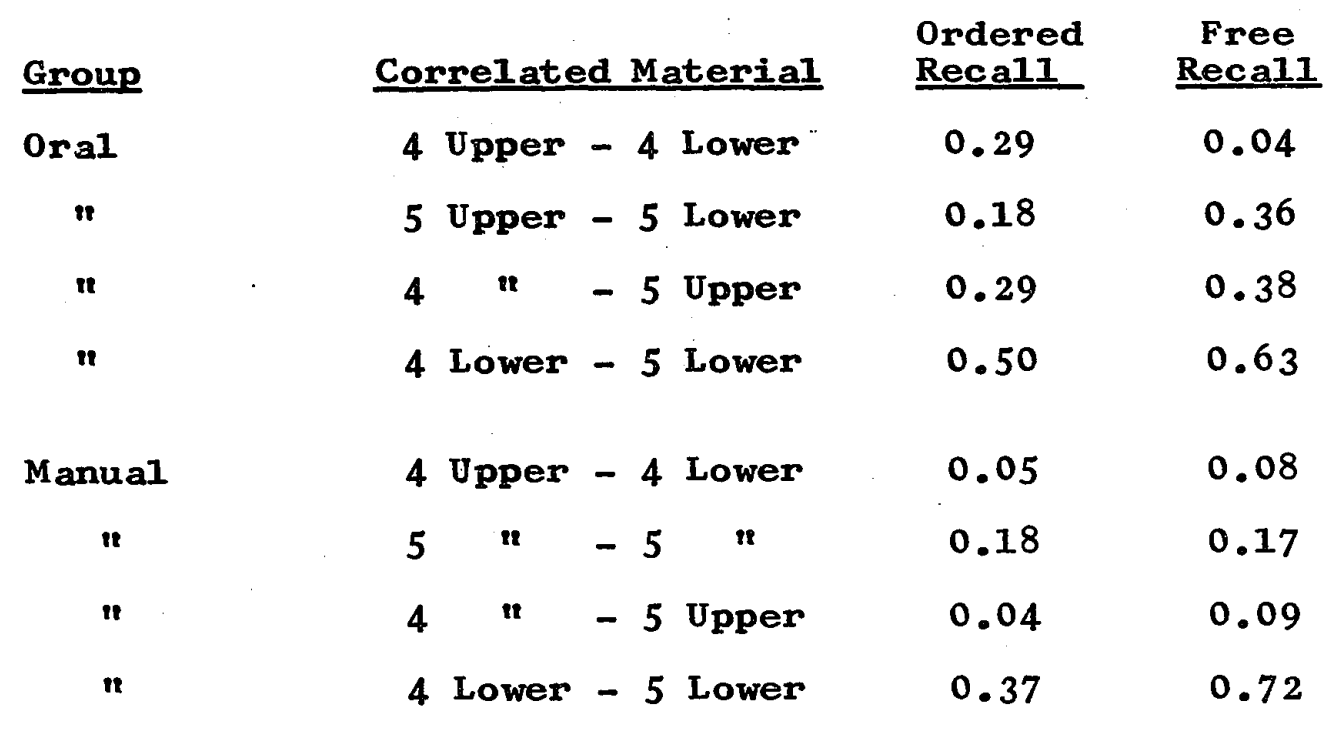


Table 2:2

Summary of Correlations Between Groups for

Both Criteria, Case and Sequence Length

\begin{tabular}{lccc} 
Group & Material Correlated & $\begin{array}{c}\text { Ordered } \\
\text { Recal1 }\end{array}$ & $\begin{array}{c}\text { Free } \\
\text { Recal1 }\end{array}$ \\
\cline { 2 - 4 } Oral & 4 Upper & 0.13 & 0.13 \\
vs & 4 Lower & 0.46 & 0.77 \\
Manual & 5 Upper & 0.13 & 0.03 \\
& 5 Lower & 0.53 & 0.52
\end{tabular}

Table 2:3

Correlations with Kuennapas and Janson (1969)

For Both Criteria in Lower Case

$\begin{array}{clcc}\text { Group } & & \begin{array}{c}\text { Ordered } \\ \text { Recal1 }\end{array} & \begin{array}{c}\text { Free } \\ \text { Recal1 }\end{array} \\ \begin{array}{c}\text { Oral } 4 \\ \text { " Lower }\end{array} & 0.58 & 0.38 \\ \text { Manual } & 4 \text { Lower } & 0.20 & 0.30 \\ \text { n } & 5 \text { Lower } & 0.42 & 0.37 \\ & & 0.32 & 0.30\end{array}$


(1969) data and the respective criteria of Experiment 2 in lower case. The implications of these tables are summarized below for the two groups.

1. Oral Deaf Group. Tine moderate correlations between upper and lower case indicate that this group was using both visual coding and some other method as well. The confusion matrices for both criterion do show evidence of visual coding: For example, $N-H, R-B, a-b, b-d, q-g$. The latter confusion which dominated the previous experiment was still important, but less frequent here. Fowever, the matrices show that this group used another encoding method beyond the visual, particularly mith five-letter sequences. For example, G-D, D-G, T-D, E-T, G-F, D-E, b-e, d-e, t-e, d-t, $g-t$, g-e, were all consistemtly confused. This alternative method of encoding, probably acoustic or articulatory, would explain the lower correlation data using five-letter sequences.

2. Manual Deaf Group. With four-Ietier sequences this group made very few confusions. This could have lowered the reliabilities of the confusion natrices, making the correlations difficult to interpret. Fre only confusion which occurs consistently is $q-g$ and even this is much more infrequent than in the previous experinent. With five-letter sequences they made many more compusions. While visual coding is evident from, for example, the $H-N, h-n$, and $q-g$ confusions, some other abstract code is once again evident. 
While analysis of the confusion data reveals no obvious code (acoustic, articulatory, or finger spelling) which can generally explain all of the confusions made by this group with this sequence length, some confusions were observed which could reasonably be explained in terms of similar finger-spelling positions (e.g., N-E, n-e, N-A, n-a, E-A, H-G) .

Analysis of the confusion matrices also revealed that this deaf group made significantly fewer acoustic or articulation errors than the orally trained group. This would explain the low correlations between the two groups in upper case. The lower case correlations would still be influenced to a large degree by the $q-g$ confusion.

The correlations with Kuennapas et al. (1969) are interesting. The Oral group under the Ordered Recall criterion showed by their lower correlations with five-letter sequences that they were using both visual and some other method (probably acoustic or articulation) of encoding the longer sequences. While the Manual group did show a lower correlation with five-letter sequences it appears that the visual method is still important, but some other abstract code (not acoustic or articulation) is used as well.

A principal Components analysis followed by varimax rotation was performed on the data from the confusion matrices in an endeavour to ascertain the coding methods used by the two groups. 
The results are shown below, in Tables 2.4 and 2.5 for both criteria. The components are identified as follows:

Component A. This once again represents the visual encoding of lower case sequences. The low loadings for the Oral Deaf group with five-1etter sequences in lower case, further suggests that this group used a different method of encoding under that condition.

Component B. This component shows high loadings for the Oral Deaf group in lower case for five-letter sequences, and the Manual Deaf group upper case for four-letter sequences. Two components may have merged under this analysis. However, an attempt to extract a fourth component failed to separate them.

Component $C_{\text {. This component represents the visual }}$ upper case factor for the Oral Deaf only. No consistent visual upper case occurred for the Manual Deaf under the Ordered Recall criterion. While a high loading for upper case with five-letter sequences did occur under the Free Recall criterion, the negative loading for four-letter sequences indicates that a different coding method was used between sequence lengths, for this case.

\section{Discussion}

The major finding from this experiment was that visual confusions still occurred when a delay was introduced between presentation and recall. This clearly establishes the existence of a visual memory code beyond the level of 
Table 2:4

\section{Princ:ipal Component Analysis Under Ordered Recall Criterion (Experiment 2)}

$\begin{array}{llcrrr}\text { Group } & & & \text { Component A } & \text { Component B } & \text { Component C } \\ \text { Oral } & 4 & \text { Upper } & 0.205 & -0.131 & 0.706 \\ \text { Manual } & 4 & " & -0.103 & 1.006 & 0.085 \\ \text { Oral } & 4 & \text { Lower } & 0.866 & 0.064 & 0.274 \\ \text { Manual } & 4 & \text { " } & 0.623 & 0.043 & 0.182 \\ \text { Oral } & 5 & \text { Upper } & -0.064 & 0.081 & 0.787 \\ \text { Manual } & 5 & " & 0.451 & -0.022 & 0.486 \\ \text { Oral } & 5 & \text { Lower } & 0.422 & 0.392 & 0.151 \\ \text { Manual } & 5 & \text { " } & 0.875 & 0.152 & -0.201\end{array}$


Table 2:5

Principal Components Analysis Using

Free Recall Criterion (Experiment 2)

$\begin{array}{llcrrr}\text { Group } & & & \text { Component A } & \text { Component B } & \text { Component C } \\ \text { Oral } & 4 & \text { Upper } & -0.009 & 0.112 & 0.701 \\ \text { Manual } & 4 & \text { " } & 0.058 & -0.440 & 0.549 \\ \text { Oral } & 4 & \text { Lower } & 0.954 & 0.019 & -0.056 \\ \text { Manual } & 4 & \text { " } & 0.876 & -0.088 & 0.078 \\ \text { Oral } & 5 & \text { Upper } & 0.018 & -0.018 & 0.865 \\ \text { Manual } & 5 & \text { " } & 0.076 & 0.912 & 0.073 \\ \text { Oral } & 5 & \text { Lower } & 0.714 & 0.144 & 0.417 \\ \text { Manual } & 5 & \text { " } & 0.917 & 0.187 & -0.145\end{array}$


iconic storage. Further, the confusions could not be attributed to perceptual errors, since the $\underline{S} s$ always wrote down the letters correctly during presentation. The rehearsal strategies of the two groups were interesting. Firstly, let us consider the Oral Deaf groups. All members of this group verbalized during presentation and retention interval. They did not use the same strategy as outlined in Experiment 1. Some of this group rehearsed in cumulative fashion until written recall while others tended to group or "chunk" the items. This is in agreement with existing evidence on rehearsal with normal hearing subjects (Corballis, 1966, 1969; Miller, 1956; Wickelgren, 1969). By comparison, the Manual group encoded "silent1y" but some of them used finger spelling both during presentation and the retention interval. While the encoding methods were different it was hard to analyze whether the Manual group did rehearse in cumulative fashion or not. Neither group showed either a marked primacy or recency effect for either length or criteria.

The Principal Components analysis revealed that, for five-letter upper-case sequences, Manual and Oral groups loaded on different components. If it can be assumed that four items is the visual memory span for the deaf, then the four-item sequences could be encoded visually. However, an additional item overloads this span; to overcome this, it 
appears that the $\underline{S}$ s used some additional encoding technique which was related to mode of communication. For example, the orally trained deaf supplemented the visual with acoustic or articulation components, whereas the manually trained deaf Ss supplemented visual store with kinaesthetic input, at least to some extent.

While several authors have drawn attention to the differences between the visual and auditory modalities in the processing of information for short-term serial recall

(Conrad, 1964; Mackworth, 1964; Sperling, 1963), it appears that the importance of a kinaesthetic store for deaf $\underline{S}$ s has been overlooked.

Broadbent (1958, p. 241) initially suggested that a difference existed between the central processing requirements for motor skills and verbal tasks. More recent research (Adams $\&$ Dijkstra, 1966; Posner, 1967; Posner $~$ Konick, 1966) has indicated that not only does a kinaesthetic STM store exist, but that visual and kinaesthetic STM codes have different central processing requirements. Evidence supporting this hypothesis was observed in the Manual Deaf group in this experiment. It seems apparent that the encoding on the fingers during presentation and retention interval (also noted by Locke \& Locke, 1971) was not only important, but appeared to be used as a rehearsal for input into memory. The interrelations between these two STM stores is at present unknown. It seems possible that STM 
is a multicomponent storage, which must have different levels of processing. Perhaps visual store is the base store for the deaf (as evidenced in Experiments 1 and 2 , but other stores (whether kinaesthetic, articulatory or abstract) acquire much more prominence once the visual processing capacity becomes overloaded. 


\section{EXPERTMENT 3}

\section{Introduction}

The results from the experiments reported above indicate that deaf children do not perform as well as hearing children in recall of visually presented letters. The deficiency of the deaf apparently lies in the nature of the available codes. Probably the optimal strategy is to recode visually presented items into a more durable code for later serial verbal recall (irrespective of whether recall is oral or written). Hearing children can easily recode the items by an articulatory or acoustic code. By comparison, the deaf are limited in their ability to recode in this manner. While the oral deaf attempted to recode by an articulatory or acoustic dimension, they were restricted as a consequence of hearing loss. The recoding of the Manual deaf group was difficult to identify. Some evidence existed for a kinaesthetic code based on finger spelling, but this was probably not the only code. However, what was clear was that both deaf groups made extensive use of a visual shape code. This code appears to differ in duration from the brief visual code labelled by Neisser as "iconic" store. Whatever the nature of the observed visual code was, it does not seem to have been the optimal code for serial verbal recall, even for visually presented items. Assuming that the above account is basically correct 
the deaf should not be at a disadvantage where visual encoding represents an optimal strategy. The following experiment attempts to devise a task, where the stimuli cannot easily be verbalized. Consequently, the stimuli chosen were photographs of faces. As the deaf appeared to have difficulty with sequential ordering in the above experiments, recognition rather than recall measures were used. The stimuli and the task were similar to those described by Wallace (1970) and Wallace, Coltheart and Forster (1970).

In the previous evidence related to the pictorial memory of the deaf many conflicting results have been obtained. Porosyatnikov (1911) found that deaf children aged from 8 to 12 years recognized ambiguous figures less accurately than normal controls, but that there was no difference with older children. Lindner (1925), Vertes (1931), Zankov (1944) and Blair (1957) have all shown that deaf children were worse than hearing children at recognizing objects. Similarly, Rosonova (1966) found deaf children to be impaired in immediate recognition of familiar objects, although there was no difference between deaf and hearing children if the recognition test was delayed ten minutes. Rosonova also concluded that chronological age was an important factor in comparisons between deaf and hearing children. For example, Rosonova argued that the hearing surpassed the deaf in visual recognition periormance at 10 years of age, but this difference disappeared by 16 
years of age. However, these tests may not provide a satisfactory test of visual memory, since the objects used could easily be encoded verbally. Other studies have investigated visual memory for abstract patterns. Myklebust and Brutten (1953) found the deaf to be worse than hearing children for sets of dots, while Hofmarksrichter (1931) found the deaf to be superior. Rosonova (1966) found deaf children to be worse than hearing controls in memory for sequences of figures formed by broken lines or curves. However, what is not clear from all the above studies is the extent to which verbal labelling was possible.

There are advantages in using faces as stimuli in visual memory experiments. First, while faces are equally familiar to both deaf and hearing, the deaf attach particular significance to facial expressions as an additional means of communication. For example, Boese (1968) states that, for a deaf person, a "strained facial expression... can turn the sign for sick into desperately ill." This suggests that the deaf may process facial stimuli more thoroughly if not different1y. Secondly, faces differ in so many subtle ways as to defy simple labellings. The faces wereselected from identification photographs so as to avoid obvious expressions (for example, happy, sad and so on). The stimuli used were also clearly identifiable by sex, and to determine its influence, this factor was controlled in this experiment. 


\section{Method}

\section{Subjects}

Three groups of Ss, two deaf and one hearing, participated in the experiment. These $\underline{S}$ were taken from the same populations as outlined in the previous experiments. The age range of the groups was as follows: Oral Group, 10 years, 8 months to 13 years, 8 months; Manual Group, 14 years, 0 months to 20 years, 0 months; Normal Hearing Group, 14 years, 8 months to 16 years, 9 months. Each group consisted of $10 \mathrm{~S}$, , five boys and five girls.

\section{Test Materials and Procedure}

The stimuii were full-face head and shoulder photographs of students from a Teacher's Training College in Australia. Each photograph measured 2 in. by $21 / 2$ in。 The inspection series of 12 photographs were mounted in a four-by-three array on a sheet of plastic-covered cardboard. The test series of 25 photographs was similarly mounted in a five-by-five array. The inspection series for tasks consisted of either twelve male faces, twelve female faces or a combination of six male and six female faces. The corresponding test series consisted of 25 male, 25 female or a combination of 12 male and 13 female faces (see Appendix G for Inspection and Test Series for each task).

A11 Ss were given written instructions, and those in the deaf groups were also given instructions by the class teacher according to the communication method taught in the 
school. All Ss viewed the inspection series for 45 seconds, irrespective of task. There was a time delay of ten seconds between removal of inspection series and presentation of test series. No task was given during the delay period. The delay period was timed by a stopwatch. Each $\underline{S}$ was tested individually. The order of presentation for the 10 Ss in each group was varied in the following manner. Three Ss were given the tests in the following order: Males, (M), Females (F), Combination (C); three $\underline{S} s$ were given F, $C$, then $M$; while the final four SS were given C, M, then F. Ss were encouraged to guess if they could not remember twelve faces for any task. All photographs used in the test series had a number printed clearly above it, so that each S could simply respond by writing down the twelve numbers on a prepared answer sheet. There was no time limit.

\section{$\underline{\text { Results }}$}

The mean number correct for each group on each task is shown below in Table 3:1. An analysis of variance which was carried out on the data is shown in Appendix H. As can be seen from the analysis of variance, a significant Groups $x$ Faces interaction was found. However, group effects alone were not significant $[F(2,27)=3.19, .05>p<.10]$, but became significant if age was covaried out $[F(2,26)=$ 3.73, $\mathrm{p}<.05]$. To examine the simple effects, Newman-Keuls tests were carried out on the adjusted and non-adjusted means respectively. These means are shown in Tables $3: 1$ and $3: 2$ below. 
Table $3: 1$

Mean Number Correct on a Facial Recognition

Task. (Non-Adjusted Means)

\begin{tabular}{|c|c|c|c|}
\hline Stimuli & Oral Deaf & Manual Deaf & Hearing \\
\hline Male & 9.7 & 9.6 & 7.9 \\
\hline Female & 9.3 & 9.1 & $8 \cdot 3$ \\
\hline Male and Female & 9.3 & 9.8 & 9.2 \\
\hline
\end{tabular}

Table $3: 2$

Mean Number Correct on Facial Recognition

Task. (Adjusted Means)

Stimuli

Male

Female

Male and Female

\section{Oral Deaf}

11.09

10.58

11.28
Manual Deaf

8.75

8.25

7.66
Hearing

7.42

7.82

8.72

Groups underlined by common line do not differ significantly from each other. 


\section{Discussion}

The deaf groups surprisingly were clearly superior to the hearing controls in visual recognition, especially when age was covaried out. This result strikingly contrasts with the results of most of the previous experiments, and confirms that the performance of the deaf in memory experiments are due to their deficiencies in verbal labelling and serial ordering of responses. While the overall superiority of the deaf was not expected, there are two possible reasons for it.

Firstly, that the hearing subjects often attempted to make use of verbal coding. They were observed not only to verbalize more, but to overtly rehearse salient characteristics (such as big nose, wavy hair, pointed chin, and..so on). They also performed better on the series of combined male and female faces, perhaps because they coded the fact there were six of each sex and could therefore restrict their guesses to fewer alternatives. Often such coding or verbal labelling was disadvantageous. For example, in one of the inspection series, one single male face was wearing glasses, while in the corresponding test series three males with totally dissimilar faces were wearing glasses. Some hearing Ss verbalized during the test series that one of that inspection series had been wearing glasses. By looking only at that specific attribute (namely, glasses), many hearing $\underline{S}$ chose the wrong bespectacled face, while the deaf $\underline{S} s$ never 
did so.

Another reason for the superiority of the deaf groups

may have been that they have better developed visual

memories. An experimental observation seems relevant here. When the deaf Ss were presented with either test series, they wrote down the numbers of 9 or 10 faces without hesitation, and then eliminated the remainder. By comparison, the controls typically wrote down 5, 6 or 7 numbers before remarking that they could not recognize the remainder, or alternatively, that they were looking for specific attributes. The reason for this difference between the deaf and hearing groups is at present unknown. 


\section{DISCUSSION}

One of the major conclusions of this thesis is that the deaf make extensive use of visual coding in STM. Previous research has shown that normal hearing $\underline{S}$ utilize predominantly an acoustic (or articulatory) code in recall of verbal items, even when the items are presented visually (Conrad, 1964). This finding was c snfirmed by the data obtained for normal hearing Ss in Experiment 1 . Conrad and Rush (1965) and Conrad (1970) have reported that the deaf make different confusions when recalling visually presented letters. Although Conrad could not specifically state the nature of the code that the deaf use, he hypothesized that the basis of this code was visual shape. Experiments 1 and 2 of this thesis provide a more positive identification of a visual shape code than Conrad's experiments could provide. Furthermore, the final experiment showed that the deaf perform somewhat better than normal hearing $\underline{S} s$ on a facial recognition task, suggesting that they may somehow make more effective use of a visual code. It seems evident that the visual code utilized by the deaf was not restricted to sensory or "iconic" storage, but was a feature of postsensory short term store. For example, in Experiment 2, visual confusions occurred even ten seconds after presentation, which far exceeds the duration of "iconic" storage as measured by Averbach and Coriell (1961) and Sperling (1960). 
Furthermore, in Experiment 1, the Manual deaf group (with the exception of one subject, who had been orally trained. initially) often seemed to encode visually presented lower case letters according to their shapes in upper case, which is further evidence for a visual code that cannot have been sensory.

The extensive utilization of visual coding by the deaf raises the question of whether the deaf have a specially developed capacity for visual memory to compensate for their acoustic or articulatory deficiencies. For example, do they, more often than hearing persons, possess the capacity for eidetic imagery (Haber \& Haber, 1964 ; Klüver, 1928; Leask, Haber \& Haber, 1969). While research is lacking on this point, it appears from an early study that they do not (Hofmarksrichter, 1931). It is more likely, perhaps, that the deaf simply made more use of visual encoding strategies, for both verbal and non-verbal materials. By comparison, the hearing have an efficient verbal coding system and only use their visual system as a secondary code. On non-verbal tasks such as recognition of faces, this verbal strategy of the hearing may be inefficient. This is not to suggest that normal hearing Ss cannot utilize visual coding in postsensory storage, as this has already been shown to exist (Cermak, 1971; Hiles, 1971; Kroll et al., 1970). Presumably the hearing S s preferred the strategy of utilizing their acoustic (or articulatory) or verbal encoding systems which, 
at least for verbal material, provide for better retention than visual encoding. However, the deaf, with poorly developed acoustic and articulatory systems, make what use they can of their visual encoding system before resorting to alternatives.

The nature of these alternative codes was not altogether clear. In both Experiments 1 and 2, the Oral deaf group showed evidence of acoustic confusions, with fiveletter sequences. However, it should be pointed out that what are generally accepted as acoustic confusions for hearing subjects (Conrad, 1964), may be different for deaf Ss. For example, what a deaf child hears through many modern hearing aids is often so acoustically distorted that it bears little resemblance to what was actually spoken. Nevertheless, a moderate correlacion was obtained between the confusions shown between this and the hearing group. It was even less clear what code or codes the Manual group used, beyond the visual. There was at least some evidence for a kinaesthetic code based on finger spelling; some of the confusions in Experiments 1 and 2 could plausib1y be related to similarities in finger-spelling positions, and Ss were actually observed to finger spell during the retention interval in Experiment 2. However, finger spelling could not explain all of the confusions. It seems possible that post-sensory coding for this group, a.t least, was multidimensional (i.e., visual, kinaesthetic, abstract). Perhaps the manually trained deaf can benefit from material simultaneously available in kinaesthetic and visual modalities. 
Another finding with important theoretical implications requires brief elaboration. Crowder and Morton (1969) have argued that strong recency effects in serial recall reflect pre-categorical acoustic storage (P.A.S.)--or "echoic" storage in Neisser's (1967) terminology. However, the recency effects observed with five-1etter sequences for the Oral deaf in Experiment 1, clearly cannot be attributed to echoic storage. It was not clear what code did mediate recall of the final letters. As noted earlier, examination of confusions showed no distinct differences as a function of serial position; that is, there was evidence for articulatory and visual coding in the final, as well as in the earlier positions. This suggests that the distinction between pre-categorical and post-categorical storage processes based on serial position curves, may be much more complex than originally envisaged by Crowder and Morton (1969). Conrad $(1970$, p. 188), in his research with the deaf, has made a similar point.

In conclusion, it appears that only a multicomponent memory model (cf. Morton, 1970; Murray, 1969) could possibly succeed at present, in explaining the results of this thesis. Most memory models (e.g., Atkinson \& Shriffrin, 1968; Norman, 1970; Waugh \& Norman, 1965) clearly distinguish the various stages of memory, but they do not elaborate sufficiently on the multidimensionality of the codes within these stages. By comparison, the multicomponent memory 
models (Morton, 1970; Murray, 1969) clearly distinguish the multidimensional aspects of the coding in memory, but neglect the different stages. Too little is known of the different stages of memory within each coding dimension for a comprehensive model to be specified at this time. Implications of this Work for Educators of the Deaf

It seems possible that the STM codes that were discovered and discussed in this thesis have important implications for deaf educators, particularly if these codes generalize to other cognitive processes or skills, such as thinking (cf. Conrad \& Rush, 1965). However, it should be remembered that the limited sampling of both subjects and stimuli restricts the generality of these findings considerably.

The most important finding was that the deaf children made much more extensive use of visual coding. The deaf were also more efficient in their use of visual coding. This thesis could not resolve whether or not the deaf possessed a better visual memory, or whether the deaf simply utilized more efficient visual strategies. In either case, it seems reasonable to conclude that greater emphasis should be placed on the use of visual aids and techniques in deaf education.

Another important point concerns the degree of distortion in modern hearing aids. This is a much more important variable than previously acknowledged. Distortion of any degree 
in a hearing aid will underutilize the residual hearing of that child. It seems possible that many of the qualitative differences observed and reported in the literature between deaf and hearing subjects may be attributable to the constant distortion apparent in many modern aids. For example, many of the linguistic differences observed in the deaf and reliance on visual coding may possibly be directly related to this factor.

The final point relates to the comparison between the two deaf groups and their respective methods of instruction. As cited in the Introduction, there has been a long controversy over the best method to use in instructing the deaf. Recent evidence has shown the merits of manual training in deaf instruction (Morkovin, 1968; MacDougall, 1971; Stuckless E Birch, 1965; Vernon, 1968b, 1969). The results of this thesis show that the manually trained certainly suffered no disadvantage when compared with the orally trained for these types of tasks. In all experiments, the Manual group was superior to the Oral group even when age was covaried out. Considering the implications of these results and those reported by Conrad $(1970,1971)$, it would seem that manual training and communication should form an important part of curricula for any deaf child. 


\section{REFERENCES}

Adams, J. A., \& Dijkstra, S. Short-term memory for motor responses. Journal of Experimental Psychology, 1966, 71, 314-318.

Adams, J. A., Thorsheim, H. I., \& McIntyre, J.A. Item length, acoustic similarity and natural language mediation as variables in short-term memory. Journal of Experimental Psychology, 1969, 80, 39-46 (a).

Adams, J. A., McIntyre, J. S., \& Thorsheim, H. I. Response feedback and verbal retention. Journal of Experimental Psychology, 1969, 82, 290-296 (b).

Allen, D. V. Modality aspects of mediation in children with normal hearing and with impaired hearing ability.

Final report project No. 7-0837, Department of Health, Education and Welfare, December, 1969.

Allen, D. V. Acoustic interference in paired-associate learning as a function of hearing ability. Psychonomic Science, 1970, 18, 231-233.

Allen, D. V. Color-word interference in deaf and hearing children. Psychonomic Science, 1971, 24, 295-296.

Atkinson, R. C., \& Shriffrin, R. M. Human memory: A proposed system and its control processes. In $K$. W. Spence and J. T. Spence (Eds.), The psychology of learning and motivation. Vol. 2. New York: Academic Press, 1968. 
Averbach, E., \& Coriel1, A. S. Short-term memory in vision.

Be11 System Technical Journal, 1961, 40, 309-328.

Baddeley, A. D. Semantic and acoustic similarity in shortterm memory. Nature, 1964, 204, 1116-1117.

Baddeley, A. D. The influence of acoustic and semantic similarity on long-term memory for word sequences. Quarterly Journal of Experimental Psychology, 1966, 18, 302-309.

Baddeley, A. D. How does acoustic similarity influence shortterm memory? Quarterly Journal of Experimental Psychology, $1968,20,249-264$.

Baddeley, A. D. Effects of acoustic and semantic similarity on short-term paired-associate learning. British Journal of Psychology, 1970, 6I, 335-345.

Baddeley, A. D., \& Patterson, K. The relation between longterm and short-term memory. British Medical Journal, 1971, September, 237-242.

Bahrick, H. P., \& Boucher, B. Retention of visual and verbal codes of the same stimuli. Journal of Experimental Psychology, 1968, 78, 417-422.

Bender, R. Conquest of deafness. C1eveland: Press of Western Reserve University, 1960.

Bernbach, H. A multicopy model for post-perceptual memory. In D. Norman (Ed.), Mode1s of human memory. New York: Academic Press, 1970

Best, H. Deafness and the deaf in the U.S. New York: Macmillan Company, 1943. 
Birch, J. W., \& Stuckless, E. R. Relationship between early manual communication and later achievement of the deaf. U. S. Office of Education, Co-Operative research project 1769,1964 .

Blair, F. X. A study of the visual memory of deaf and hearing children. American Annals of the Deaf, 1957, 102, 254263.

Blanton, R. L. Psycholinguistic processes in the deaf. Panel presented at the meeting of the American Speech and Hearing Association, Chicago, 1965.

Blanton, R. L., \& Nunnally, J. C. Retention of trigrams by deaf and hearing subjects as a function of pronunciability. Journal of Verbal Learning $\leftleftarrows$ Verbal Behavior, $1967, \underline{6}, 428-431$.

Blanton, R. L., Nunnally, J. C., \& Odom, P. Psycholinguistic processes in the deaf. Final report, Grant No. RD1479-S. September, 1967.

Blanton, R. L., $\&$ Odom, P. B. Some possible interference and facilitation effects of pronunciability. Nashville, Tennessee, Vanderbilt University, 1968, 844-846.

Blanton, R. L., Odom, P. B., \& McIntyre, C. W. Symbolic and linguistic processes in the deaf. Final report, Grant RD-2552-S. July, 1971.

Boese, R. Towards an ethnography of the deaf. Unpublished M.A. thesis, University of California, Santa Barbara, 1968. 
Boese, R, J., \& Cicourel, A, V. Sign language acquisition and the teaching of deaf children. In D. Hymes, C. Cazden, \& V. John (Eds.), The functions of language in the classroom. New York: Teachers' College, 1971. Broadbent, D. E. Perception and communication. New York: Permagon Press, 1958.

Cermak, G. W. Short-term recognition memory for complex free-form figures. Psychonomic Science, 1971, 25, 209-211.

Chase, W. G., \& Posner, J. I. The effect of auditory and visual confusability on visual and memory search tasks. Paper presented at the meeting of the Midwestern Psychological Association. Chicago, May, 1965.

Clark, S. E. Retrieval of color information from perceptual memory. Journal of Experimental Psychology, 1969, 82, 263-266.

Cohen, G. A comparison of semantic, acoustic and visual criteria for matching of word pairs. Perception and Psychophysics, 1968, 4, 203-204. Cole, R. A., Haber, R. N., \& Bales, B. D. Mechanisms of aural encoding: 1 . Distinctive features for consonants. Perception and Psychophysics, 1968, 3, 281-284.

Cole, R. A., Sales, B. D., \& Haber, R. N. Mechanisms of aural encoding: II. The role of distinctive features in articulation and rehearsal. Perception and Psychophysics, 1969, 6, 343-348. 
Conrad, R. Serial order intrusions in immediate memory. British Journal of Psychology, 1960, 51, 45-48.

Conrad, R. An association between memory errors and errors due to acoustic masking of speech. Nature, 1962, 193, 1314-1315.

Conrad, R. Acoustic confusion in immediate memory. British Journal of Psychology, 1964, 55, 75-84.

Conrad, R. Short-term memory processes in the deaf. British Journal of Psychology, 1970, 61, 179-195.

Conrad, $R$. The effect of vocalizing on comprehension in the profoundly deaf. British Journal of Psychology, 1971, 62, 147-150.

Conrad, R., \& Hul1, A. J. Information, acoustic confusion and memory span. British Journal of Psychology, 1964, 55, 429-43.2.

Conrad, R., \& Hull, A. J. Input modality and the serial position curve in short-term memory. Psychonomic Science, 1968, 10, 135-136.

Conrad, R., \& Rush, M. L. On the nature of short-term memory encoding by the deaf. Journal of Speech and Learning Disorders, 1965, 30, 336-343.

Corballis, M. C. Rehearsal and decay in immediate recall of visually and aurally presented items. Canadian Journal of Psychology, 1966, 20, 43-51.

Corballis, M. C. Patterns of rehearsal on immediate memory. British Journal of Psychology, 1969, 60, 41-49. 
Craik, F. I. M. Modality effects in short-term storage. Journal of Verbal Learning and Verbal Behavior, 1969, 8, 658-664.

Craik, F. I. M. Primary memory. Bxitish Medical Journal, 1971, September, 231-236.

Crowder, R. G., \& Morton, J. Precategorical acoustic storage (PAS). Perception and Psychophysics, 1969, 5, 365-373.

Dainoff, $M$. Time course of visual coding. Journal of Experimental Psychology, 1970, 86, 214-224. Dainoff, M., \& Haber, R. N. How much help do repeated presentations give to recognition processes? Perception and Psychophysics, 1967, ㄹ, 131-136.

Dainoff, M., $\&$ Haber, R. N. The effect of acoustic confusability on levels of information processing. Canadian Journal of Psychology, 1970, 24, 98-108. Dainoff, M., \& Marvin, J. Time course of visual and auditory encoding. Journal of Experimental Psychology, 1970, $\underline{86}, 214-224$.

Dale, H. C. A., \& Gregory, M. Evidence of semantic encoding in short-term memory. Psychonomic Science, 1966, 5, 153-154.

Davis, H., \& Silverman, S. R. (Eds.). Hearing and deafness. New York: Holt, Rinehart \& Winston, 1967.

De Land, F. The story of lip-reading. Its genesis and development. Alexander Graham Bell Association for the Deaf, Inc. Washington, D.C., 1968. 
Dick, A. 0. Visual information processing and the memory trace. Unpublished doctoral dissertation, University of Water1oo, 1967.

Dick, A. 0. Relations between the sensory register and shortterm storage in tachistoscopic recognition. Journal of Experimental Psychology, 1969, 2, 276-284.

Dick, A. O. Visual processing and the use of redundant information in tachistoscopic recognition. Canadian Journal of Psychology, 1970, 24, 133-141 (a).

Dick, A. 0. On the problem of selection in short-term visual (iconic) memory. Canadian Journal of Psychology, 1971, 25, 250-263.

Dornbush, R. L. Shadowing in bisensory memory. Quarterly Journal of Experimental Psychology, 1966, 72, 667-677. Ewing, A. W. G. Educational guidance and the deaf child. Manchester, Eng.: Manchester University Press, 1957. Fry, D. B. The development of the phonological system in the normal and the deaf child. In F. Smith \& G. A. Miller (Eds.), The genesis of language. Cambridge, Mass.: M.I.T. Press, 1966.

Furth, H. G. Conceptual performance in deaf adults. Journal of Abnormal and Social Psychology, 1964, 69, 676-681.

Furth, H. G. Thinking without 1anguage. New York: Free Press, 1966.

Furth, H. G. Linguistic deficiency and thinking: Research with deaf subjects 1964-1969. Psychological Bulletin, $1971,76,58-72$. 
Glanzer, M. Encoding in the perceptual (visual) serial

position effect. Journal of verbal learning and verbal

Behavior, 1966 , 5, 92-97.

Glucksberg, S., Fisher, D. G., \& Monty, R. H. Brief visual memory as a function of visual and acoustic confusability. Paper presented at the meeting of the American Psychological Association. Washington, D.C., September, 1967. Goetzinger, C. P., \& Huber, T. G. A study of immediate and delayed visual retention with deaf and hearing adolescents. American Annalis of the Deaf, 1964, 109, 293-305. Graham, F., \& Kenda11, B. Memory-for-designs test. Missoula, Mont.: Psychological Test Specialists, 1946.

Haber, R. N. Effect of prior knowledge of the stimulus on the recognition process. Journal of Experimental Psycho1ogy, 1965, 69, 282-286.

Haber, R. N., $\&$ Haber, R. B. Eidetic imagery: 1: Frequency. Perceptual and Motor Skills, 1964, 19, 131-138.

Haber, R. N., \& Standing, L. Clarity and recognition of masked and degraded stimuli. Psychonomic Science, 1968, 13, 83-84.

Haber, R. N., \& Standing, L. G. Direct measures of shortterm visual storage. Quarterly Journal of Experimental Psychology, 1969, 21, 43-54.

Hartman, S., \& Elliott, L. L. Performance of deaf and hearing on a short-term memory task. Psychonomic Science, 1965, 3, 573-574. 
Hebb, D. O. Organization of behavior: A neuropsychological theory. New York: Wiley, 1949.

Heider, F. K., \& Heider, G. M. A comparison of sentence structure of deaf and hearing children. Psychological Monographs, 1940, 52, 42-103.

Hershenson, M. Stimulus structure, cognitive structure and the perception of letter arrays. Journal of Experimental Psychology, 1969, 79, 327-335.

Hiles, D. R. Visual confusions in immediate memory. Unpublished M.A. thesis, McGill University, July, 1971. Hintzman. D. L. Classification and aural coding in shortterm memory. Psychonomic Science, 1965, 3, 161-162.

Hintzman, D. L. Articulatory coding in short-term memory. Journal of Verbal Learning and Verbal Behavior, 1967, 6, $312-316$.

Hofmarksrichter, $K$. Visuette kompensation und eidetik bei taubstummen. Arch. f. d. ges. Psychol., 1931, 2, $329-402$.

Johnson, W. L., $\&$ Chamberlin, C. M. Semantic and acoustic similarity and their effects on short-term retention. Psychonomic Science, 1970, 19, 217-218.

Kaiser, H. F. The varimax criterion for analytic rotation in factor analysis. Psychometrika, 1958, 23, 187-200. Kaplan, G. A., Yonas, A., \& Schurcliff, A. Visual and acoustic confusability in a visual search task. Perception and Psychophysics, 1966, 1, 172-174. 
Kates, S., Kates, W., \& Michaeh, J. Cognitive processes in deaf and hearing adolescents and adults. Psychological Monographs, 1962, 76, 32. Whole 551 .

Keele, S. W., \& Chase, W. G. Short-term visual storage. Perception and Psychophysics, 1967, 2, 383-386.

Kintsch, W., $\&$ Buschke, H. Homophones and synonyms in STM. Journal of Experimental Psychology, 1969, 80, 403-408. Knox, H. V. Knox cube imitation test. Chicago: C. H. Stoelting Co., 1914.

Kro11, N. E., Parks, T., Parkinson, S. R., Bieber, S. L., ש Johnson, A. L. Short-term memory while shadowing: Recall of visually and of aurally presented letters. Journal of Experimental Psychology, 1970, 85, 220-224. Kuennapas, T. Visual perception of capital letters; multidimensional ratio scaling and multidimensional similarity. Scandinavian Journal of Psychology, 1966, 1 , 189-196.

Kuennapas, T. Visual memory of capital letters. Multidimensional ratio scaling and multidimensional simi1arity. Perceptual and Motor Skills, 1967, 25, 345-350. Kuennapas, T., \& Janson, A. J. Multidimensional similarity of letters. Perceptual and Motor Ski11s, 1969, 28, 3-12.

Klüver, H. Studies on the eidetic type and eidetic imagery. Psychological Bulletin, 1928, 25, 69-104. 
Leask, J., Haber, R. N., \& Haber, R. B. Eidetic imagery in children: II. Longitudinal and experimental results. Psychonomic Monograph Supplements, 1969, 3 (Whole No. 35 ).

Liberman, A. M., Cooper, F. S., Shankweiler, D. P., \& Studdert-Kennedy, M. Perception of the speech code. Psychological Review, 1967, 24, 431-461.

Lindner, R. Das taubstumme kind in verglachen mit vol1sinnigen schul kindern. Liepzig. Verlag der Buchhandlung, 1925 .

Locke, J. Short-term memory encoding strategies of the deaf. Psychonomic Science, 1970, 18, 233-234 (a).

Locke, J. Subvocal speech and speech. American Speech and Hearing Association, 1970, 12, 8-14 (b).

Locke, J., \& Fehr, F. S. Subvocal rehearsal as a form of speech. Journal of Verbal Learning and Verbal Behavior, 1970, 2, 495-498.

Locke, J. L., \& Locke, V. I. Deaf children's phonetic; visual and dactylic coding in a grapheme recall task. Journal of Experimental Psychology, 1971, 89, 142-146. Mackworth, J. Visual image and the memory trace. Canadian Journal of Psychology, 1962, 16, 55-59.

Mackworth, J. Duration of the visual image. Canadian Journal of Psychology, 1963, 17, 62-81.

Mackworth, J. Auditory short-term memory - Canadian Journal of Psychology, 1964, 18, 292-303. 
Margrain, S. A. Short-term memory as a function of input modality. Quarterly Journal of Experimental Psychology, $1967,19,109-114$.

Meadows, $K$. Effect of early manual communication and family climate. Unpublished doctoral dissertation, University of California, Berkeley, 1967.

Melton, A. W. Implications of short-term memory for a general theory of memory. Journal of Verbal Learning and Verbal Behavior, 1963, 2, 1-21.

Merritt, M. A. Communication methods in education of the deaf. A review of the literature. Unpublished M.A. thesis, Denton, Texas, 1965.

Miller, G. A. The magical number seven, plus or minus two: Some limits on our capacity for processing information. Psychological Review, 1956, 63, 81-97.

Miller, G. A., \& Nicely, P. E. An analysis of the perceptual confusions among English consonants. Journal of the Acoustical Society of America, 1955, 22, 338-352. Milner, B. Visual recognition-recall after right temporal lobe excision in man. Neuropsychologia, 1968, $\underline{6}$, 191-209.

Montgomery, G. W. Relationship of oral skills to manual communication in profoundly deaf students. American Annals of Deaf, 1966, 111, 557-565.

Morkovin, B. V. Through the barriers of deafness and isolation. New York: Macmillan, 1960. 
Morkovin, B. V. Language in the general development of the pre-school deaf child: A review of research in the Soviet Union. American Speech and Hearing Association, $1968,11,195-199$.

Morton, J. A functional model for memory. In D. A. Norman (Ed.), Models for human memory. New York: Academic Press, 1970 .

Morton, J., Crowder, R. G., \& Prussin, H. A. Experiments with the stimulus suffix effect. Journal of Experimental Psychology, 1971, 21, 169-190.

Murjock, B. B. Short term memory for associations. In D. Norman (Ed.), Models of human memory. New York:

Academic Press, 1970.

Murdock, B. B., \& Walker, K. D. Modality effects in free recall. Journal of Verbal Learning and Verbal Behavior, $1969, \underline{8}, 665-676$.

Murray, D. J. The effect of white noise upon the recall of vocalized 1ists. Canadian Journal of Psychology, 1965, 19, $333-345$.

Murray, D. J. Vocalization at presentation and the recall of lists varying in association value. Journal of Verbal Learning and Verbal Behavior, 1966, 5, 488-491. Murray, D. J. Overt versus covert rehearsal on short-term memory: Psychonomic Science, 1967, Z, 363-364. Murray, D. Articulation and acoustic confusability in STM. Journal of Experimental Psychology, 1968, 78, 679-684. 
Murray, D. J. Modality-specific cues as factors determining short-term memory performance. Paper presented at AAAS symposium, Boston, 1969.

Myklebust, H. The psychology of deafness. New York: Grune E Stratton, 1964 .

Myklebust, H. R., \& Brutten, M. A study of the visual perception of deaf children. Acta oto-laryng., Stockh., 1953, Suppl。105, 126 p.

McAndrew, H. Rigidity and isolation: A study of the deaf and the blind. Journal of Abnormal and Social Psychology, $1948,43,476-494$.

MacDougall, J.C. The education of the deaf in Canada. Canadian Psychologist, 1971, 12, 534-540.

MacDougal1, J. C., \& Rabinovitch, M. S. Imagery and learning in deaf and hearing children. Psychonomic Science, 1971, 22, 347-349.

McGuigan, F. Covert linguistic in deaf subjects during thinking. Journal of Comparative and Physiological Psychology, 1971, 75, 417-420.

McLinden, M. M. C. Learning with different associative cues by normal-hearing and hearing-impaired children. Unpublished data, Wayne State University, 1959.

Neisser, U. Cognitive psychology. New York: Appleton-CenturyCrofts, 1967.

Norman, D. A. Toward a theory of memory and attention. Psychological Review, 1968, 75, 522-536. 
Norman, D. A. Memory and attention. New York: Wiley, 1969.

Norman, D. A. Models of human memory. New York: Academic Press, 1970 .

Odom, P. B., \& Blanton, R. L. Phrase-learning in deaf and hearing subjects. Journal of Speech and Hearing Research, $1967,10,600-605$.

Odom, P. B., \& Blanton, R. I. Rule learning in deaf and hearing subjects. Vanderbilt University. American Journiz1 of Psychology, 1.967, 으, 391-397.

Odom, P. B., Blanton, R. L., \& McIntyre; C. K. Coding medium and word recall by deaf and hearing subjects. Journal of Speech and Hearing Research, 1970, 13, 55-58.

oleron, P. Conceptual thinking of the deaf. American Annals of the Deaf, 1953, 28, 304-310.

Olssen, J. E., \& Furth, H. G. Visual memory span in the deaf. American Journal of Psychology, 1966, 79, 480484 .

Parkinson, S. R., Parks, T. E., E Kroll, N. E. A. Visual and auditory short-term memory; effects of phonemically similar auditory shadow material during the retention interval. Journal of Experimental Psychology, 1971, 87, 274-280.

Pintner, R., Eisenson, J., \& Stanton, M. The psychology of the physically handicapped. New York: Crofts, 1941. 
Pintnex, R., \& Paterson, D. G. Learning tests with deaf children. Psychological Monographs, 1916, 20 (No. 88). Pintner, R., \& Paterson, D. G. A comparison of deaf and hearing children in visual memory for digits. Journal of Experimental Psychology, 1917, 2, 76-88.

Porosyatnikov. Reported in R. M. Boskis \& A. I. Meshcheryakov (Eds.), Sensory defects and mental development, Symposium 33, p. 103. Moscow International Congress of Psychology, 1966.

Posner, M. I. Rate of presentation and order of recall in immediate memory. British Journal of Psychology, 1964, 55, 303-306.

Posner, M. I. Short term memory systems in human information processing. Acta Psychologia, Amsterdam, 1967, 27, 267-284 (a).

Posner, M. I. Characteristics of visual and kinaesthetic memory codes. Journal of Experimental Psychology, 1967, 25, 103-107 (b)

Posner, M. I. Abstraction and the process of recognition. In J. T. Spence \& G. H. Bower (Eds.), Psychology of learning and motivation: Advances in research and theory. Vo1. 3. New York: Academic Press, 1969. Posner, J. I., Boies, S. J., Eichelman, W. Ho, E Taylor, R. L. Retention of visual and name codes of single letters. Journal of Experimental Psychology, 1969, 79, (1 PT2). 
Posner, M. I., \& Keele, S. W. Decay of visual information from a single letter. Science, 1967, 158, 137-139. Posner, M. I., \& Konick, A. F, Short term retention of visual and kinaesthetic information. Journal of Organizational Behavior and Human Performance, 1966, 1, 71-88.

Quigley, S. P. The influence of fingerspelling on the development of language, communication, and educational achievement in deaf children. Institute for Research on Exceptional Children, University of Illinois, 1969. Quigley, S. P., \& Frisina, D. Institutionalization and psychoeducational development of deaf children. Council for Exceptional Children Research Monograph, 1961, Series A, No. 3 .

Reamer, J. C. Mental and educational measurement with deaf children. Psychological Monographs, 1921, 132, (No. 29).

Ross, B. M. Sequential visual memory and the limited magic of the number seven. Journal of Experimental Psychology, 1969, 80, 339-347.

Rosonova, T. V. Pictorial memory of deaf children. In R. M. Boskis \& A. I. Meshcheryakov (Eds.), Sensory defects and mental development. Symposium 33, pp. 103-114. Moscow, International Congress of Psychology, 1966. Sales, B. D., Cole, R. A., \& Haber, R. N. Mechanisms of aural encoding: V. Environmental effects of consonants on vowel encoding. Perception and Psychophysics, 1969, 으, $361-365$. 
Sales, D. B., Haber, R. N., \& Cole, A. R. Mechanisms of aural encoding III: Distinctive features for vowels. Perception and Psychophysics, 1968, 4, 321-327.

Sales, B. D., Haber, R. N., \& Cole, R. A. Mechanisms of aural encoding IV: Hear-see, say-write interactions for vowels. Perception and Psychophysics, 1969, 6, 385-390.

Shepard, R. N. Recognition memory for words, sentences, and pictures. Journal of Verbal Learning and Verbal Behavior, $1967, \underline{6}, 156-163$.

Sperling, G. The information available in brief visual presentations. Psychological Monographs, 1960, 74(Whole No. 498).

Sperling, G. A model for visual memory tasks. Human Factors, $1963 ;$, $19-36$.

Sperling, G. Successive approximations to a model for short term memory. Acta Psychologica, 1967, 27, 285292.

Sperling, G. Phonemic model of short-term auditory memory. Paper presented at the meeting of the American Psychological Association, San Francisco, September, 1968. Standing, L., \& Haber, R. N. Visual search and memory under degraded and masked presentation. Psychonomic Science, $1968, \underline{13}, 81-82$. 


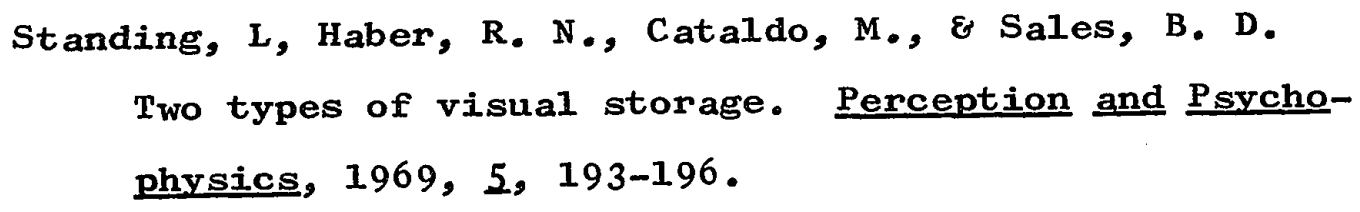

Tinker, M. A. The relative legibility of the letters, the digits, and of certain mathematical signs. Journal of Psychology, 1928, 1, 472-496. 
Vernon, M. Current etiological factors in deafness. American Annals of the Deaf, 1968, 113, 106-115 (a). Vernon, $M$. Fifty years of research on the intelligence of the deaf and hard of hearing. Journal of the Rehabilitation of the Deaf, 1968, 1, 1-11 (b).

Vernon, $M$. Sociological and psychological factors associated with hearing 1oss. Journal of Speech and Hearing Research, 1969, 12, 541-563.

Vertes, J. 0. The memory of deaf-mute children. $\underline{\text { Zsch }}$. f. päd. Psychol., 1931, 32, 136-142.

Wallace, G. Reminiscence in recognition memory for faces. Unpublished M.A. thesis, Monash University, 1970. Wallace, G., Coltheart, M., \& Forster, K. I. Reminiscence in recognition memory for faces. Psychonomic Science, $1970, \underline{18}, 335-336$.

Waugh, N. C., \& Norman, D. A. Primary memory. Psychological Review, 1965, 72, 89-104.

Whetnall, E., \& Fry, D. B. The deaf child. London: Thomas, 1966.

Wickelgren, W. A. Acoustic similarity and intrusion errors in short-term memory. Journal of Experimental Psychology, 1965, 20, 102-108 (a).

Wickelgren, W. A. Distinctive features and errors in shortterm memory for English vowels. Journal of the Acoustical Society of America, 1965, 38, 583-588 (b). 
Wickelgren, W. A. Short-term memory for phonemically similar 1ists. American Journal of Psychology, 1965, 78, 567574 (c).

Wickelgren, W. A. Similarity and intrusions in short-term memory for consonant-vowel diagrams. Quarterly Journal of Experimental Psychology, 1965, 17, 241-246 (d). Wickelgren, W. A. Acoustic similarity and retroactive interference in short-term memory. Journal of Verbal Learning and Verbal Behavior, 1965, 44, 53-61 (e). Wickelgren, W. A. Distinctive features and errors in STM for English consonants. Journal of the Acoustical Society of America, 1966, 39, 388-398 (a). Wickelgren, W. A. Phonemic similarity and interference in short-term memory for single letters. Journal of Experimental Psychology, 1966, 71, 396-404 (b). Wickelgren, W. A. Short-term recognition memory for single letters and phonemic similarity of retro-active interference. Quarterly Journal of Experimental Psychology, $1966, \underline{18}, 55-62$ (c). Wickelgren, W. A. Auditory or articulatory coding in verbal short-term memory. Psychological Review, 1969, 2, 232-235.

Wickelgren, W. Multitrace strength theory. In D. Norman (ed.), Models of human memory. New York: Academic Press, 1970. 
Withrow, F. B. Immediate memory span of deaf and normally hearing children. Exceptional Children, 1968, 35, 33-41.

Zankov, L. V. The memory of school children: The psychology and pedagogy of memory. Moscow, 1944. 


\title{
TABLE OF APPENDICES
}

\author{
Appendix A: Finger Spelling Alphabet \\ Appendix B: Experiment 1: Confusion Matrices \\ Appendix C: Experiment 1: Analyses of Variance \\ Appendix D: Experiment 2: Confusion Matrices \\ Appendix E: Experiment 2: Analyses of Variance \\ Appendix F: Summary of Confusion Matrices \\ (Experiments 1 and 2) \\ Appendix G: Facial Recognition Stimuli \\ Appendix H: Analysis of Variance for Facial Recognition \\ (Experiment 3)
}


APPENDIX A

Finger Spelling Alphabet 


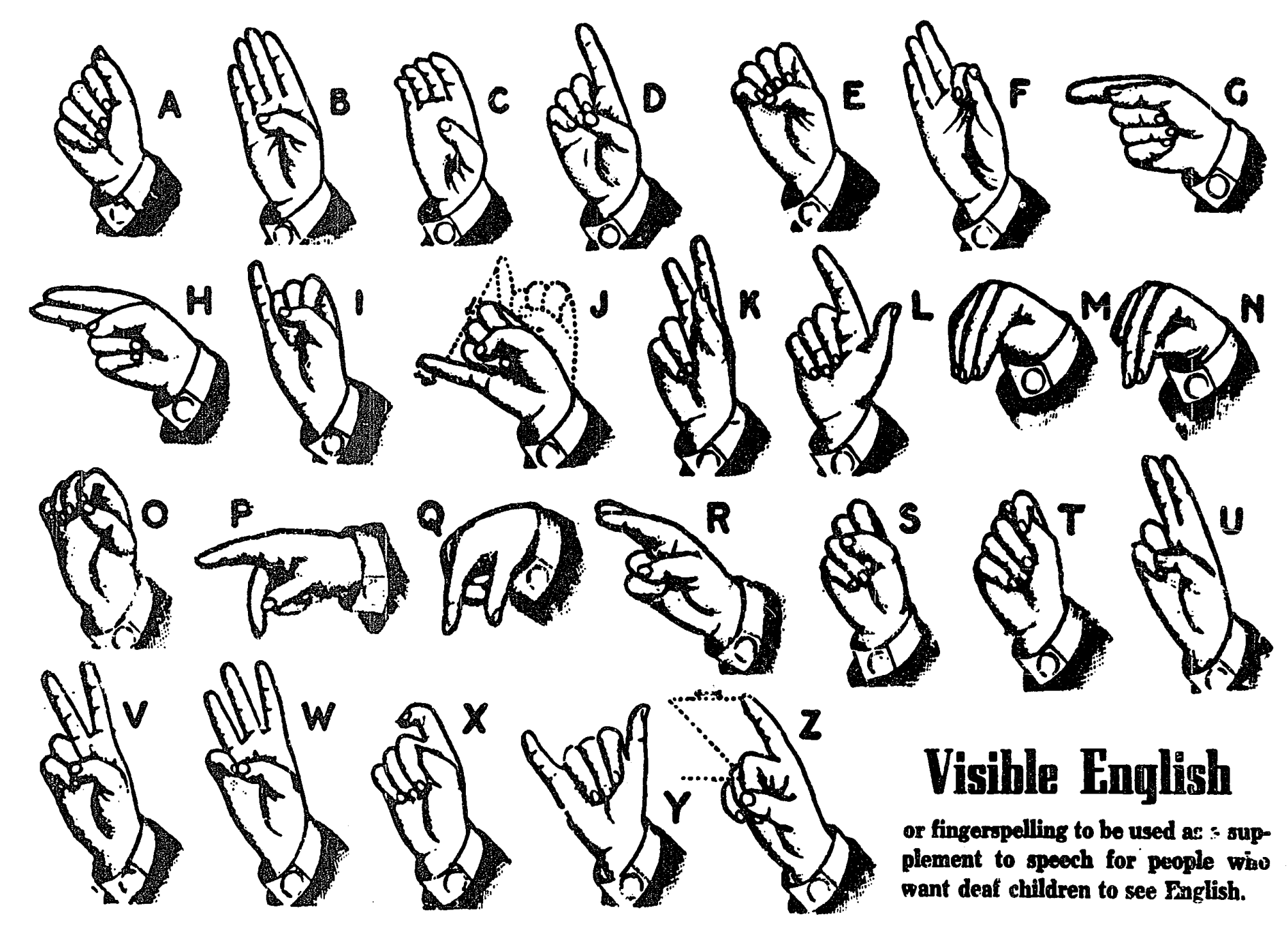


APPENDIX B

Experiment 1: Confusion Matrices 
EXPERIMENT

GROUP: Norma1 Hearing

SEQUENCE LENGTH: 4 Letters

CASE: Upper

CRITERION: ORDERED RECALL

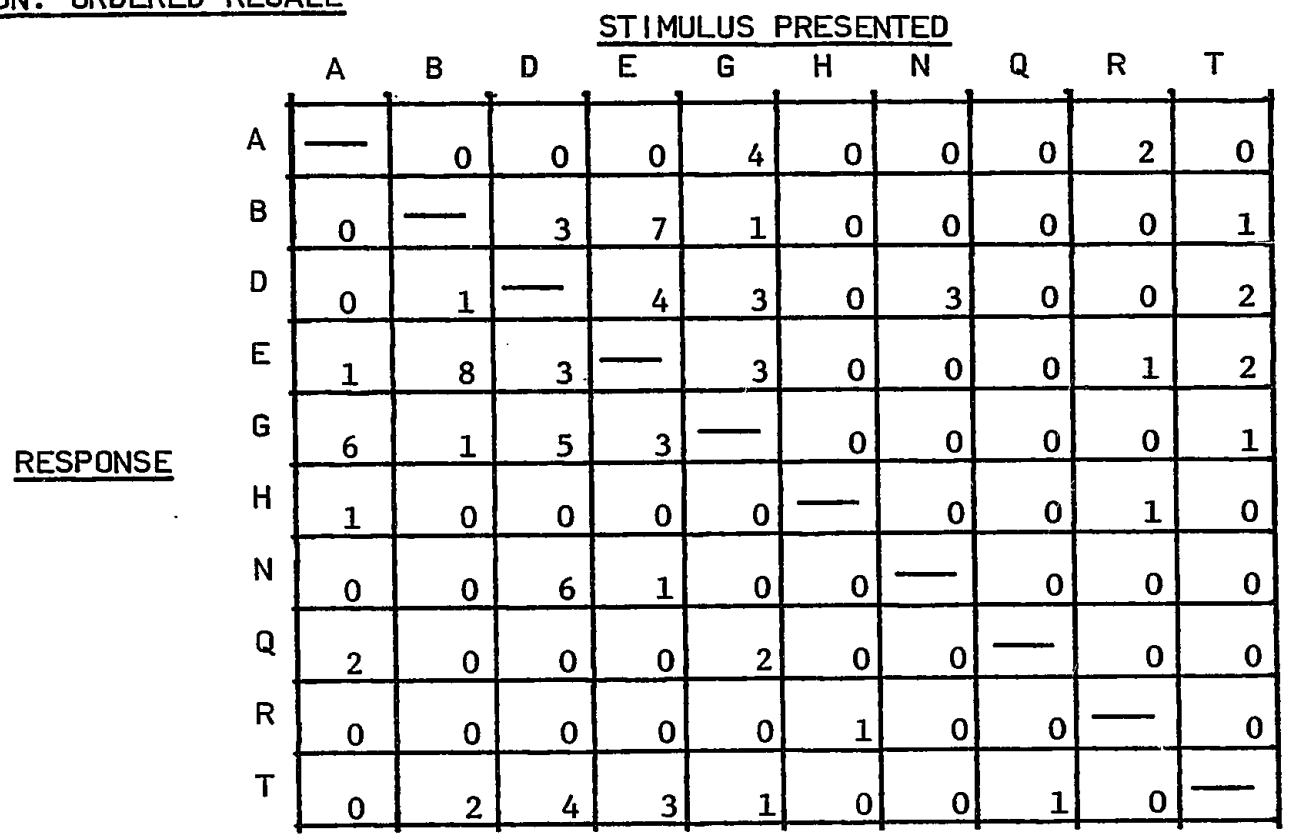

CRITERI ON: FREE RECALL

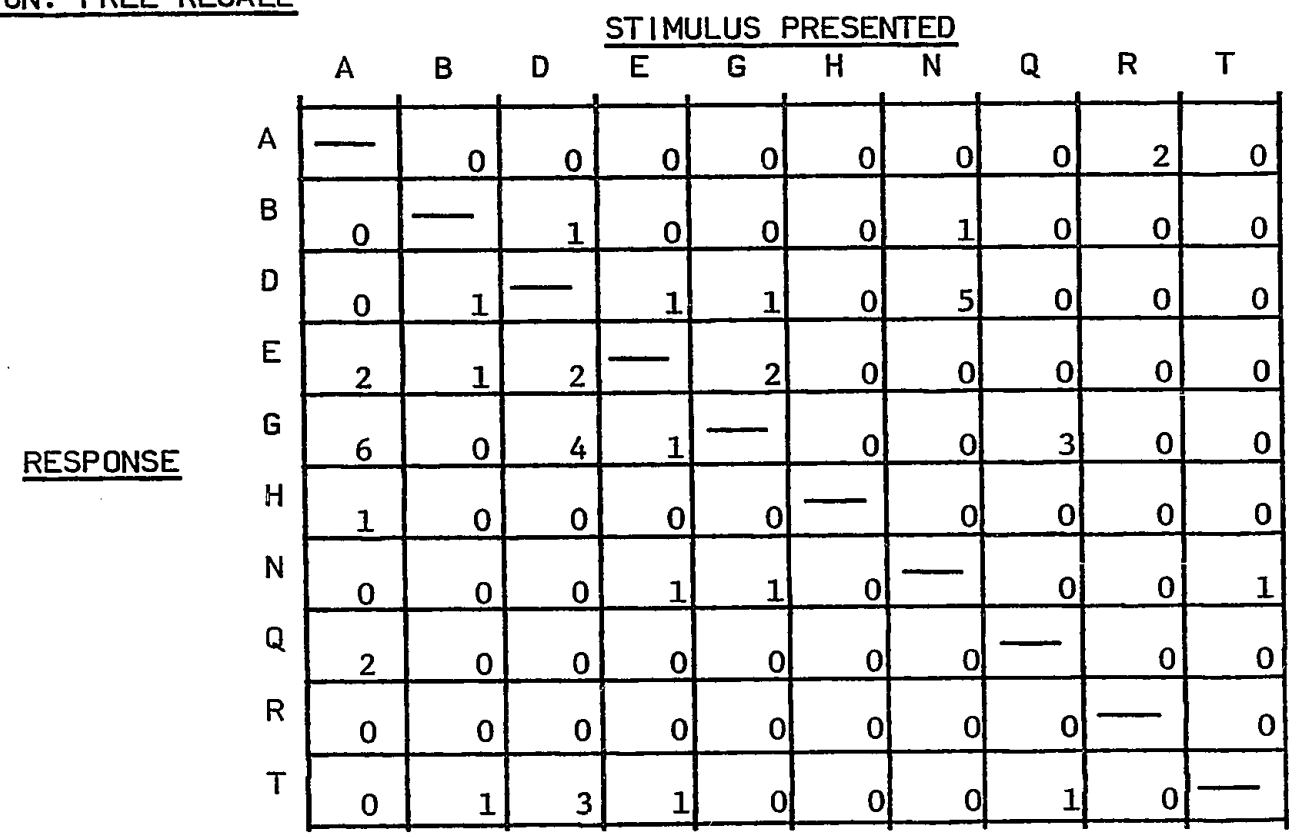


EXPERIMENT 1

CRITERION: ORDERED RECALL

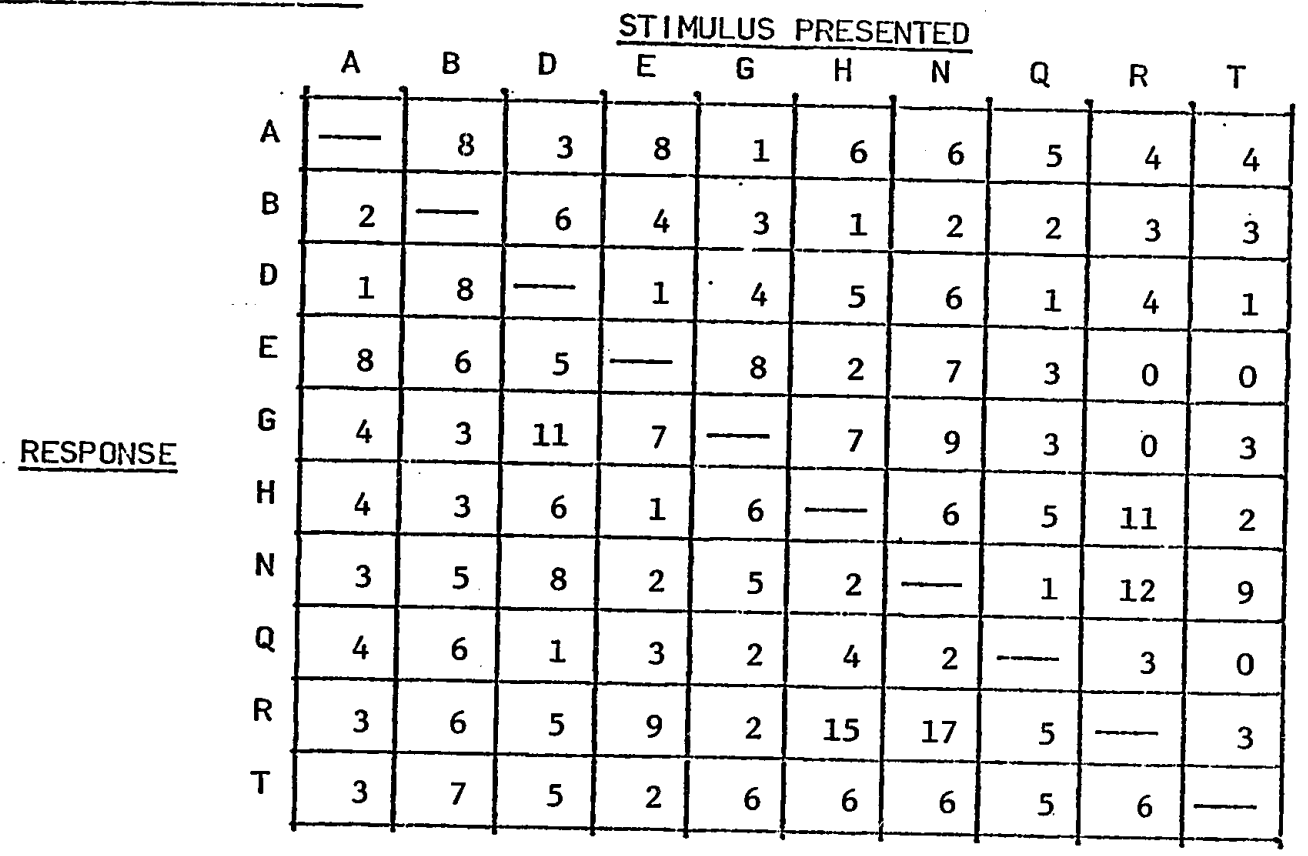

CRITERION: FREE RECALL

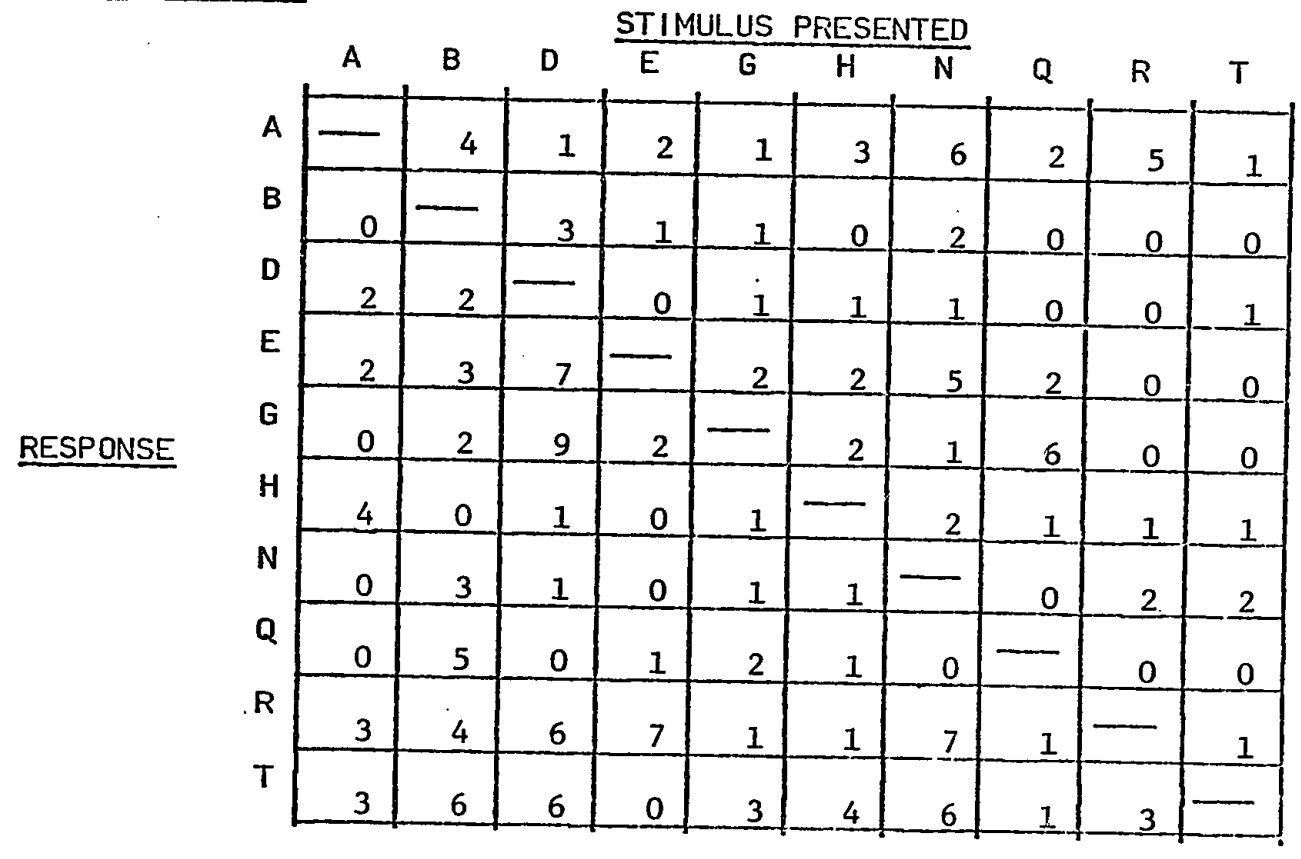


EXPERIMENT 1

GROIJP: Oral Deaf

SEQUENCE LENGTH: 4 Letters

CASE: Upper

CRITERION: OROERE.D RECALL

\begin{tabular}{|c|c|c|c|c|c|c|c|c|c|c|c|}
\hline \multicolumn{12}{|c|}{ STIMULUS PRESENTED } \\
\hline & & A & B & D & $E$ & G & $H$ & $\mathbf{N}$ & $\mathbf{Q}$ & $\mathrm{R}$ & $\mathrm{T}$ \\
\hline & A & $\square$ & 3 & 1 & 3 & 5 & 7 & 6 & 8 & 7 & 3 \\
\hline & B & 2 & - & 12 & 3 & 5 & 4 & 1 & 4 & 2 & 1 \\
\hline & D & 0 & 6 & - & 4 & 3 & 3 & 4 & 1 & 1 & 1 \\
\hline & $E$ & 3 & 2 & 4 & $\square$ & 2 & 3 & 3 & 2 & 7 & 8 \\
\hline RESPONSF & G & 3 & 6 & 2 & 3 & - & 5 & 6 & 0 & 1 & 2 \\
\hline & $\mathrm{H}$ & 4 & 3 & 1 & 1 & 1 & - & 5 & 0 & 4 & 4 \\
\hline & $\mathbf{N}$ & 4 & 1 & 2 & 6 & 2 & 8 & 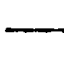 & 4 & 2 & 2 \\
\hline & $Q$ & 5 & 7 & 3 & 2 & 2 & 0 & 4 & $\longrightarrow$ & 4 & 0 \\
\hline & $\mathbf{R}$ & 2 & 4 & 5 & 7 & 5 & 7 & 8 & 4 & - & 4 \\
\hline & $T$ & 2 & 7 & 5 & 5 & 7 & 5 & 4 & 2 & 3 & $\longrightarrow$ \\
\hline
\end{tabular}

CRITERI ON: FREE RECALL

\begin{tabular}{|c|c|c|c|c|c|c|c|c|c|c|c|}
\hline \multirow{2}{*}{\multicolumn{2}{|c|}{ 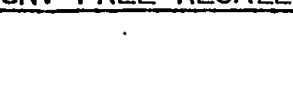 }} & \multicolumn{10}{|c|}{ STIMULUS PRESENTED } \\
\hline & & A & B & D & $E$ & $\mathbf{G}$ & $\mathrm{H}$ & $\bar{N}$ & $\mathrm{Q}$ & $\mathbf{R}$ & $T$ \\
\hline \multirow{10}{*}{ RESPONSE } & A & - & 3 & 2 & 2 & 3 & 4 & 4 & 2 & 2 & $I$ \\
\hline & B & 1 & - & 4 & 0 & 3 & 2 & 1 & 0 & 2 & 0 \\
\hline & D & 2 & 1 & - & 0 & 0 & 1 & 1 & 0 & 0 & 1 \\
\hline & $E$ & 3 & 2 & 1 & - & 5 & 2 & 3 & 1 & 5 & 1 \\
\hline & G & 0 & 1 & 2 & 2 & - & 1 & 4 & 1 & 0 & 1 \\
\hline & $H$ & 0 & 1 & 1 & 0 & 1 & $\longrightarrow$ & 2 & 0 & 0 & 0 \\
\hline & N & 1 & 1 & 4 & 0 & 4 & 5 & - & 0 & 1 & 2 \\
\hline & Q & 0 & 2 & 3 & 0 & 1 & 0 & 4 & - & 0 & 0 \\
\hline & $\mathbf{R}$ & 1 & 10 & 3 & 3 & 2 & 4 & 5 & 0 & - & 0 \\
\hline & $\mathrm{T}$ & 0 & 4 & 4 & 1 & 4 & 2 & 1 & 0 & 1 & - \\
\hline
\end{tabular}


EXPERIMENT 1

GROUP: Normal Hearing
SEQUENCE LENGTH: 4 Letters

CASE: Lower

CRITERION: ORDERED RECALL

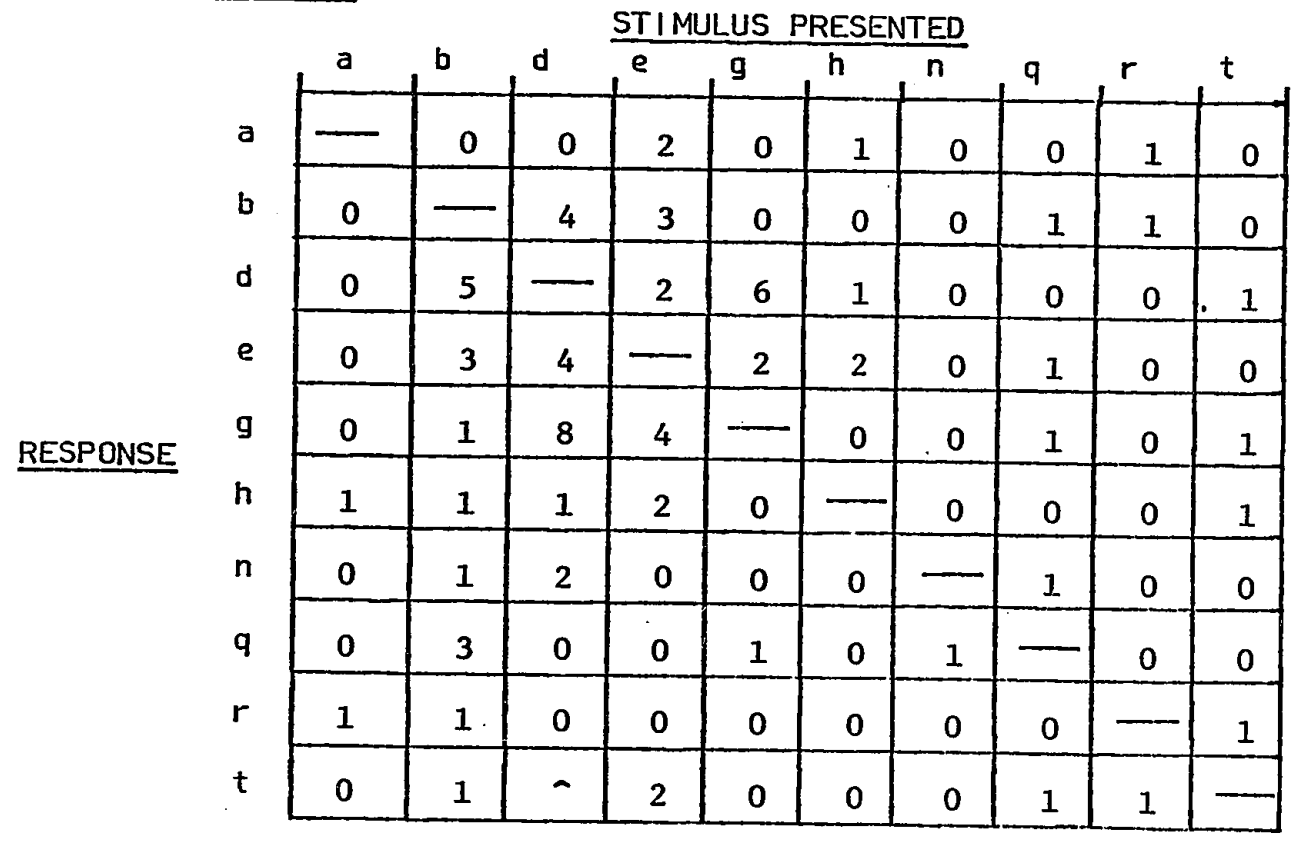

CRITERION: FREE RECALL

\begin{tabular}{|c|c|c|c|c|c|c|c|c|c|c|c|}
\hline & \multicolumn{10}{|c|}{ STIMULUS PRESENTED } \\
\hline & & a & b & d & e & $g$ & $h$ & $n$ & $q$ & $r$ & $t$ \\
\hline & $a$ & $\longrightarrow$ & 0 & 0 & 1 & 0 & 0 & 0 & 2 & 2 & 0 \\
\hline & $b$ & $\mathbf{0}$ & - & 1 & 1 & 0 & 0 & 0 & 1 & 0 & 0 \\
\hline & d & 0 & 1 & - & 0 & 4 & 0 & 0 & 1 & 0 & 0 \\
\hline & e & $\mathbf{0}$ & 1 & 1 & $\longrightarrow$ & 0 & 1 & 0 & 2 & 0 & 0 \\
\hline RESPONSE & $\mathbf{g}$ & 0 & 0 & 4 & 1 & $\longrightarrow$ & 0 & 0 & 1 & 0 & 2 \\
\hline & h & 0 & 0 & 0 & 0 & 0 & - & 0 & 0 & 0 & 1 \\
\hline . & $n$ & 0 & 0 & 1 & 1 & 0 & 0 & - & 0 & 0 & 0 \\
\hline & $q$ & 0 & 0 & 0 & 0 & 0 & 0 & 0 & - & 0 & 1 \\
\hline & $r$ & 0 & 0 & 0 & 0 & 0 & 0 & 0 & 0 & - & 0 \\
\hline & $t$ & 0 & 1 & 0 & 0 & 0 & 0 & 0 & 0 & 0 & - \\
\hline
\end{tabular}


EXPERIMENT 1

GROUP: Manual Deaf

CRITER ION: ORDERED RECALL

\begin{tabular}{|c|c|c|c|c|c|c|c|c|c|c|c|}
\hline NL & & & & & $1 \mathrm{M}$ & JS & IESE & $E D$ & & & \\
\hline & & $a$ & & d & 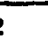 & 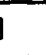 & $h$ & $n$ & $q$ & $r$ & $t$ \\
\hline & a & 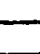 & 1 & 2 & 5 & 5 & 11 & 9 & 8 & 4 & 4 \\
\hline & b & 4 & $\longrightarrow$ & 4 & 0 & 2 & 5 & 1 & 3 & 4 & 2 \\
\hline & d & 1 & 6 & $\longrightarrow$ & 2 & 2 & 9 & 7 & 2 & 0 & 6 \\
\hline & e & 3 & 3 & 2 & 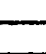 & 6 & 2 & 2 & 1 & 6 & 4 \\
\hline & g & 6 & 4 & 11 & 4 & 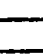 & 7 & 13 & 69 & 3 & 3 \\
\hline & h & 5 & 8 & 3 & 1 & 7 & & 4 & 1 & 6 & 3 \\
\hline & $n$ & 6 & 1 & 4 & 1 & 2 & 6 & - & 2 & 0 & 5 \\
\hline & $q$ & 2 & 1 & 1 & 0 & 4 & 0 & 1. & س. & 0 & 1 \\
\hline & $r$ & 5 & 6 & 1 & 12 & 3 & 8 & 8 & 3 & - & 5 \\
\hline & $t$ & 4 & 3 & 11 & -- & 1 & 6 & 3 & 3 & 3 & \\
\hline
\end{tabular}

CRITERI ON: FREE RECALL

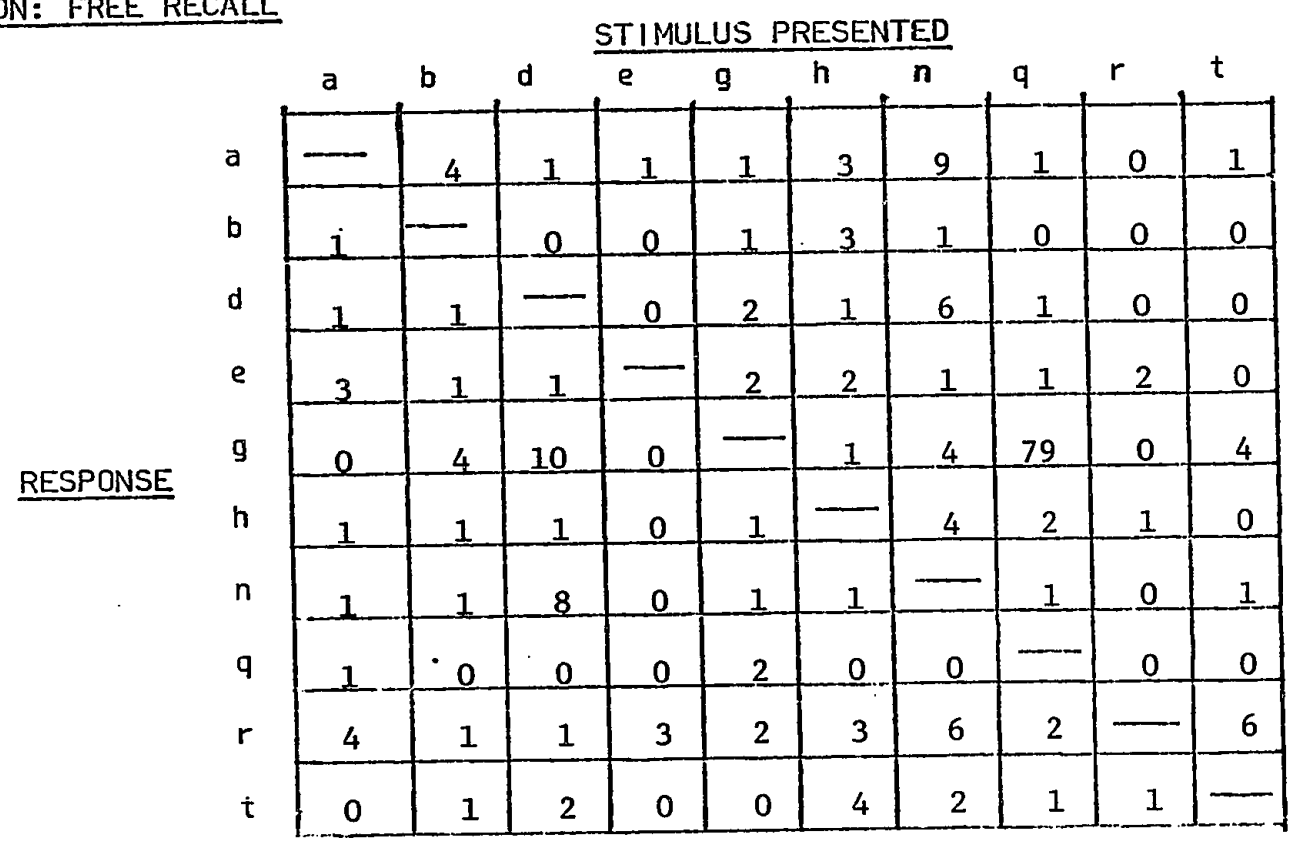


EXPERIMENT 1

GROUP: Oral Deaf

CRITER ION: ORDERED RECALL

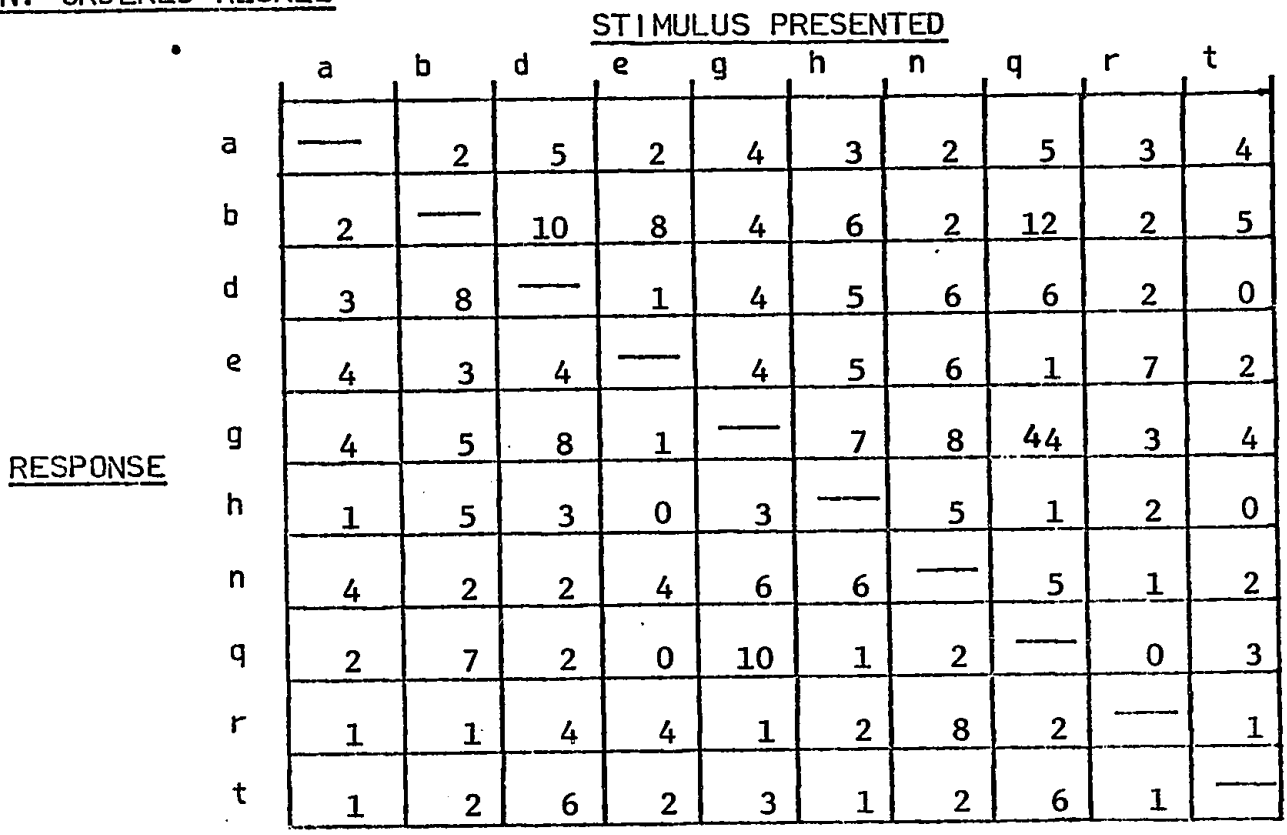

SEQUENCE LENGTH: 4 Letters

CASE: Lower 


\section{EXPERIMENT 1}

GRDUP: Normal Hearing

CRITERION: ORDERED RECALL

\begin{tabular}{|c|c|c|c|c|c|c|c|c|c|c|c|}
\hline & & & & & STIM & US & RESE & ED & & & \\
\hline & & A & B & D & $E$ & G & $H$ & $N$ & $Q$ & $R$ & $T$ \\
\hline & A & - & 4 & 2 & 9 & 8 & 11 & 3 & 2 & 1 & 1 \\
\hline & B & 4 & - & 21 & 4 & 16 & 1 & 1 & 1 & 4 & 7 \\
\hline & D & 1 & 14 & - & 4 & 15 & 0 & 1 & 6 & 1 & 3 \\
\hline & $E$ & 6 & 13 & 6 & - & 17 & 3 & 3 & 5 & 10 & 9 \\
\hline Donce & $\mathbf{G}$ & 4 & 6 & 11 & 10 & $\longrightarrow$ & 2 & 3 & 1 & 3 & 2 \\
\hline & $H$ & 11 & 3 & 0 & 4 & 2 & - & 3 & 3 & 2 & 1 \\
\hline & $\mathbf{N}$ & 4 & 0 & 2 & 5 & 6 & 6 & - & 2 & 2 & 1 \\
\hline & $\mathbf{Q}$ & 3 & 7 & 3 & 1 & 3 & 0 & 1 & $\cdots$ & 0 & 7 \\
\hline & $R$ & 5 & 5 & 3 & 9 & 5 & 2 & 1 & 2 & - & 5 \\
\hline . & $T$ & 2 & 7 & 10 & 9 & 3 & 1 & 2 & 1 & 3 & \\
\hline
\end{tabular}

SEQUENCE LENGTH: 5 Letters

\section{CASE: Upper}

CRITERI ON: FREE RECALL

\begin{tabular}{|c|c|c|c|c|c|c|c|c|c|c|c|}
\hline \multirow{2}{*}{\multicolumn{2}{|c|}{ (1) }} & \multicolumn{10}{|c|}{ STIMULUS PRESENTED } \\
\hline & & A & B & D & $E$ & $\mathbf{G}$ & $\mathrm{H}$ & $\bar{N}$ & Q & $R$ & $T$ \\
\hline \multirow{4}{*}{. } & A & - & 0 & 1 & 5 & 2 & 3 & 0 & 2 & 0 & 1 \\
\hline & B & 1 & - & 6 & 2 & 2 & 1 & 1 & 1 & 0 & 1 \\
\hline & D & 1 & 2 & & 2 & 3 & 0 & 1 & 2 & 0 & 4 \\
\hline & $E$ & 3 & 6 & 3 & - & 12 & 2 & 1 & 0 & 0 & 5 \\
\hline \multirow{6}{*}{ RESPONSE } & $\mathbf{G}$ & 0 & 1 & 2 & 1 & - & $\boldsymbol{b}$ & 0 & 0 & 0 & 0 \\
\hline & $H$ & 2 & 0 & 0 & 3 & 2 & - & 1 & 2 & 0 & 0 \\
\hline & $\mathbf{N}$ & 2 & 0 & 5 & 3 & 5 & 1 & - & 1 & 1 & 0 \\
\hline & $\mathbf{Q}$ & 0 & 2 & 3 & 0 & 1 & 0 & 0 & - & 0 & 0 \\
\hline & $\mathrm{R}$ & 2 & 3 & 3 & 2 & 3 & 0 & 2 & 0 & - & 2 \\
\hline & $T$ & 0 & 2 & 5 & 4 & 2 & 0 & 1 & 0 & 1 & - \\
\hline
\end{tabular}


EXPERIMENT 1

CRITERION: ORDERED RECALL

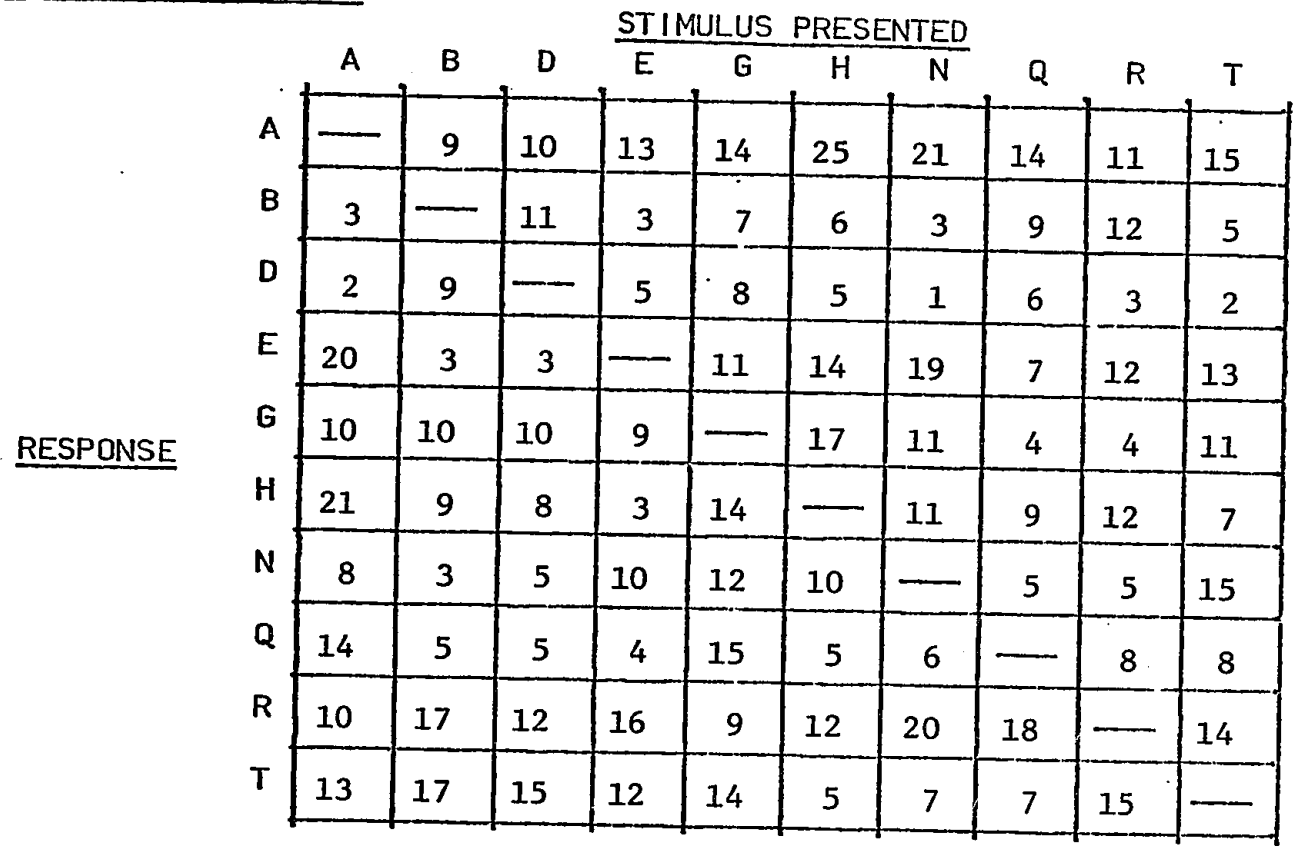

CRITERI ON: FREE RECALL

\begin{tabular}{|c|c|c|c|c|c|c|c|c|c|c|c|}
\hline & \multicolumn{10}{|c|}{ STIMULUS PRESENTED } \\
\hline & & $A$ & B & D & $\bar{E}$ & $\mathbf{G}$ & $\mathrm{H}$ & $\bar{N}$ & $Q$ & $\mathrm{R}$ & $T$ \\
\hline & A & $\longrightarrow$ & 4 & 8 & 3 & 9 & 7 & 13 & 5 & 5 & 2 \\
\hline & B & 1 & $\longrightarrow$ & 8 & 1 & 0 & 7 & 2 & 0 & 0 & 4 \\
\hline & D & 0 & 5 & 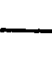 & 1 & $1^{\circ}$ & 3 & 0 & 2 & 0 & 1 \\
\hline & $E$ & 3 & 5 & 7 & $\longrightarrow$ & 9 & 4 & 3 & 3 & 3 & 1 \\
\hline RESPONSE & G & 3 & 2 & 8 & 3 & - & 8 & 8 & 2 & 1 & 5 \\
\hline & H & 5 & 3 & 9 & 4 & 5 & 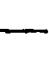 & 10 & 2 & 3 & 1 \\
\hline & $\mathbf{N}$ & 4. & 4 & 8 & 1 & 5 & 3 & $\longrightarrow$ & 2 & 0 & 1 \\
\hline & $\mathbf{Q}$ & 1 & 1 & 7 & 1 & 4 & 0 & 2 & - & 1 & 0 \\
\hline & $R$ & 5 & 5 & 5 & 2 & 4 & 7 & 16 & 3 & 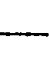 & 3 \\
\hline & $T$ & 5 & 7 & 8 & 5 & 9 & 3 & 3 & 0 & 3 & - \\
\hline
\end{tabular}


EXPERIMENT 1 .

GROUP: Oral Deaf

SEQUENCE LENGTH: 5 Letters

CASE: Upper

CRITERION: ORDERED RECALL

\begin{tabular}{|c|c|c|c|c|c|c|c|c|c|c|c|}
\hline & & & & & STIN & US & RES & TED & & & \\
\hline & & A & B & D & $E$ & $G$ & $\mathrm{H}$ & $N$ & $Q$ & $R$ & $\mathrm{~T}$ \\
\hline & A & $\longrightarrow$ & 4 & 5 & 6 & 7 & 6 & 7 & 4 & 7 & 4 \\
\hline & B & 4 & - & 7 & 6 & 1 & 6 & 2 & 6 & 9 & 3 \\
\hline & D & 1 & 8 & $\longrightarrow$ & 10 & 7 & 7 & 4 & 2 & 1 & 3 \\
\hline & $E$ & 7 & 6 & 11 & L & 8 & 11 & 14 & 3 & 13 & 6 \\
\hline & $\mathbf{G}$ & 5 & 3 & 7 & 2 & {[} & 4 & 8 & 9 & 6 & 9 \\
\hline & $H$ & 9 & 4 & 9 & 7 & 4 & - & 5 & 5 & 7 & 8 \\
\hline & $\mathbf{N}$ & 3 & 6 & 5 & 6 & 9 & 6 & $\ldots$ & 4 & 5 & 2 \\
\hline & $\mathbf{Q}$ & 2 & 7 & 5 & 2 & 2 & 2 & 6 & 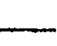 & 3 & 10 \\
\hline & $\mathbf{R}$ & 2 & 11 & 6 & 4 & 4 & 2 & 4 & 9 & r & 2 \\
\hline & $T$ & 4 & 2 & 7 & 9 & 5 & 7 & 5 & 6 & 8 & - \\
\hline
\end{tabular}

CRITERI ON: FREE RECALL

\begin{tabular}{|c|c|c|c|c|c|c|c|c|c|c|}
\hline \multirow[t]{2}{*}{. } & \multicolumn{10}{|c|}{ STIMULUS PRESENTED } \\
\hline & A & B & $\mathbf{D}$ & $E$ & $\bar{G}$ & $\bar{H}$ & $\bar{N}$ & Q & $\mathrm{R}$ & $\mathrm{T}$ \\
\hline A & $\longrightarrow$ & 6 & 4 & 0 & 4 & 3 & 4 & 2 & 2 & 5 \\
\hline B & 0 & - & 2 & 6 & 3 & 4 & 1 & 0 & 6 & 0 \\
\hline D & 2 & 2 & {[} & 3 & 9 & 2 & 5 & 3 & 2 & 0 \\
\hline $\mathbf{E}$ & 7 & 7 & 6 & & 5 & 8 & 8 & 4 & 4 & 4 \\
\hline DECPONCF & 3 & 1 & 10 & 1 & - & 1 & 4 & 6 & 1 & 2 \\
\hline$H$ & 4 & 9 & 4 & 1 & 2 & - & 4 & 4 & 2 & 2 \\
\hline $\mathbf{N}$ & 2 & 3 & 4 & 0 & $\cdot 6$ & 2 & $\longrightarrow$ & 2 & 3 & 2 \\
\hline $\mathbf{Q}$ & 0 & 2 & 2 & 1 & 2 & 1 & 1 & - & 0 & 0 \\
\hline$R$ & 0 & 1 & 1 & 0 & 1 & 6 & 2 & 0 & - & 2 \\
\hline$T$ & 2 & 0 & 4 & 2 & 3 & 1 & 6 & 3 & 6 & $\longrightarrow$ \\
\hline
\end{tabular}


EXPERIMENT 1

GROUP:

Normal Hearing
SEQUENCE LENGTH: 5 Letters

CASE: Lower

CRITERION: ORDERED RECALL

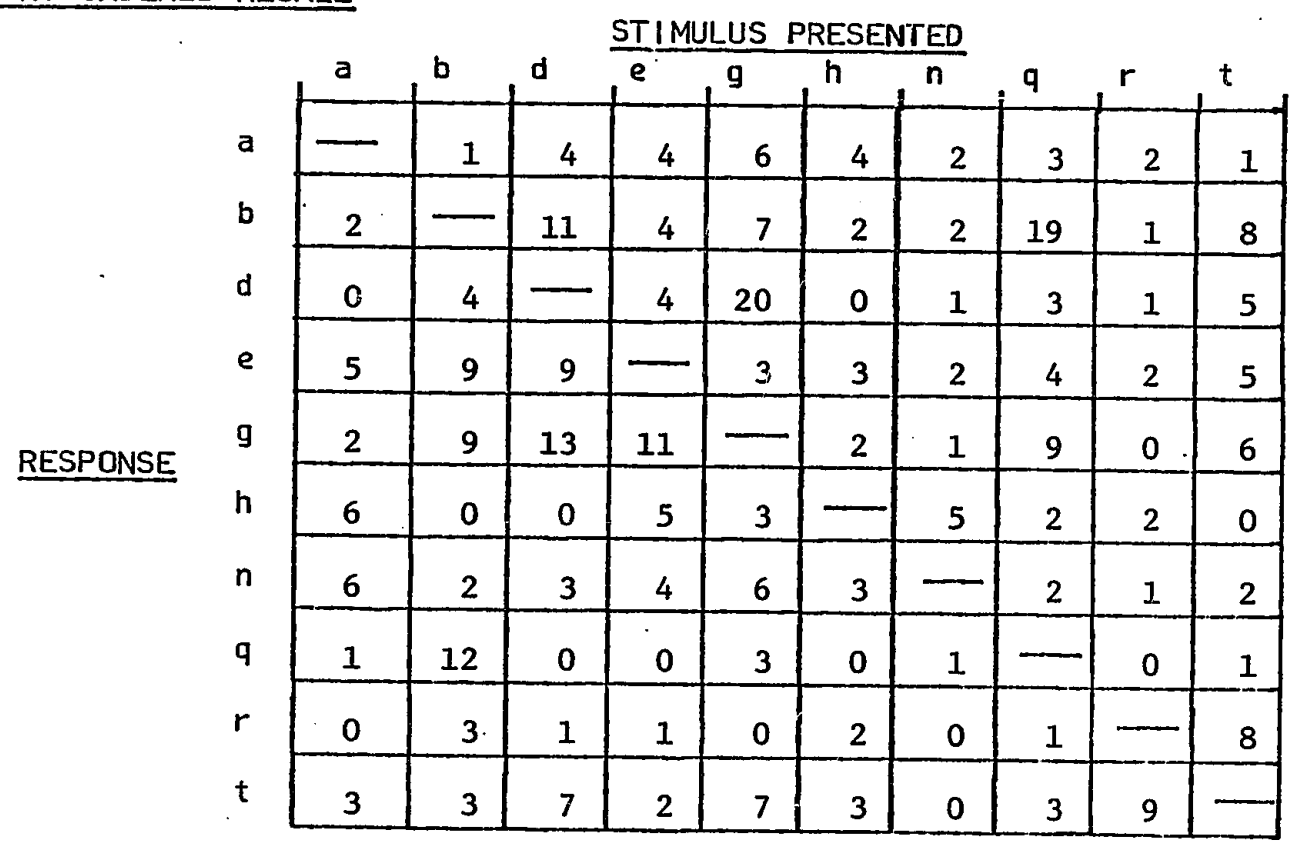

CRITERION: FREE RECALL

\begin{tabular}{|c|c|c|c|c|c|c|c|c|c|c|c|}
\hline & \multicolumn{10}{|c|}{ STIMULUS PRESENTED } \\
\hline & & a & b & d & e & 9 & $\mathrm{~h}$ & $n$ & $q$ & $r$ & $t$ \\
\hline & $a$ & - & 0 & 2 & 1 & 3 & 2 & 0 & 3 & 2 & 2 \\
\hline & $b$ & 1 & - & 3 & 2 & 4 & 0 & 0 & 25 & 0 & 3 \\
\hline & d & 0 & 0 & $\ldots$ & 0 & 4 & 0 & 1 & 3 & 0 & 2 \\
\hline & e & 4 & 7 & 2 & - & 4 & 2 & 0 & 3 & 0 & 2 \\
\hline & $\mathbf{g}$ & 0 & 1 & 3 & 3 & - & 0 & 0 & 16 & 0 & 3 \\
\hline & h & 5 & 1 & 0 & 2 & 0 & - & 0 & 1 & 1 & 0 \\
\hline . & $n$ & 1 & 0 & 2 & 1 & 2 & 2 & - & 1 & 2 & 1 \\
\hline & $q$ & 1 & - 8 & 1 & 0 & 1 & 0 & 0 & $\longrightarrow$ & 0 & 0 \\
\hline & $r$ & 0 & 2 & 1 & 2 & 0 & 0 & 0 & 0 & - & 0 \\
\hline & $t$ & 0 & 1 & 7 & 3 & 1 & 0 & 1 & 3 & 0 & - \\
\hline
\end{tabular}


EXPERIMENT 1

GROUP: Manual Deaf

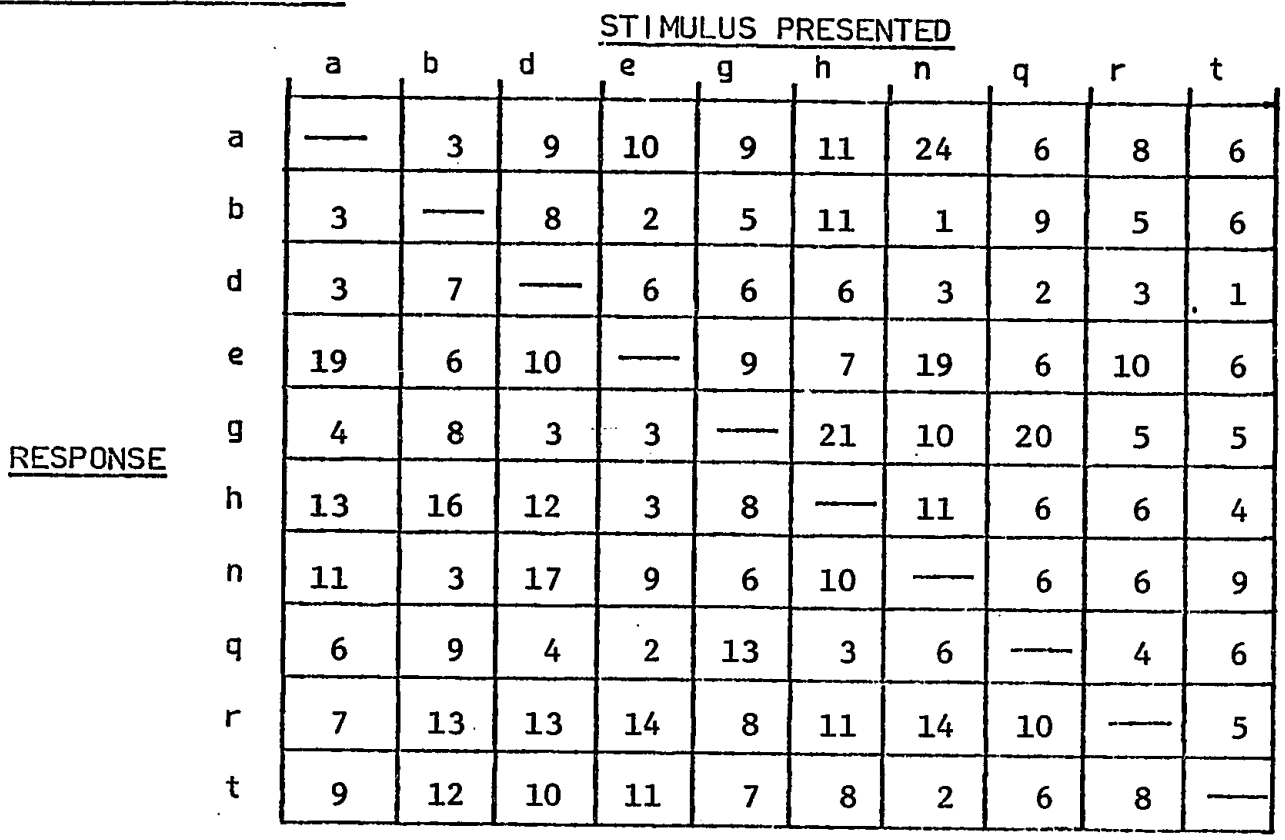

CRITERION: FREE RECALL

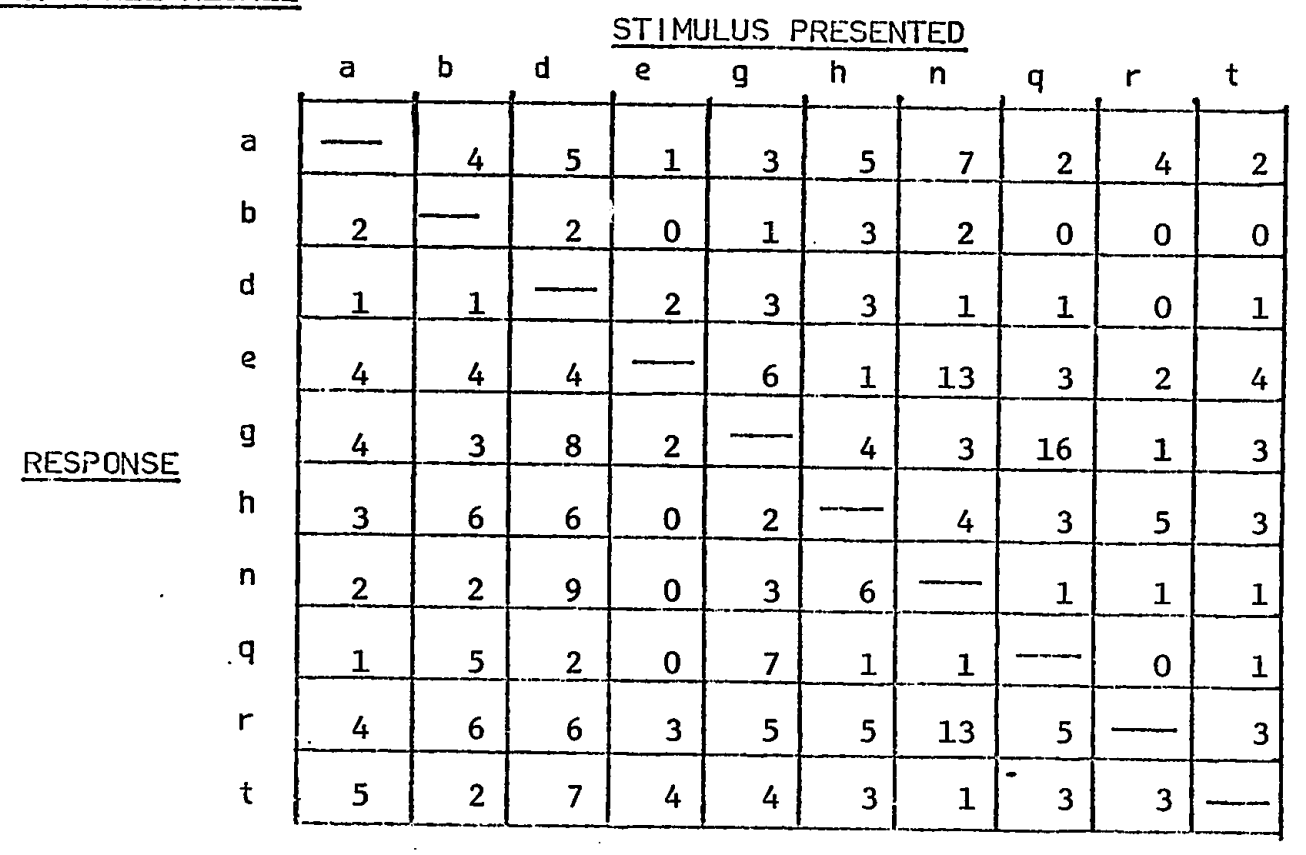


EXPERIMENT 1

GROUP:

Oral Deaf

CRITERION: ORDERED RECALL

\begin{tabular}{|c|c|c|c|c|c|c|c|c|c|c|c|}
\hline \multirow{2}{*}{\multicolumn{2}{|c|}{ 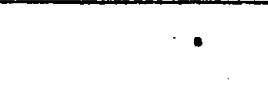 }} & \multicolumn{10}{|c|}{ STIMULUS PRESENTED } \\
\hline & & a & b & d & e & g & $\bar{h}$ & $n$ & $\mathbf{q}$ & $r$ & $t$ \\
\hline \multirow{5}{*}{ RESPONSE } & a & $\longrightarrow$ & 4 & 3 & 6 & 2 & 6 & 16 & 8 & 9 & 2 \\
\hline & b & 4 & 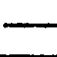 & 13 & 4 & 4 & 11 & 4 & 8 & 5 & 9 \\
\hline & d & 4 & 8 & $\longrightarrow$ & 1 & 4 & 9 & 2 & 5 & 3 & 3 \\
\hline & e & 15 & 12 & 9 & $\longrightarrow$ & 9 & 7 & 13 & 3 & 11 & 9 \\
\hline & $\mathbf{g}$ & 6 & 1 & 10 & 3 & $\longrightarrow$ & 2 & 1 & 24 & 5 & 6 \\
\hline & $\mathrm{h}$ & 6 & 6 & 9 & 3 & 10 & - & 12 & 2 & 5 & 8 \\
\hline & $\mathrm{n}$ & 4 & 5 & 3 & 6 & 9 & 7 & - & 4 & 4 & 4 \\
\hline & $q$ & 0 & 3 & 3 & 4 & 14 & 3 & 4 & $\longrightarrow$ & 2 & 9 \\
\hline & $r$ & 4 & 6 & 4 & 4 & 5 & 3 & 6 & 3 & - & 4 \\
\hline & $t$ & 6 & 5 & 16 & 6 & 8 & 3 & 5 & 2 & 11 & \\
\hline
\end{tabular}

SEQUENCE LENGTH: 5 Letters

CASE: Lower

CRITERION: FREE RECALL

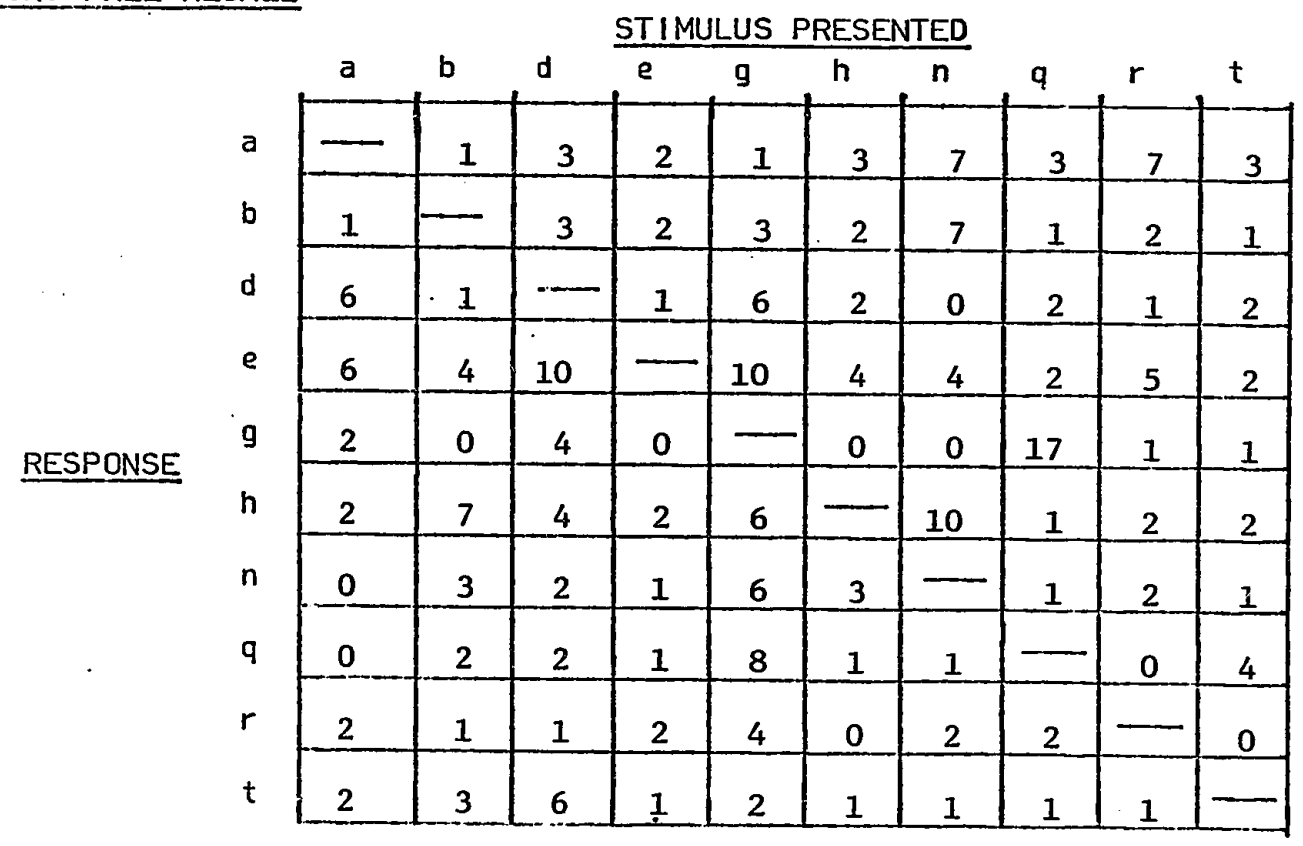


APPENDIX C

Summary of Analyses of Variance (Experiment 1) 
Table C:I

Summary of Analysis of Variance under Ordered Recall Criterion--using Four-letter Sequences

\begin{tabular}{lrrr} 
Source & df & Mean Square & \multicolumn{1}{c}{} \\
Subjects (S) & & & \\
Case (C) & 1 & 0.17 & 0.03 \\
Groups (G) & 2 & 411.79 & $59.21 * *$ \\
Position (P) & 3 & 57.10 & $49.58^{* * *}$ \\
S (G) & 21 & 6.95 & \\
CG & 2 & 1.56 & 0.28 \\
CP & 3 & 0.66 & 0.47 \\
GP & 6 & 13.28 & $11.53^{* * *}$ \\
CS (G) & 21 & 5.60 & \\
SP (G) & 63 & 1.15 & 0.48 \\
CGP & 6 & 0.67 & \\
CSP (G) & 63 & 1.40 & \\
& & &
\end{tabular}


Table C: 2

Summary of Analysis of Variance Under Free Recall Criterion--Using Four-letter Sequences

\begin{tabular}{|c|c|c|c|}
\hline Source & $\underline{\text { df }}$ & Mean Square & $\mathbf{F}$ \\
\hline Subjects (s) & & & \\
\hline Case (C) & 1 & 1.22 & 0.30 \\
\hline Groups (G) & 2 & 176.55 & $29.54^{* * *}$ \\
\hline Position (P) & 3 & 29.51 & $30.78 * *$ \\
\hline$S(G)$ & 21 & 5.96 & \\
\hline $\mathbf{C G}$ & 2 & 4.85 & 1.18 \\
\hline $\mathrm{CP}$ & 3 & 0.34 & 0.32 \\
\hline GP & 6 & 6.69 & $6.98 * *$ \\
\hline $\operatorname{CS}(G)$ & 21 & 4.10 & \\
\hline$S P \quad(G)$ & 63 & 0.95 & \\
\hline CGP & 6 & 1.18 & 1.12 \\
\hline $\operatorname{CSP}(G)$ & 63 & 1.06 & \\
\hline
\end{tabular}


Table $C: 3$

Summary of Analysis of Variance under Ordered Recall Criterion--using Five-letter Sequences

$\begin{array}{lrrr}\text { Source } & \text { df } & \text { Mean Square } & \text { F } \\ \text { Subjects (S) } & & & \\ \text { Case (C) } & 1 & 7.23 & 0.68 \\ \text { Groups (G) } & 2 & 529.91 & 35.51 * * \\ \text { Position (P) } & 4 & 59.59 & 40.62 * * \\ \text { S (G) } & 21 & 14.92 & \\ \text { CG } & 2 & 14.41 & 1.35 \\ \text { CP } & 4 & 1.97 & 0.72 \\ \text { GP } & 8 & 42.43 & 28.93 * * \\ \text { CS (G) } & 21 & 10.66 & \\ \text { SP (G) } & 84 & 1.47 & 0.13 \\ \text { CGP } & 8 & 0.36 & \\ \text { CSP (G) } & 82 & 2.71 & \\ & & & \end{array}$




\section{Table $C: 4$}

\section{Summary of Analysis of Variance Under Free \\ Recall Criterion--Using Five-letter Sequences}

\begin{tabular}{|c|c|c|c|}
\hline Source & $\underline{\text { df }}$ & Mean Square & $\mathbf{F}$ \\
\hline \multicolumn{4}{|l|}{ Subjects (S) } \\
\hline Case (C) & 1 & 1.30 & 0.24 \\
\hline Groups (G) & 2 & 871.83 & $43.57 * *$ \\
\hline Position (P) & 4 & 59.60 & $12.33 * *$ \\
\hline$S(G)$ & 21 & 210.08 & \\
\hline CG & 2 & 19.55 & 1.80 \\
\hline $\mathbf{C P}$ & 4 & 4.61 & 0.66 \\
\hline GP & 8 & 151.50 & $15.67 * *$ \\
\hline $\operatorname{CS}(G)$ & 21 & $114 \cdot 33$ & \\
\hline SP (G) & 84 & 101.48 & \\
\hline CGP & 8 & 7.24 & 0.52 \\
\hline $\operatorname{CSP}(G)$ & 84 & $147 \cdot 54$ & \\
\hline
\end{tabular}


APPENDIX D

Confusion Matrices (Experiment 2) 
EXPERIMENT 2

GROUP: Manual Deaf

SEQUENCE LENGTH: 5 Letters

CASE: Upper

CRITERION: ORDERED RECALL

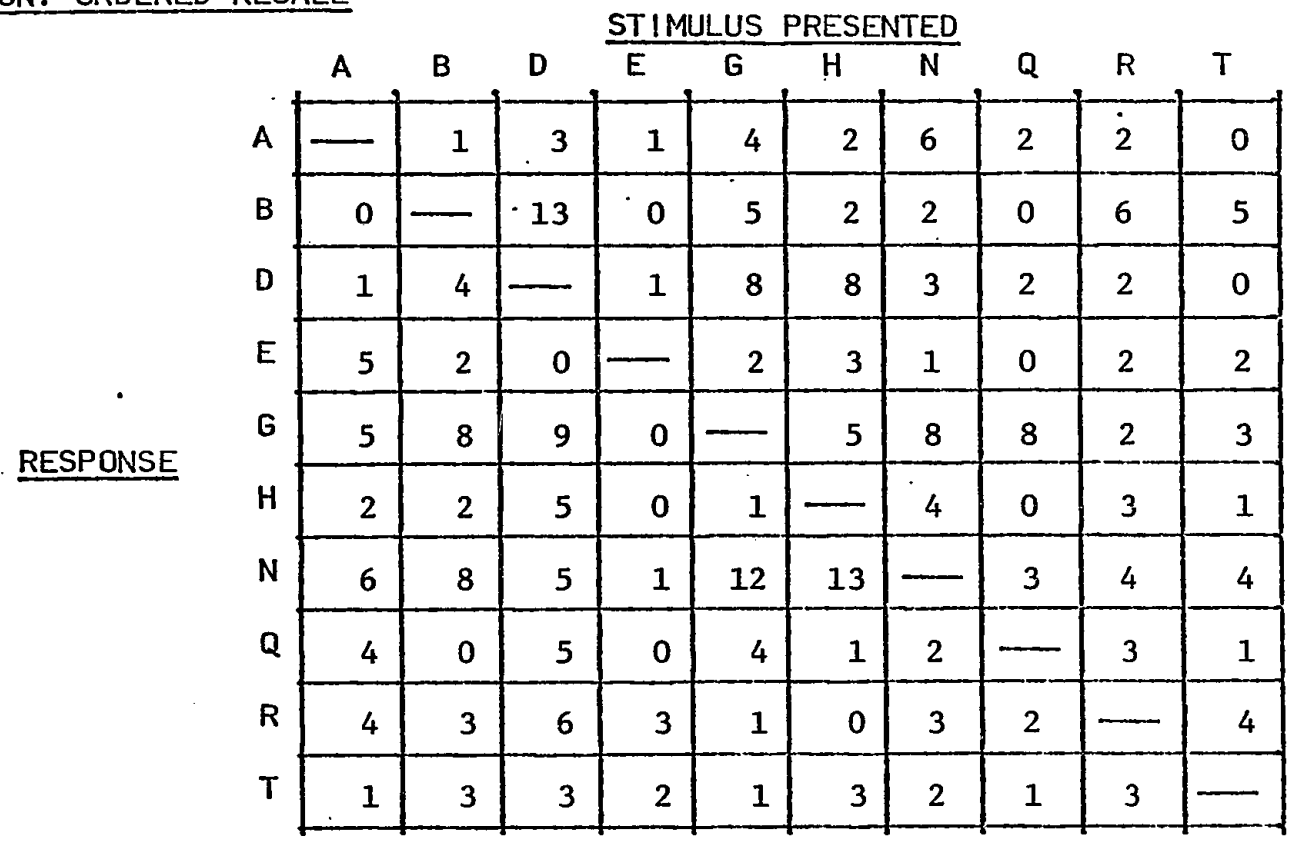

CRITERI ON: FREE RECALL

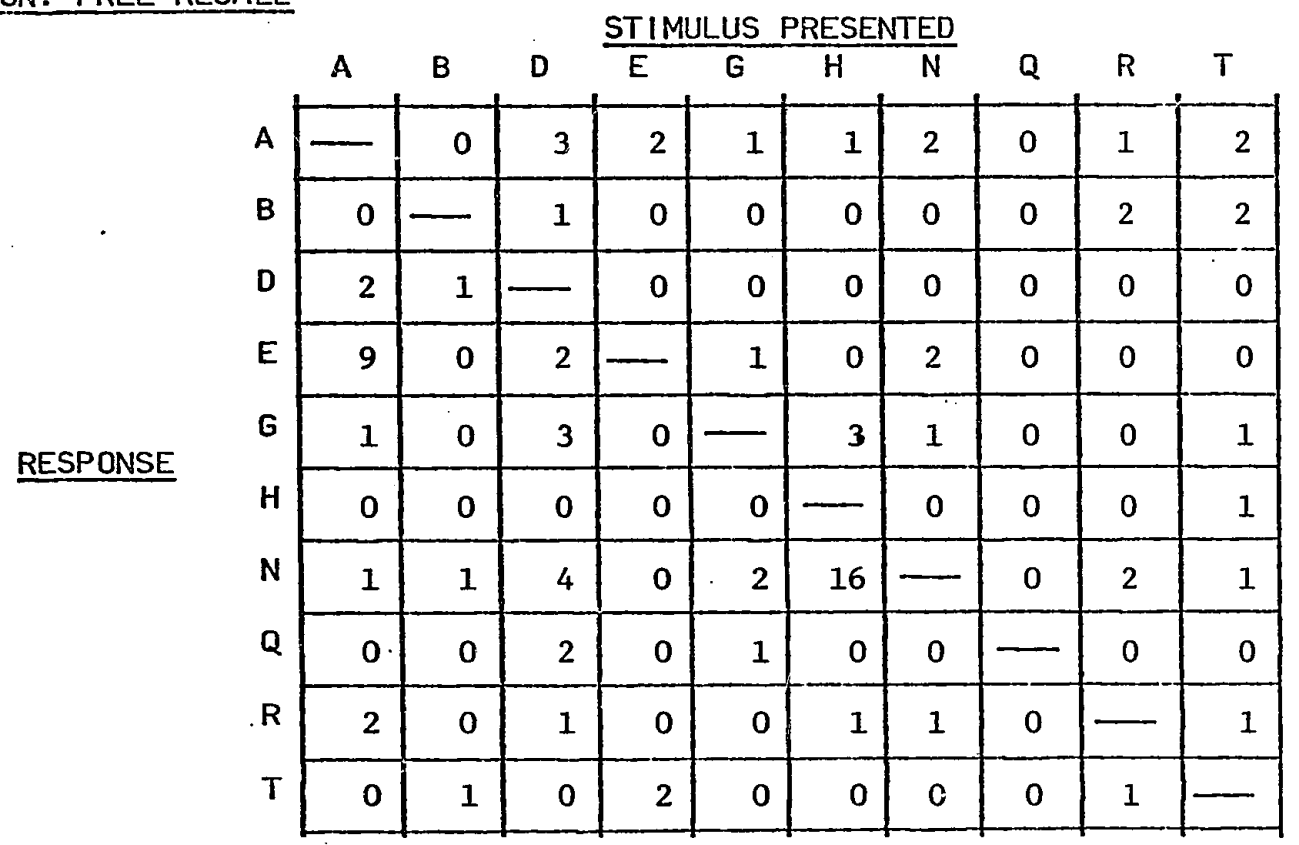


EXPERIMENT 2

GROUP: Oral Deaf

SEQUENCE LENGTH: 5 Letters

CASE: Upper

CRITERION: ORDERED RECALL

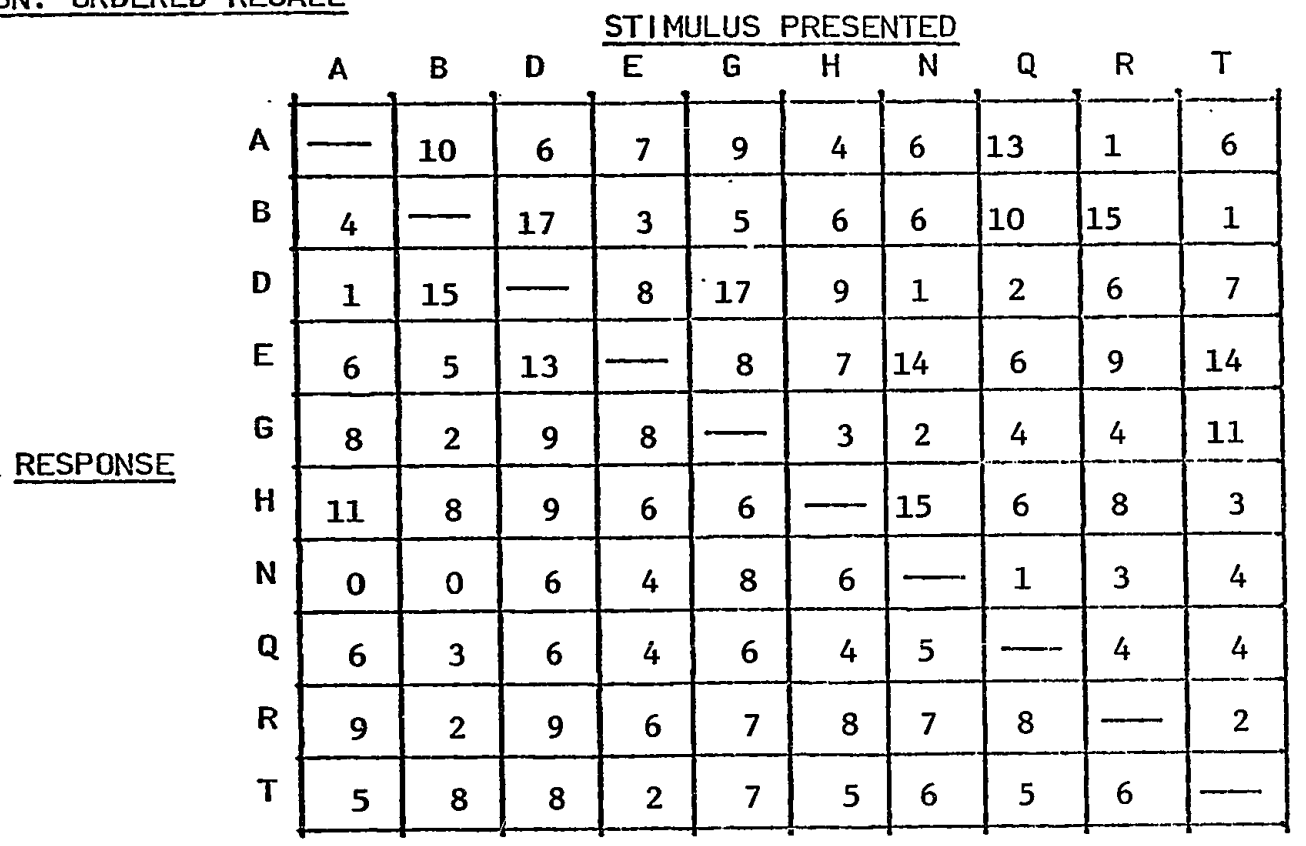

CRITERI ON: FREE RECALL

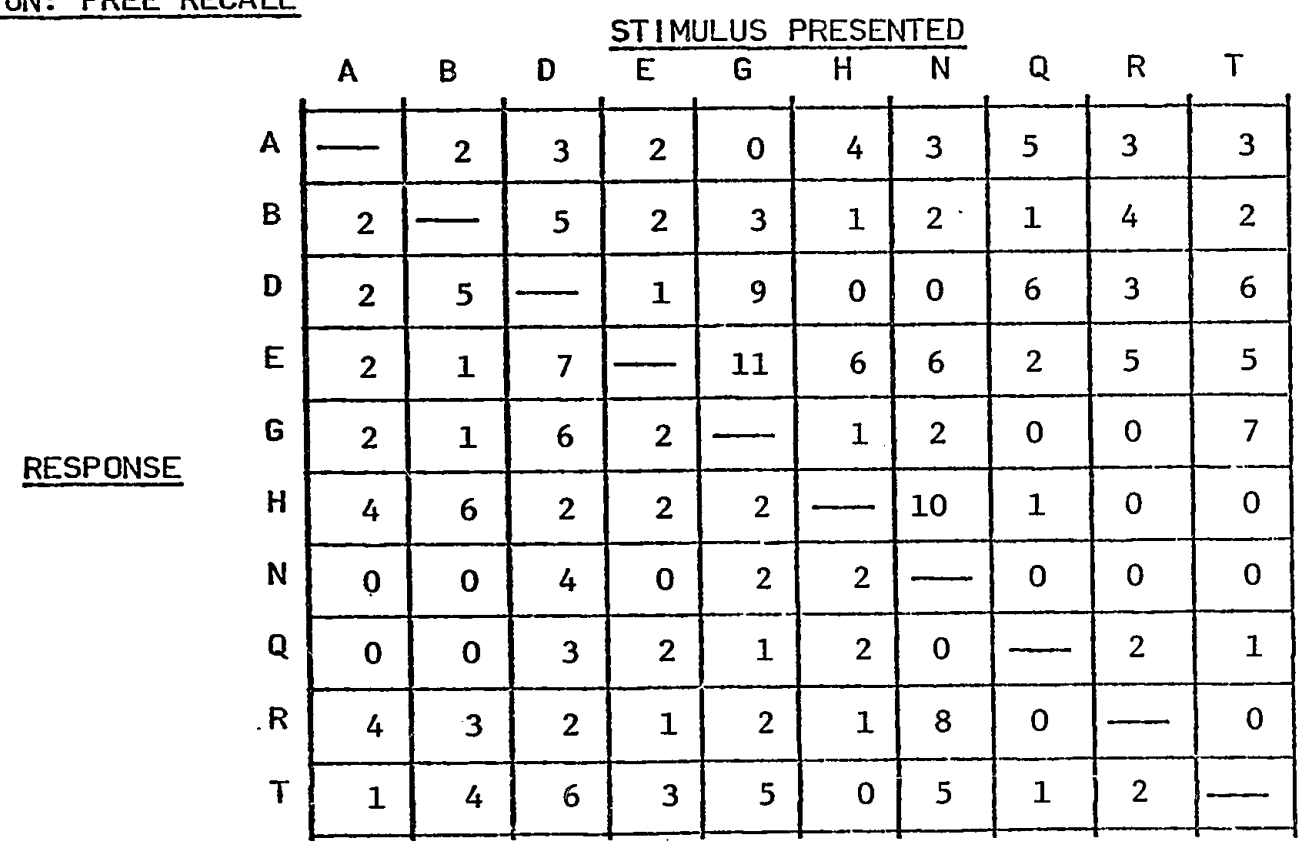


EXPERIMENT $\underline{2}$

GROUP: Manual Deaf

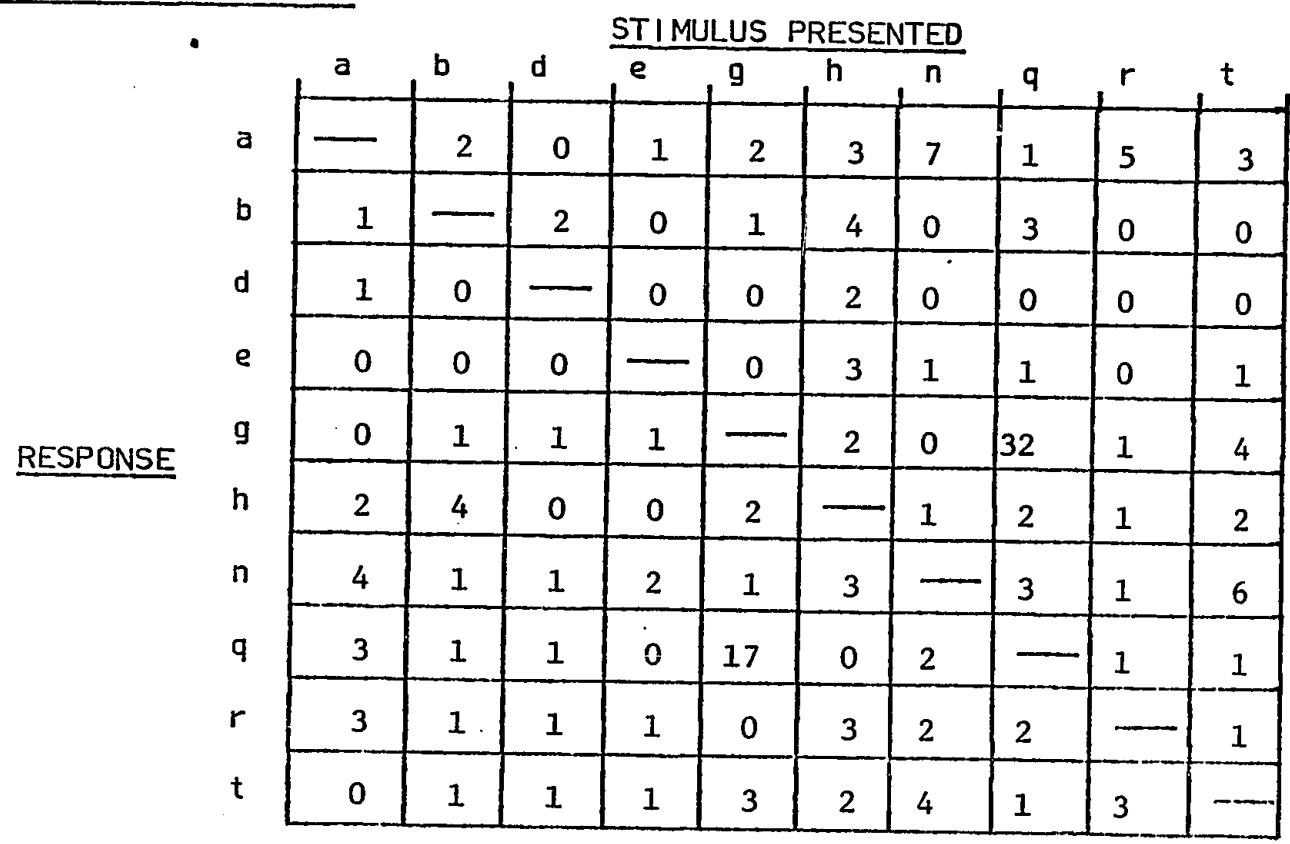

CRITERION: FREE RECALL

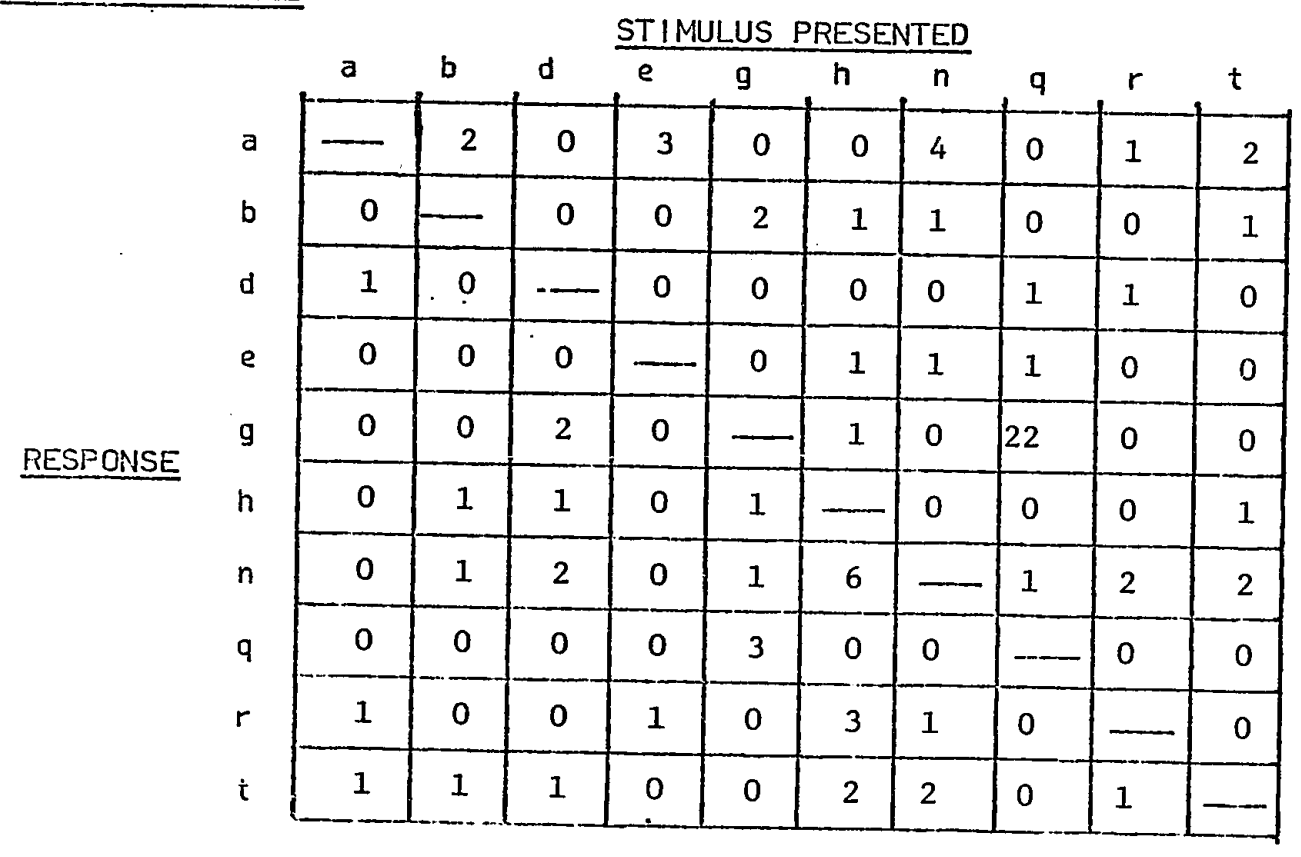

SEQUENCE LENGTH: 5 Letters

CASE: Lower

CRITER ION: ORDERED RECALL 
EXPERIMENI 2

GROUP: Ora1 Deaf

CRITER ION: ORDERED RECALL

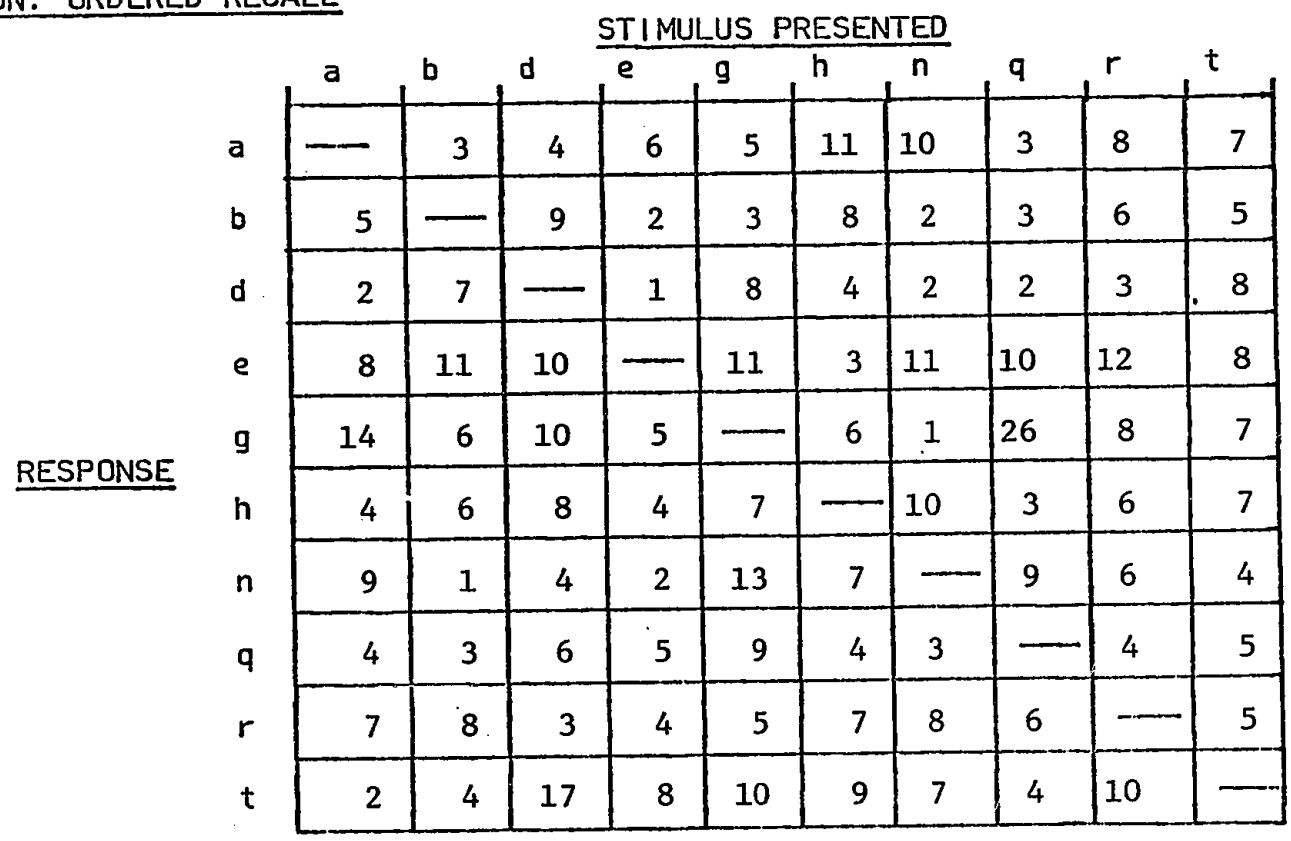

CRITERI ON: FREE RECALL

\begin{tabular}{|c|c|c|c|c|c|c|c|c|c|c|c|}
\hline \multirow{2}{*}{\multicolumn{2}{|c|}{ 20- }} & \multicolumn{10}{|c|}{ STIMULUS PRESENTED } \\
\hline & & $a$ & b & d & e & 9 & $\mathrm{~h}$ & $n$ & $q$ & $r$ & $t$ \\
\hline & $\mathrm{a}$ & - & 2 & 4 & 0 & 2 & 4 & 4 & 3 & 3 & 0 \\
\hline & b & 1 & - & 7 & 0 & 2 & 0 & 0 & 2 & 0 & 5 \\
\hline & d & 1 & 3 & - & 0 & 4 & 2 & 1 & 0 & 2 & 0 \\
\hline & e & 1 & 6 & 8 & - & 9 & 1 & 2 & 2 & 2 & 7 \\
\hline & $\mathbf{g}$ & 5 & 1 & 3 & 0 & - & 2 & 0 & 16 & 0 & 6 \\
\hline RESPONSE & $h_{1}$ & 1 & 5 & 3 & 0 & 1 & Lـ & 4 & 1 & 0 & 3 \\
\hline & $n$ & 1 & 0 & 1 & 0 & 1 & 5 & - & 2 & 3 & 2 \\
\hline & $q$ & 1 & 0 & 4 & 0 & 3 & 1 & 0 & $\longrightarrow$ & 1 & 1 \\
\hline & $r$ & 0 & 3 & 1 & 4 & 0 & 0 & 6 & 0 & - & 0 \\
\hline & $t$ & 1 & 1 & 7 & 5 & 6 & 4 & 0 & 1 & 5 & - \\
\hline
\end{tabular}

SEQUENCE LENGTH: 5 Letters

CASE: Lower 
EXPERIMENT 2

GROUP:

SEQUENCE LENGTH: 4 Letters

CASE: Upper

CRITERION: ORDERED RECALL

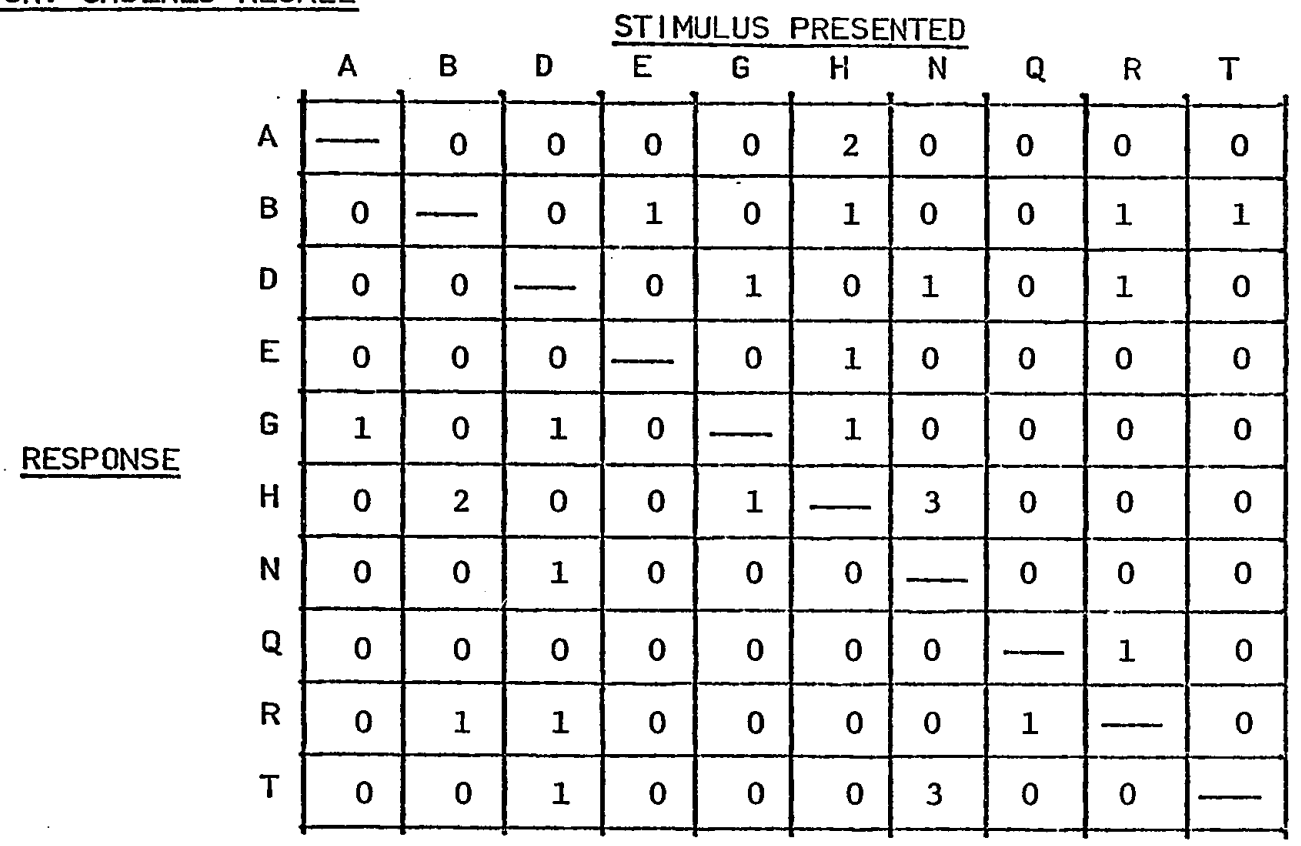

CRITERI ON: FREE RECALL

\begin{tabular}{|c|c|c|c|c|c|c|c|c|c|c|c|}
\hline \multicolumn{12}{|c|}{ STIMULUS PRESENTED } \\
\hline & & A & B & D & $E$ & G & $\mathrm{H}$ & $\bar{N}$ & $\mathrm{Q}$ & $\mathrm{R}$ & $T$ \\
\hline & A & {[} & 0 & 0 & 0 & 0 & 3 & 0 & 0 & 0 & 0 \\
\hline & B & 0 & - & 0 & 0 & 0 & 1 & 0 & 0 & 0 & 0 \\
\hline & D & 0 & 0 & - & 0 & 0 & 0 & 0 & 0 & 0 & 0 \\
\hline & $E$ & 0 & 0 & 0 & - & 0 & 2 & 0 & 0 & 0 & 0 \\
\hline PECPONCF & G & 1 & 0 & 0 & 0 & $\longrightarrow$ & 0 & 0 & 0 & 0 & 0 \\
\hline & $H$ & 0 & 2 & 0 & 0 & 0 & - & 4 & 0 & 0 & 0 \\
\hline & $\mathrm{N}$ & 0 & 0 & 0 & 0 & $\cdot 0$ & 0 & - & 0 & 0 & 0 \\
\hline & $\mathbf{Q}$ & 0 & 0 & 0 & 0 & 0 & 0 & 0 & - & 0 & 0 \\
\hline & $\mathbf{R}$ & 0 & 0 & 0 & 0 & 0 & 0 & 0 & 0 & - & 0 \\
\hline & $\mathrm{T}$ & 0 & 0 & 2 & 1 & 0 & 0 & 3 & 0 & 0 & - \\
\hline
\end{tabular}


EXPERIMENT 2

GROUP: Oral Deaf

CRITERION: ORDERED RECALL

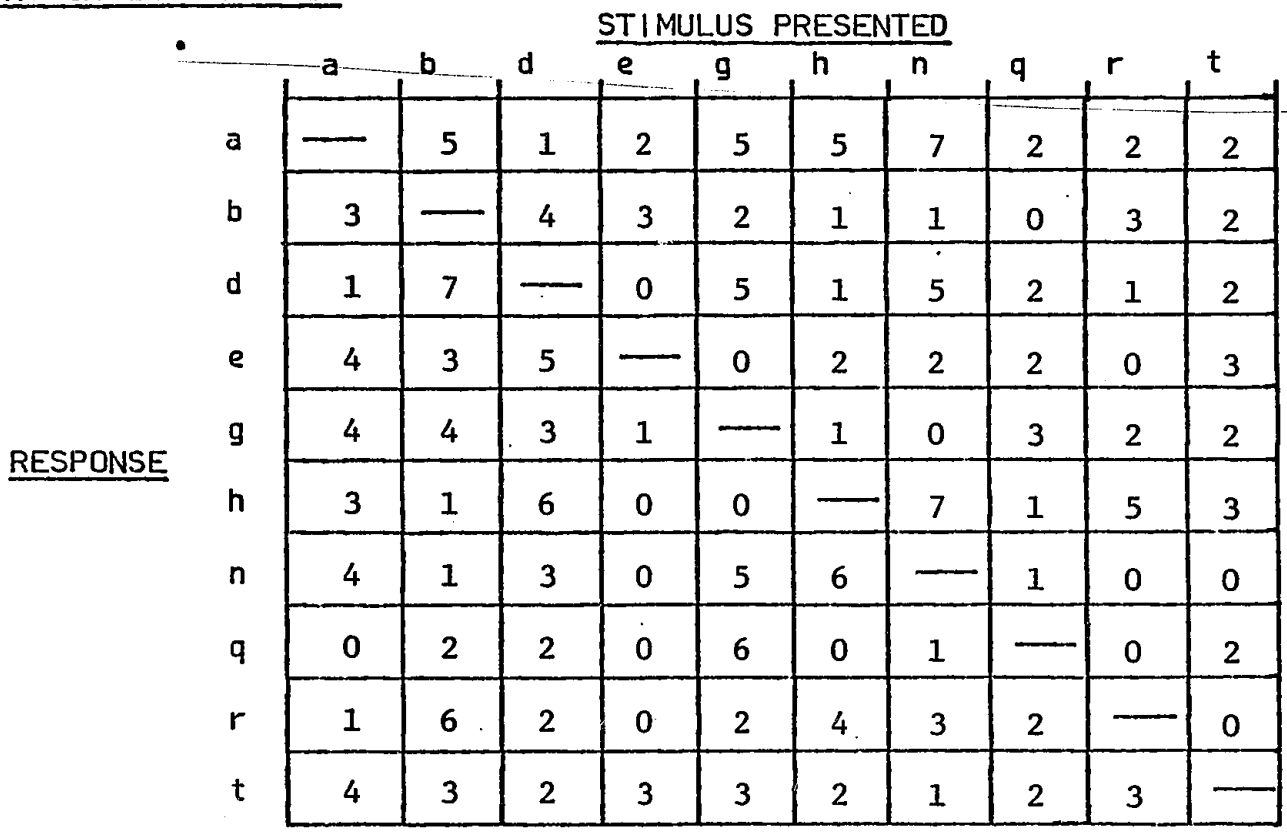

SEQUENCE LENGTH: 4 Letters

CASE: Lower 
EXPERIMENT $\underline{2}$

GROUP: Manual Deaf

CRITER ION: ORDERED RECALL

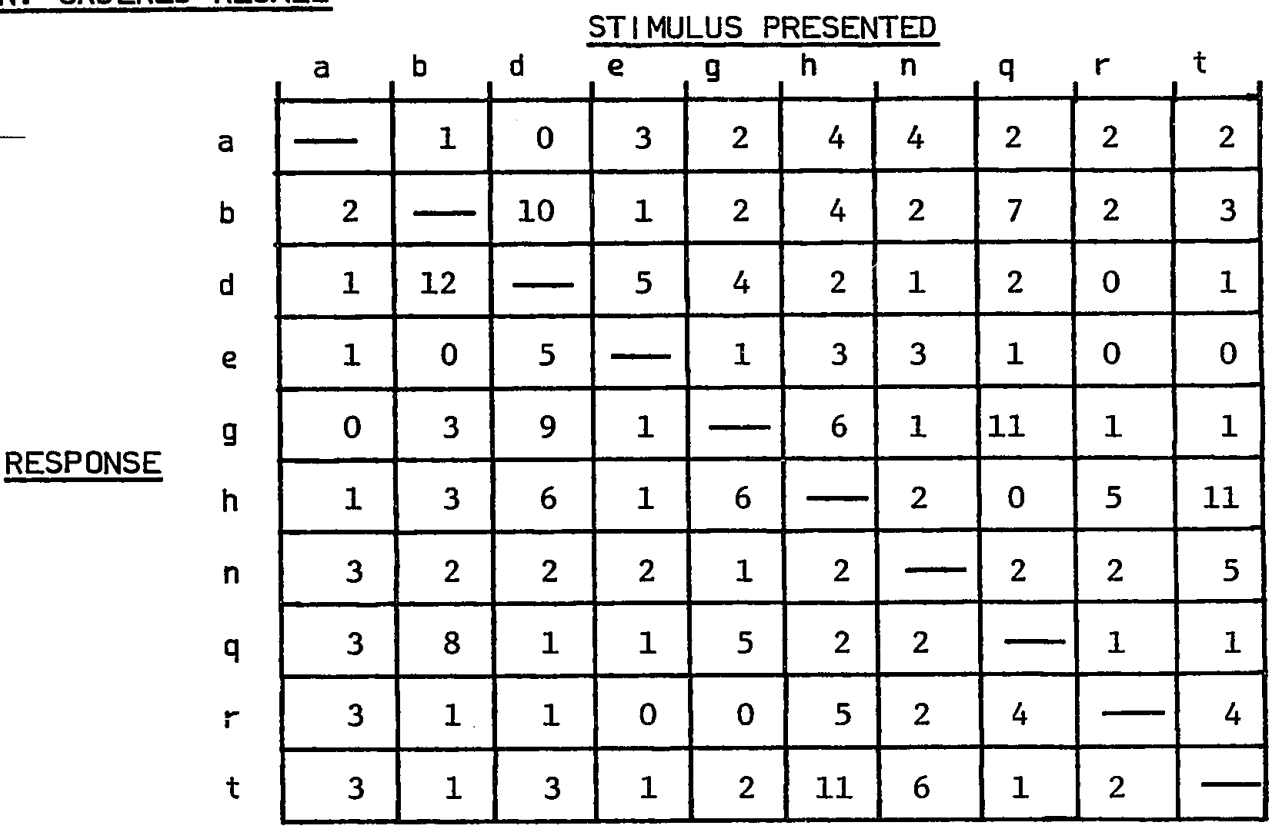

CRITERI ON: FREE RECALL

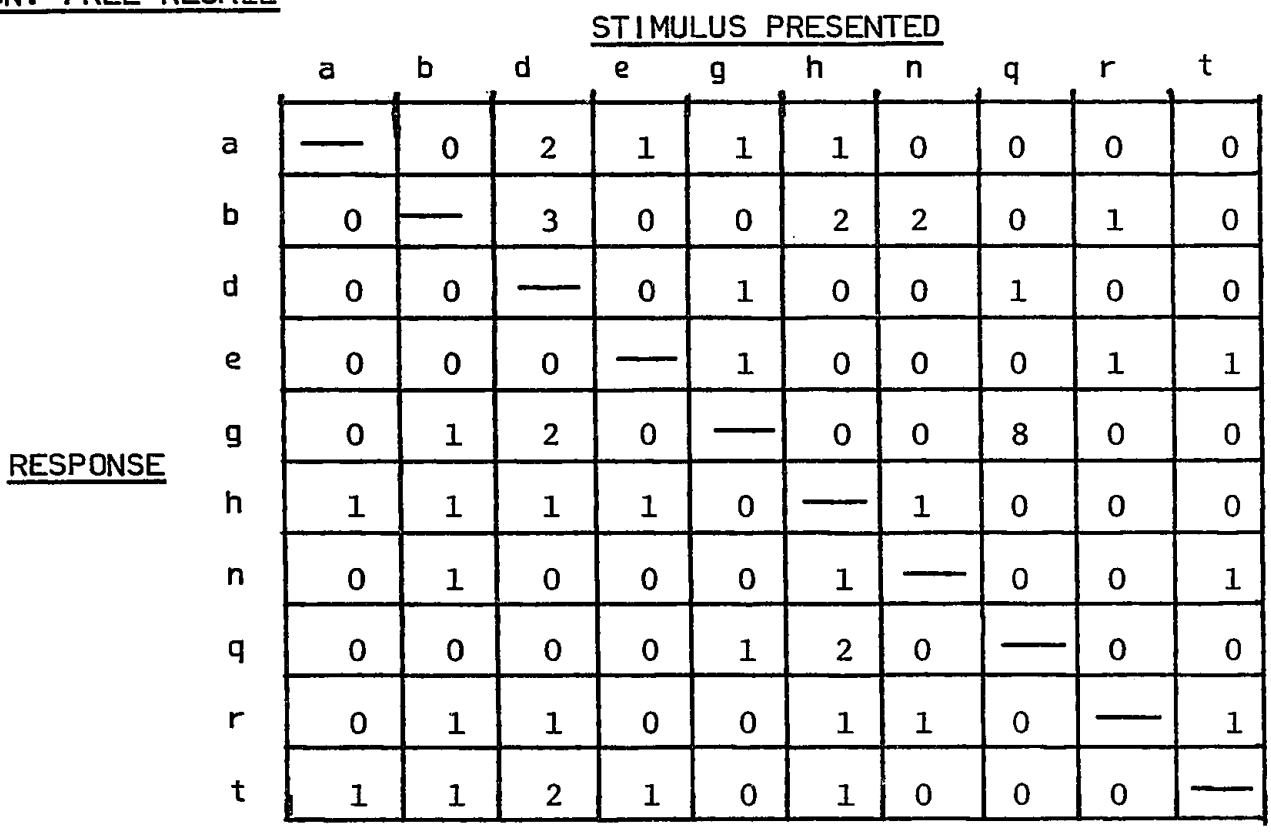

CASE: Lower
SEQUENCE LENGTH: 4 Letters 
EXPERIMENT 2

GROUP: Oral Deaf

CRITERION: ORDERED RECALL

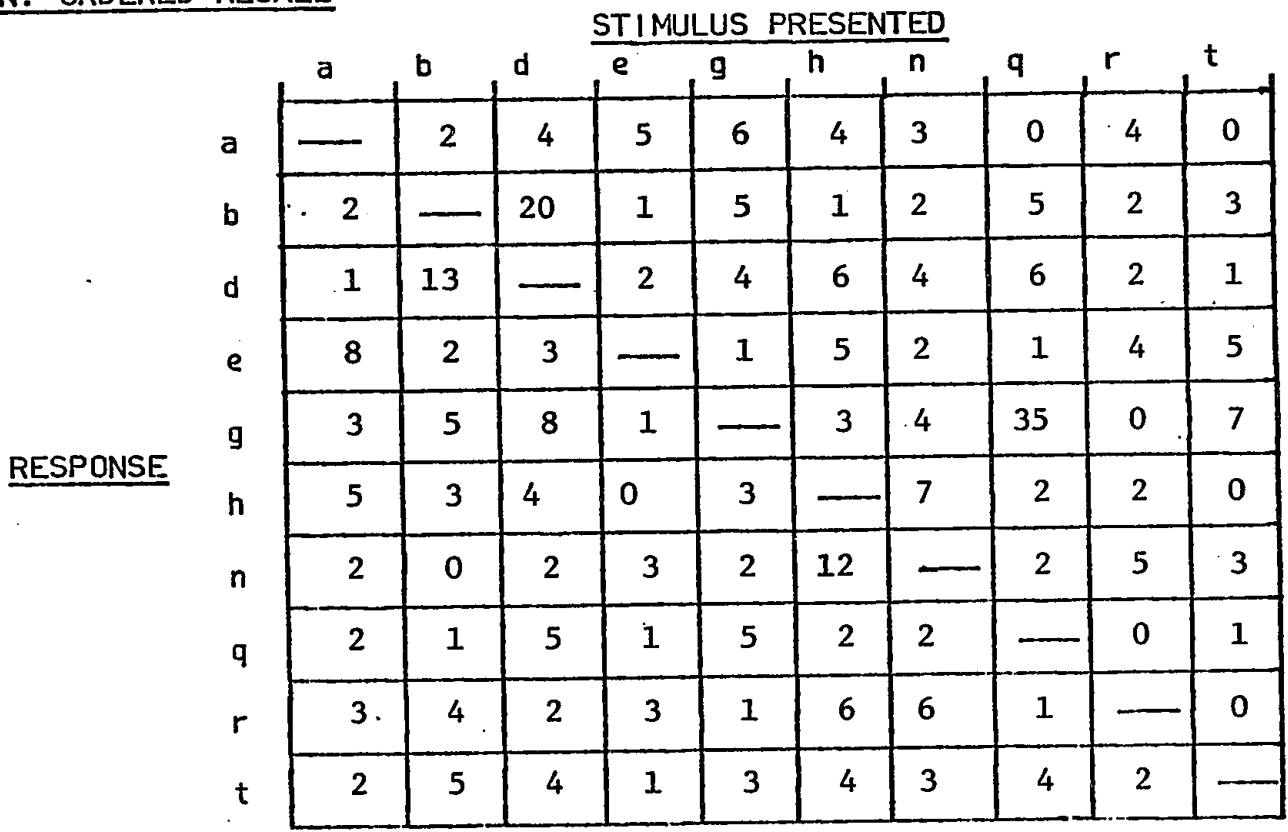

SEQUENCE LENGTH: 4 Letters

CASE: Lower 
APPENDIX E

Summary of Analysis of Variance (Experiment 2) 
Table E:1

Summary of Analysis of Variance Under Ordered

Recall Criterion--Using Four-letter Sequences

\begin{tabular}{|c|c|c|c|}
\hline Source & $\underline{d f}$ & Mean Square & $\mathbf{F}$ \\
\hline \multicolumn{4}{|l|}{ Subjects (s) } \\
\hline Case (C) & 1 & 95.06 & $7.87 *$ \\
\hline Groups (G) & 1 & 172.62 & $12.20 * *$ \\
\hline Position (P) & 3 & $7 \cdot 35$ & $15.15^{* * *}$ \\
\hline$S(G)$ & 16 & 14.15 & \\
\hline $\mathbf{C G}$ & 1 & 0.34 & 0.03 \\
\hline $\mathbf{C P}$ & 3 & 1.70 & 2.96 \\
\hline GP & 3 & 0.41 & 0.85 \\
\hline $\operatorname{cs}(G)$ & 16 & 12.08 & \\
\hline$S P \quad(G)$ & 48 & 0.48 & \\
\hline CGP & 3 & 0.88 & 1.54 \\
\hline $\operatorname{CsP}(G)$ & 48 & 0.57 & \\
\hline
\end{tabular}


Table E: 2

Summary of Analysis of Variance Under Free

Recall Criterion--Using Four-letter Sequences

\begin{tabular}{|c|c|c|c|}
\hline Source & df & Mean Square & $\mathbf{F}$ \\
\hline Subjects (S) & & & \\
\hline Case (C) & 1 & 12.48 & 3.13 \\
\hline Groups (G) & 1 & 58.01 & $22.87 * *$ \\
\hline Position (P) & 3 & 0.43 & 2.63 \\
\hline$S(G)$ & 16 & 2.54 & \\
\hline $\mathbf{C G}$ & 1 & 7.65 & 1.92 \\
\hline $\mathbf{C P}$ & 3 & 0.19 & 0.09 \\
\hline GP & 3 & 0.34 & 2.09 \\
\hline $\operatorname{Cs}(G)$ & 16 & 3.98 & \\
\hline$S P(G)$ & 48 & 0.16 & \\
\hline CGP & 3 & 0.73 & 0.04 \\
\hline $\operatorname{CSP}(G)$ & 48 & 0.18 & \\
\hline
\end{tabular}


Table E: 3

Summary of Analysis of Variance Under Ordered Recall Criterion--Using Five-letter Sequences

$\begin{array}{lrrr}\text { Source } & \text { df } & \text { Mean Square } & \text { F } \\ \text { Subjects (S) } & & & 0.60 \\ \text { Case (C) } & 1 & 9.04 & 67.15^{* * *} \\ \text { Groups (G) } & 1 & 972.23 & 12.30 * * \\ \text { Position (P) } & 4 & 14.19 & \\ \text { S (G) } & 16 & 14.48 & 0.52 \\ \text { CG } & 1 & 7.88 & 1.79 \\ \text { CP } & 4 & 1.92 & 1.94 \\ \text { GP } & 4 & 2.25 & \\ \text { CS (G) } & 16 & 15.15 & \\ \text { SP (G) } & 64 & 1.15 & \\ \text { CGP } & 4 & 4.12 & \\ \text { CSP (G) } & 64 & 1.07 & \\ & & & \end{array}$




\section{Table E: 4}

\section{Summary of Analysis of Variance Under Free}

Recall Criterion--Using Five-letter Sequences

\begin{tabular}{|c|c|c|c|}
\hline Source & $\underline{\text { df }}$ & Mean Square & $\mathbf{F}$ \\
\hline Subjects (S) & & & \\
\hline Case (C) & 1 & 5.03 & 0.40 \\
\hline Groups (G) & 1 & 530.77 & $70.10 * *$ \\
\hline Position (P) & 4 & 0.93 & 2.08 \\
\hline$S$ (G) & 16 & 7.57 & \\
\hline $\mathrm{CG}$ & 1 & .0 .87 & 0.07 \\
\hline CP & 4 & 0.34 & 0.71 \\
\hline GP & 4 & 0.84 & 1.87 \\
\hline $\operatorname{Cs}(G)$ & 16 & 12.58 & \\
\hline SP (G) & 64 & 0.45 & \\
\hline CGP & 4 & 0.49 & 1.01 \\
\hline $\operatorname{CSP}(G)$ & 64 & 0.48 & \\
\hline
\end{tabular}


APPENDIX F

Summary of Confusion Matrices

(Experiments 1 and 2) 
Summary of Product Moment Correlations for Both Free and Ordered Recall

(Experiment 1)

Key Upper Diagonal: Free Recal1

Lower " : Ordered Recall 


\begin{tabular}{|c|c|c|c|c|c|c|c|c|c|c|c|c|c|c|}
\hline & & & HEA & ING & & & ANUAL & DEAF & & & RAL D & EAF & & \\
\hline & & $E$ & $t$ & G & $\widetilde{H}$ & 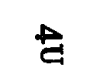 & 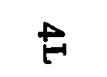 & u & $\widetilde{U}$ & e & $\notin$ & G & u & \\
\hline & $4 U$ & - & .25 & .15 & .19 & .23 & .28 & .01 & .18 & -.04 & .21 & .27 & .28 & $4 \mathrm{U}$ \\
\hline HEARING & $4 \mathrm{~L}$ & .52 & - & .09 & .26 & .21 & .13 & .02 & .05 & -.01 & .12 & .30 & .18 & $4 \mathrm{~L}$ \\
\hline & $5 \mathrm{U}$ & .41 & .54 & - & .18 & .11 & -.08 & .28 & .11 & .34 & -.11 & .12 & .22 & $5 \mathrm{U}$ \\
\hline & $5 L$ & .29 & .57 & .43 & - & .13 & .41 & -.10 & .16 & -.03 & .55 & .08 & .27 & $5 \mathrm{~L}$ \\
\hline & $4 U$ & .08 & .15 & .05 & -.02 & - & .29 & .42 & .53 & .36 & .24 & .23 & .32 & $4 U$ \\
\hline MANUAL & $4 \mathrm{~L}$ & -.03 & .04 & .02 & .36 & .10 & - & .05 & .56 & .02 & .88 & .20 & .55 & $4 \mathrm{~L}$ \\
\hline DEAF & $5 \mathrm{U}$ & -.15 & -.13 & .16 & .06 & .33 & .30 & - & .50 & .51 & .06 & .17 & .21 & $5 U$ \\
\hline & $5 \mathrm{~L}$ & -.05 & .09 & .13 & .23 & .31 & .41 & .66 & - & .38 & .50 & .34 & .48 & $5 \mathrm{~L}$ \\
\hline & $4 \mathrm{U}$ & .06 & .04 & .33 & .07 & .23 & -.01 & .39 & .27 & - & .04 & .13 & .14 & $4 \mathrm{U}$ \\
\hline ORAL & $4 \mathrm{~L}$ & .03 & .13 & .04 & .49 & .01 & .85 & .18 & .38 & .02 & - & .18 & .55 & $4 \mathrm{~L}$ \\
\hline DEAF & $5 \mathrm{U}$ &. .06 & .21 & .14 & .13 & -.05 & .13 & .25 & .32 & .07 & .16 & - & .38 & $5 \mathrm{U}$ \\
\hline & $5 \mathrm{~L}$ & .08 & .14 & .20 & .34 & .02 & .51 & .35 & .47 & .05 & .56 & .38 & - & $5 \mathrm{~L}$ \\
\hline
\end{tabular}




\begin{tabular}{|c|c|c|c|c|c|c|c|c|c|}
\hline & & & 旁 & 舀 & & & 병 & 乩 & \\
\hline & $4 \mathrm{U}$ & - & .08 & .38 & -.03 & .13 & .01 & -.09 & .11 \\
\hline MANUAL & $4 \mathrm{~L}$ & .06 & - & .00 & .72 & .11 & .77 & .07 & .53 \\
\hline DEAF & $5 \mathrm{U}$ & .05 & .20 & - & .18 & .00 & .07 & .03 & .13 \\
\hline & $5 \mathrm{~L}$ & .09 & .38 & .19 & - & -.08 & .87 & -.12 & .36 \\
\hline & $4 U$ & .13 & .20 & .32 & .12 & - & -.04 & .38 & .21 \\
\hline ORAL & $4 L$ & .05 & .46 & .48 & .66 & .29 & - & .00 & .63 \\
\hline DEAF & $5 \mathrm{U}$ & .11 & .15 & .13 & -.10 & .29 & .22 & - & .52 \\
\hline & $5 \mathrm{~L}$ & -.03 & .27 & .23 & .53 & .32 & .50 & .18 & - \\
\hline
\end{tabular}

Summary of Product Moment Correlations, Ordered and Free Recall Criterion (Experiment 2)

Key: Upper Diagonal: Free Recal1

Lower " : Ordered Recall 
APPENDIX G

Facial Recognition Stimuli

(Experiment 3)

\begin{abstract}
Index
G:1 -- Inspection Series--Male Stimuli

G:2 -- Test Series--Male Stimuli

G:3 -- Inspection Series--Female Stimuli

G:4 - Test Series--Female Stimuli

G:5 -- Inspection Series-Male \& Female Stimuli

G:6 - Test Series--Male \& Female Stimuli
\end{abstract}




\section{INSPECTION SERIES}
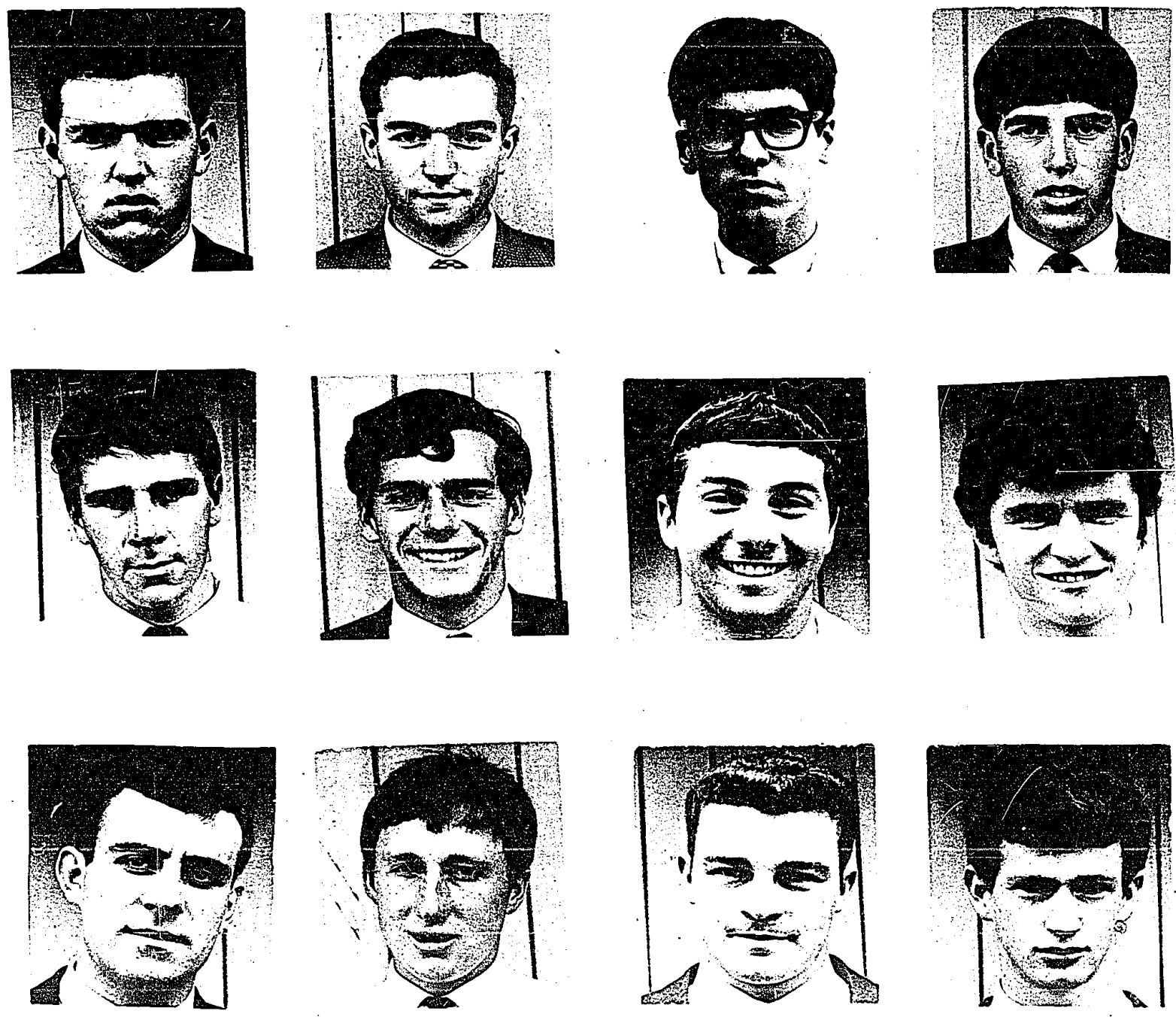


\section{INSPECTION SERIES}
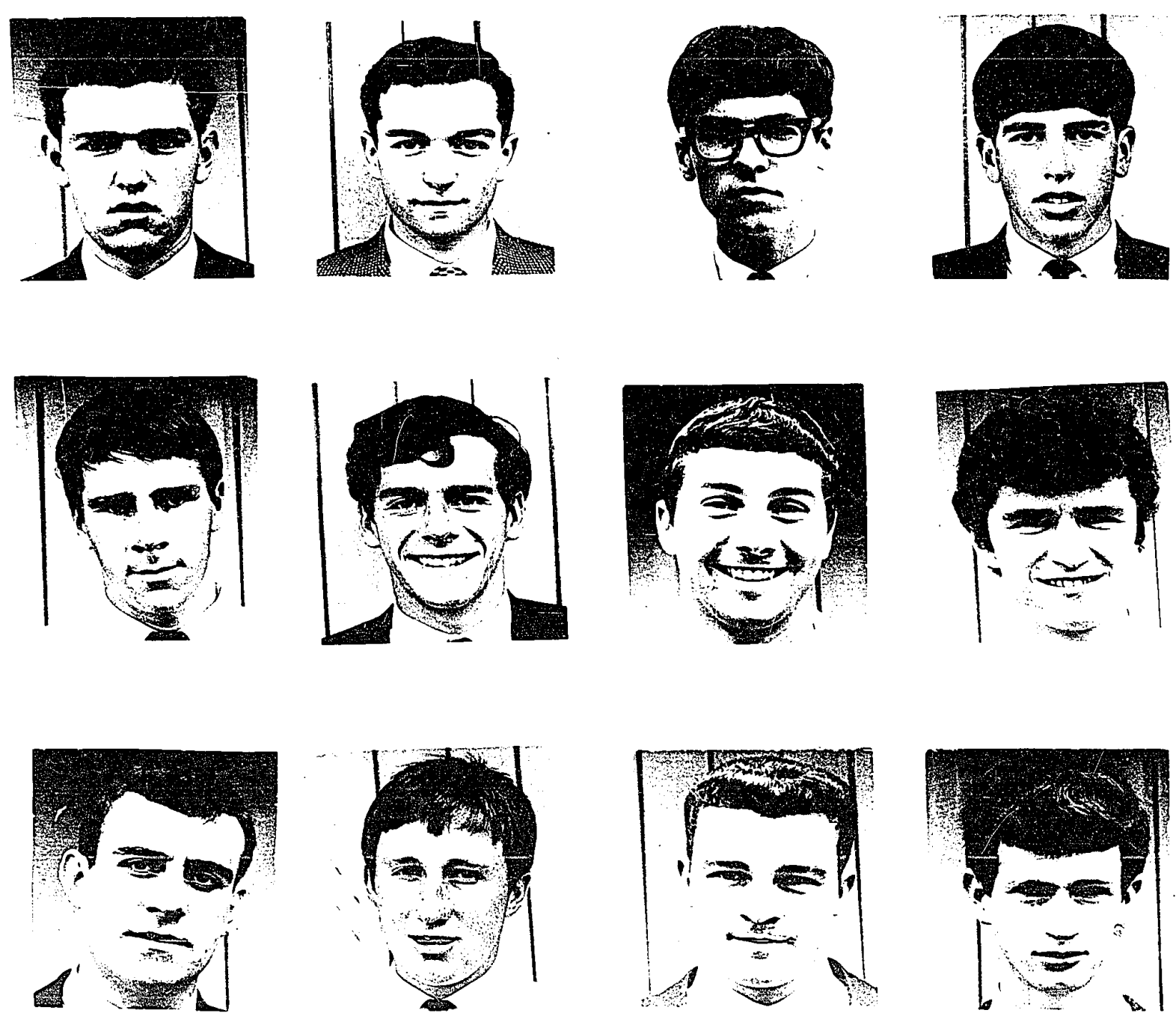
1

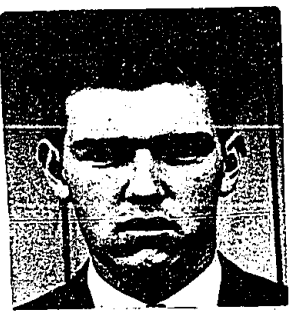

6

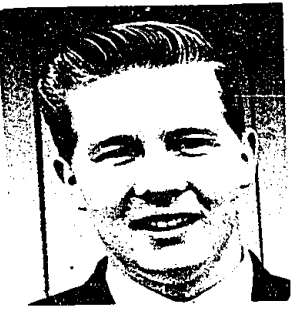

11

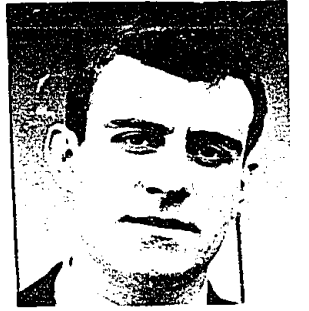

10

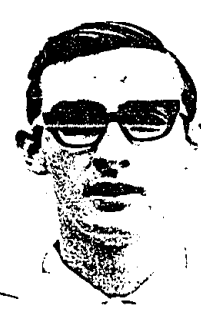

7

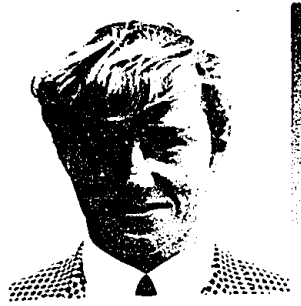

12

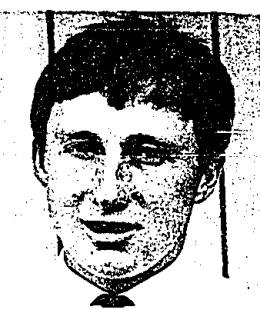

17

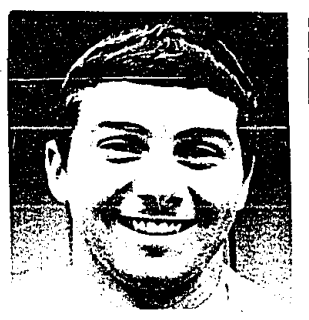

8

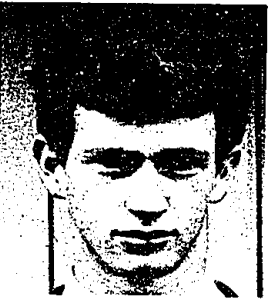

13
4

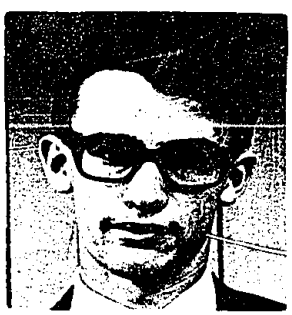

9

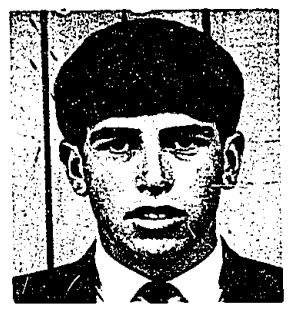

14

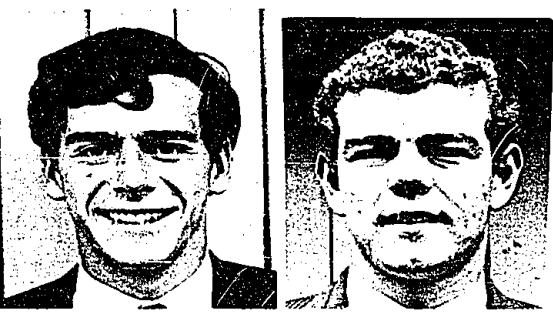

18

19

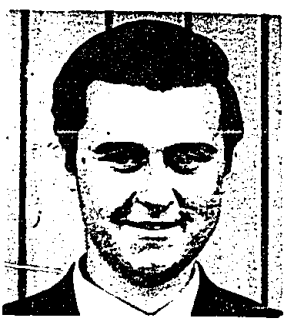

10

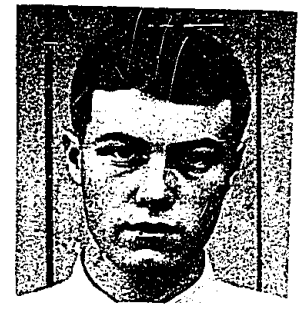

15

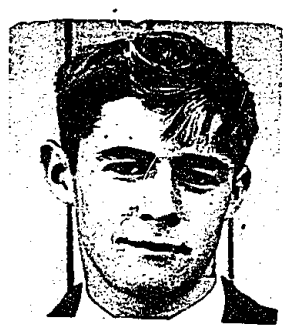

20

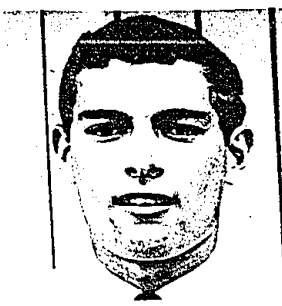

21

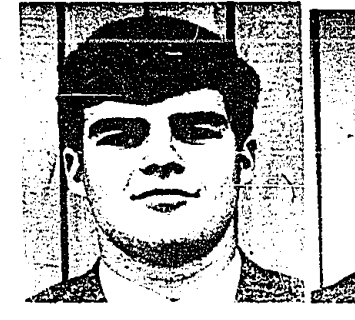

22

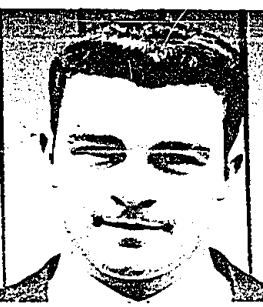

23

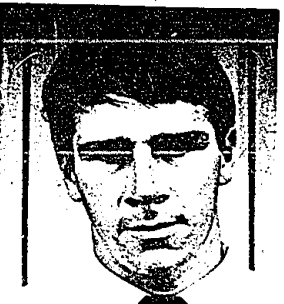

24

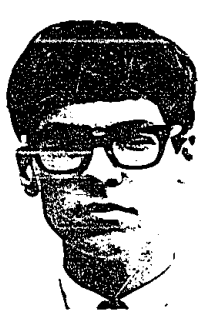

25
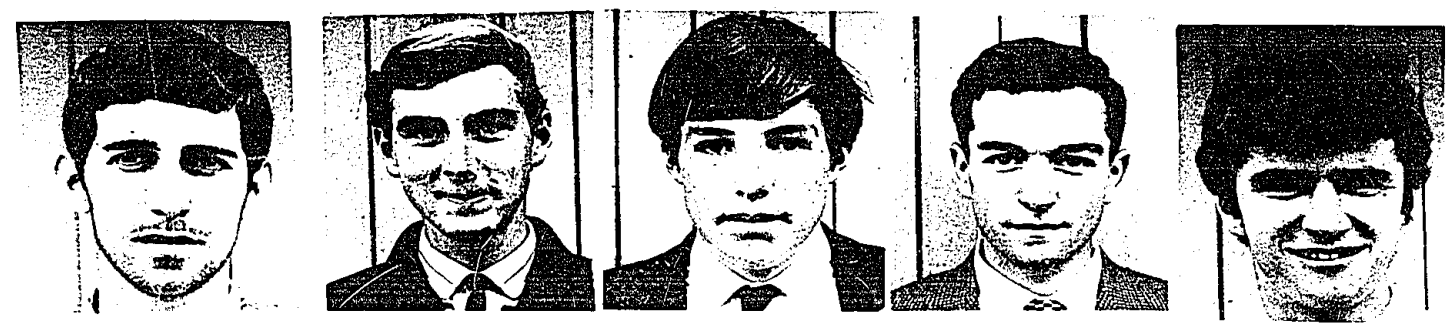
1

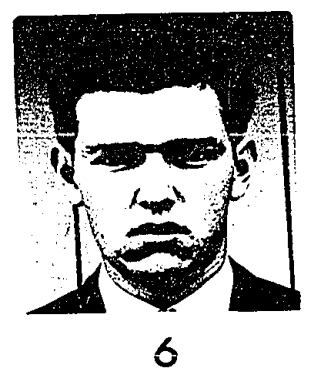

6

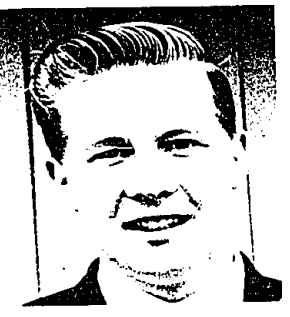

11

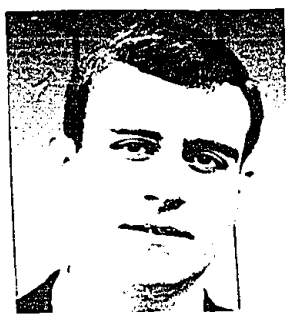

16
2
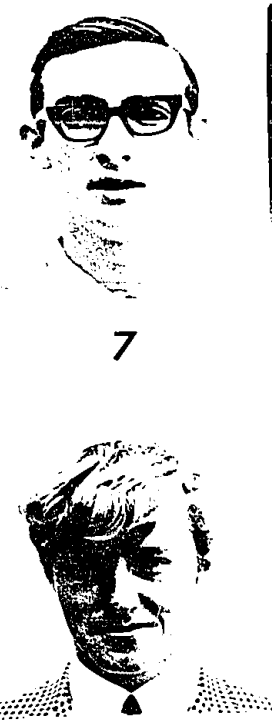

12

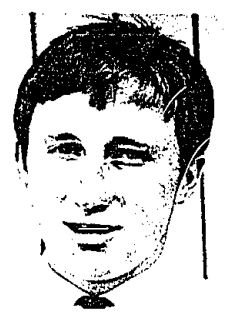

17
3

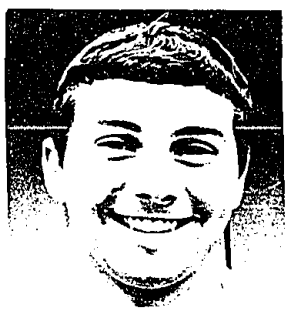

8
4

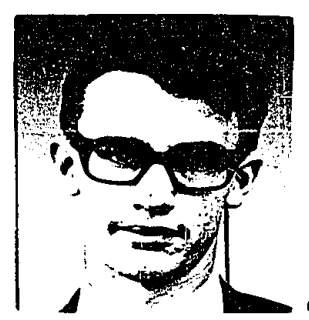

9

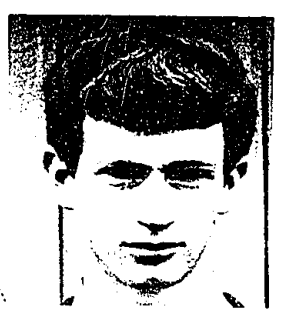

13

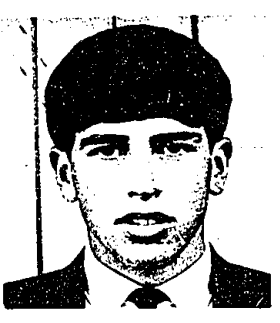

14

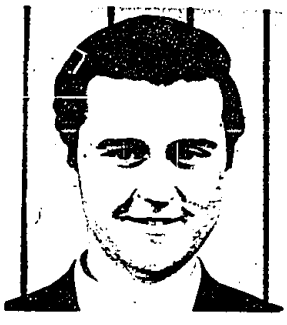

10

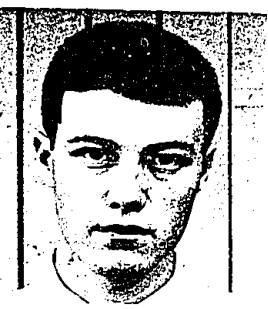

15
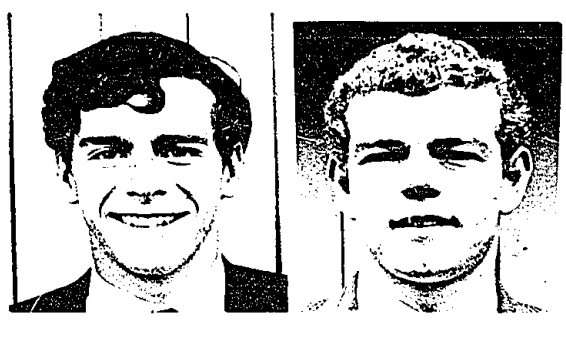

19

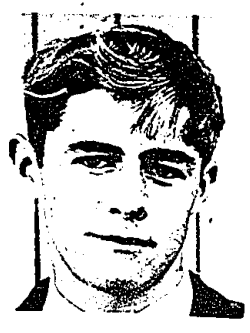

20

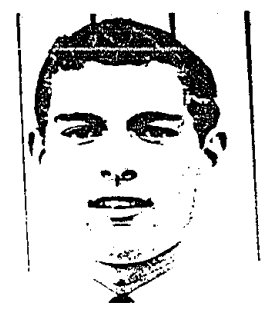

21

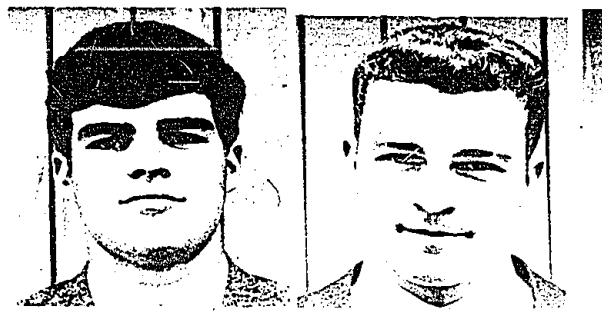

22

23

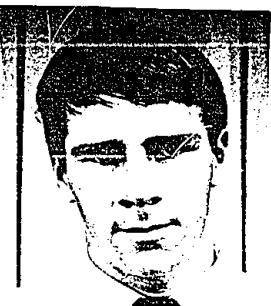

24

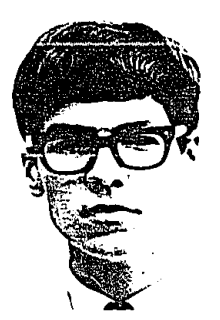

25
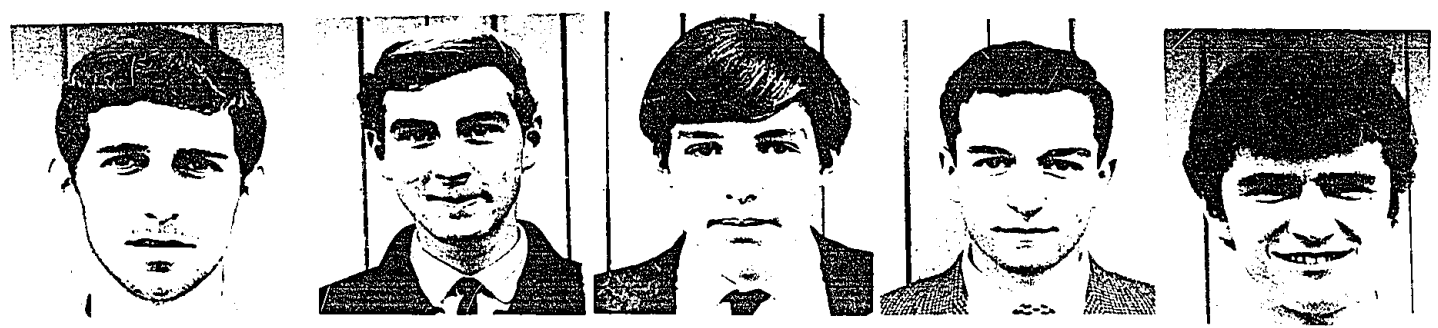


\section{INSPECTION SERIES}
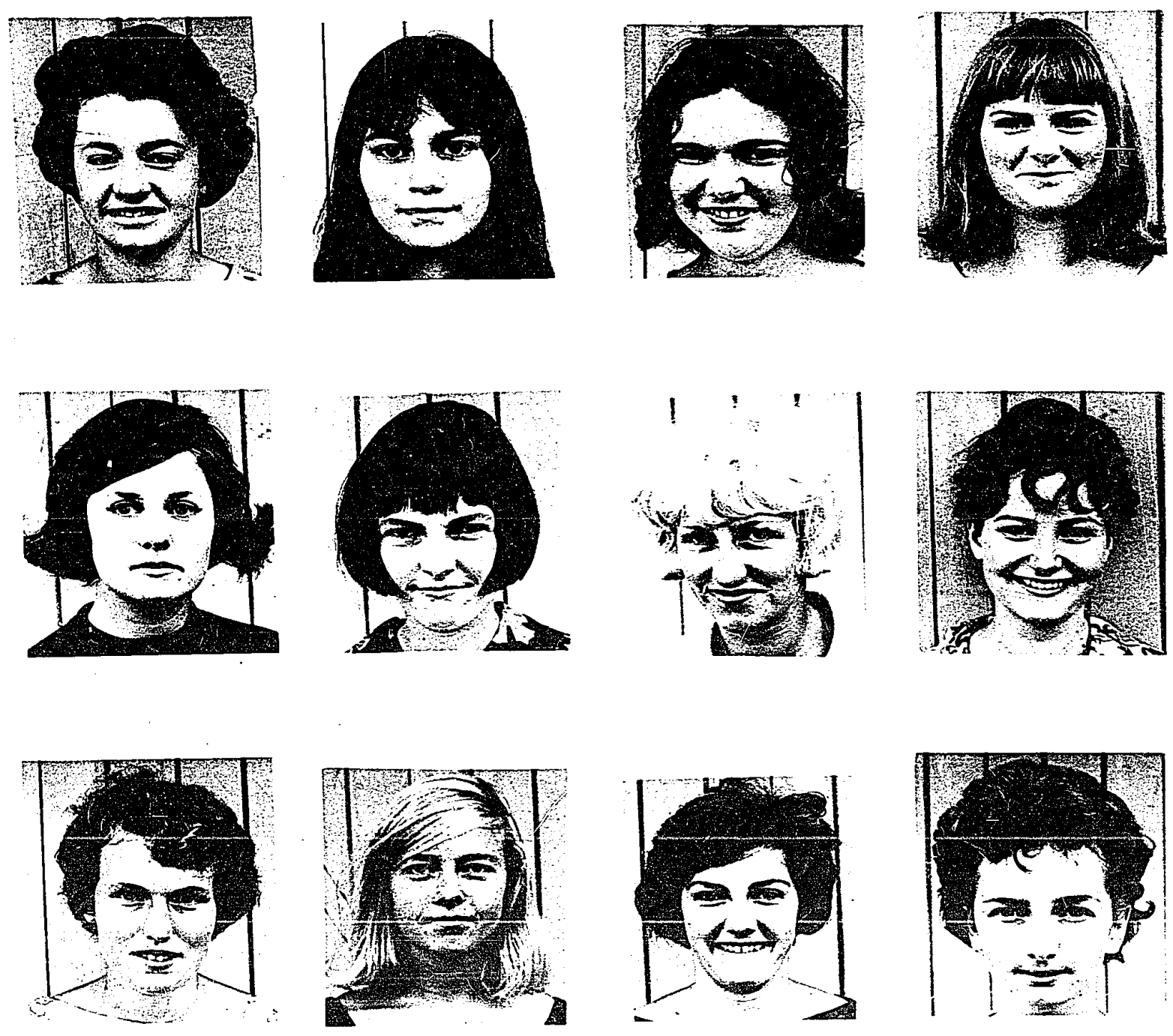


\section{INSPECTION SERIES}
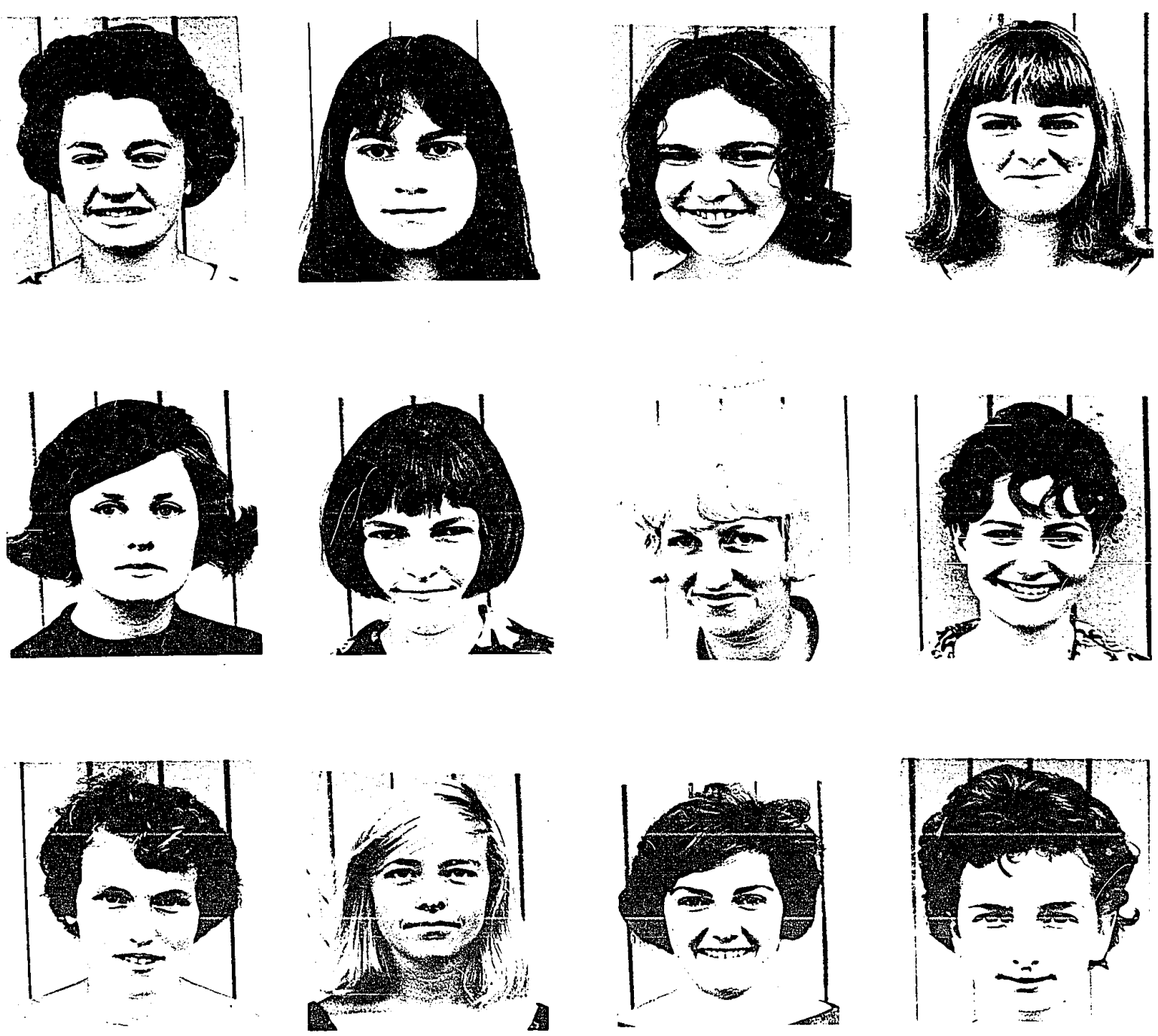

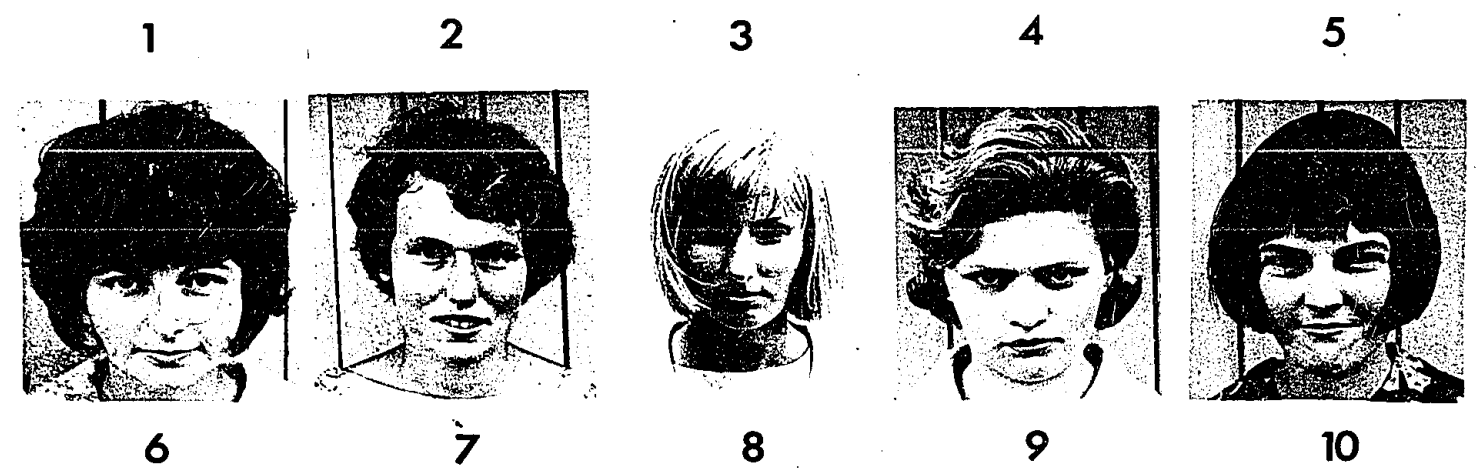

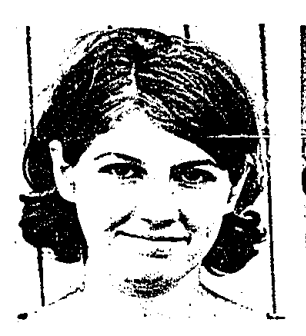

11

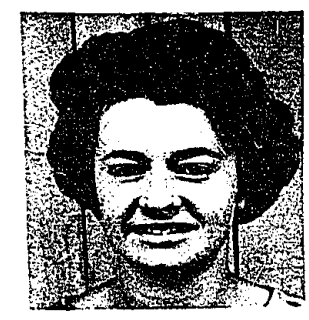

16

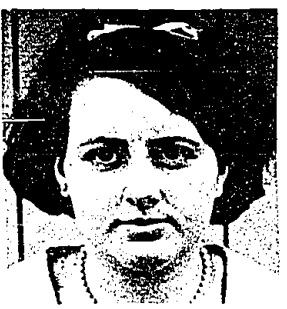

12

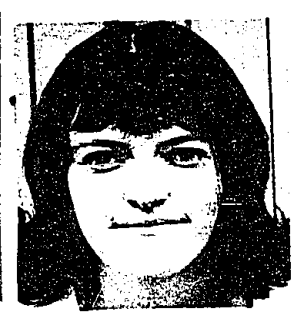

17

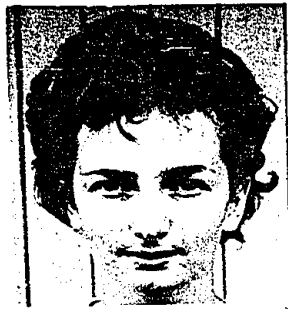

13

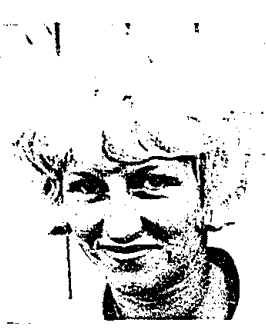

14

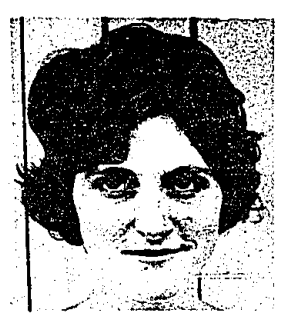

18

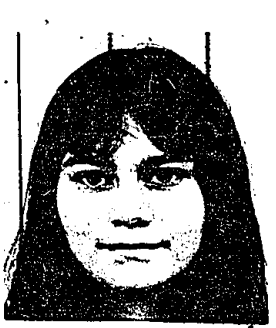

19

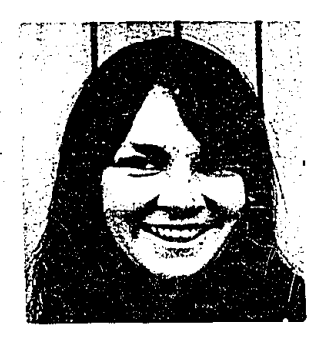

15
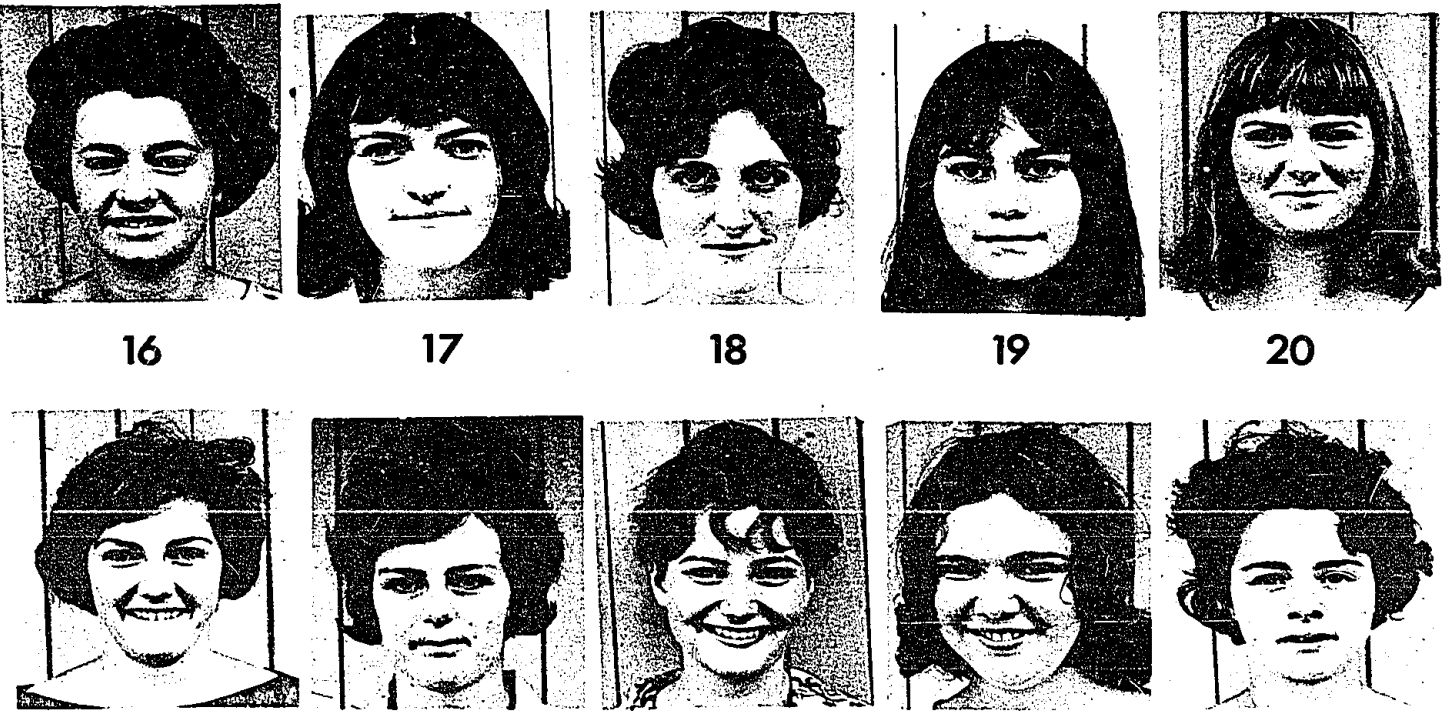

20

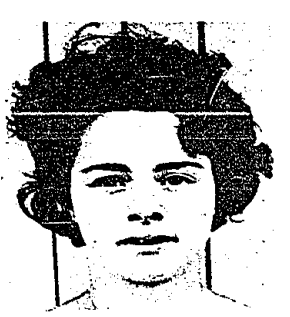

$$
21
$$

22

23

$$
24
$$

25
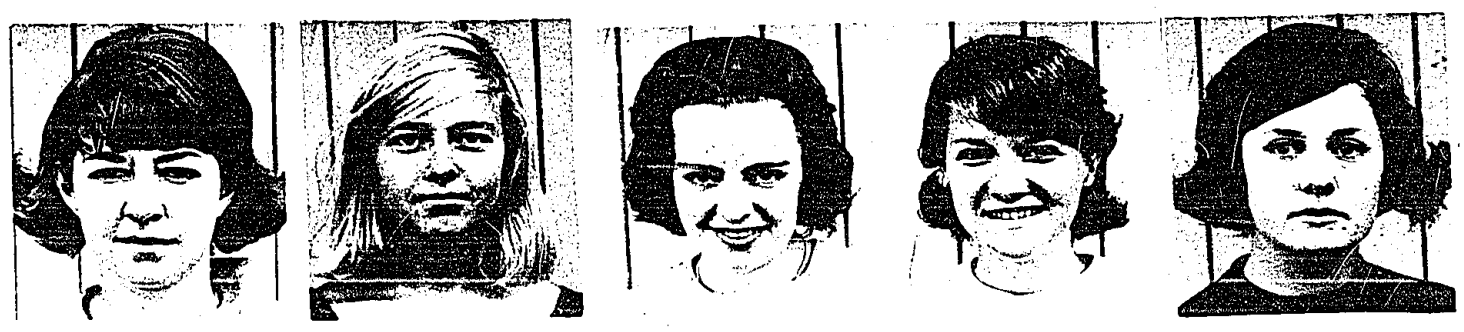


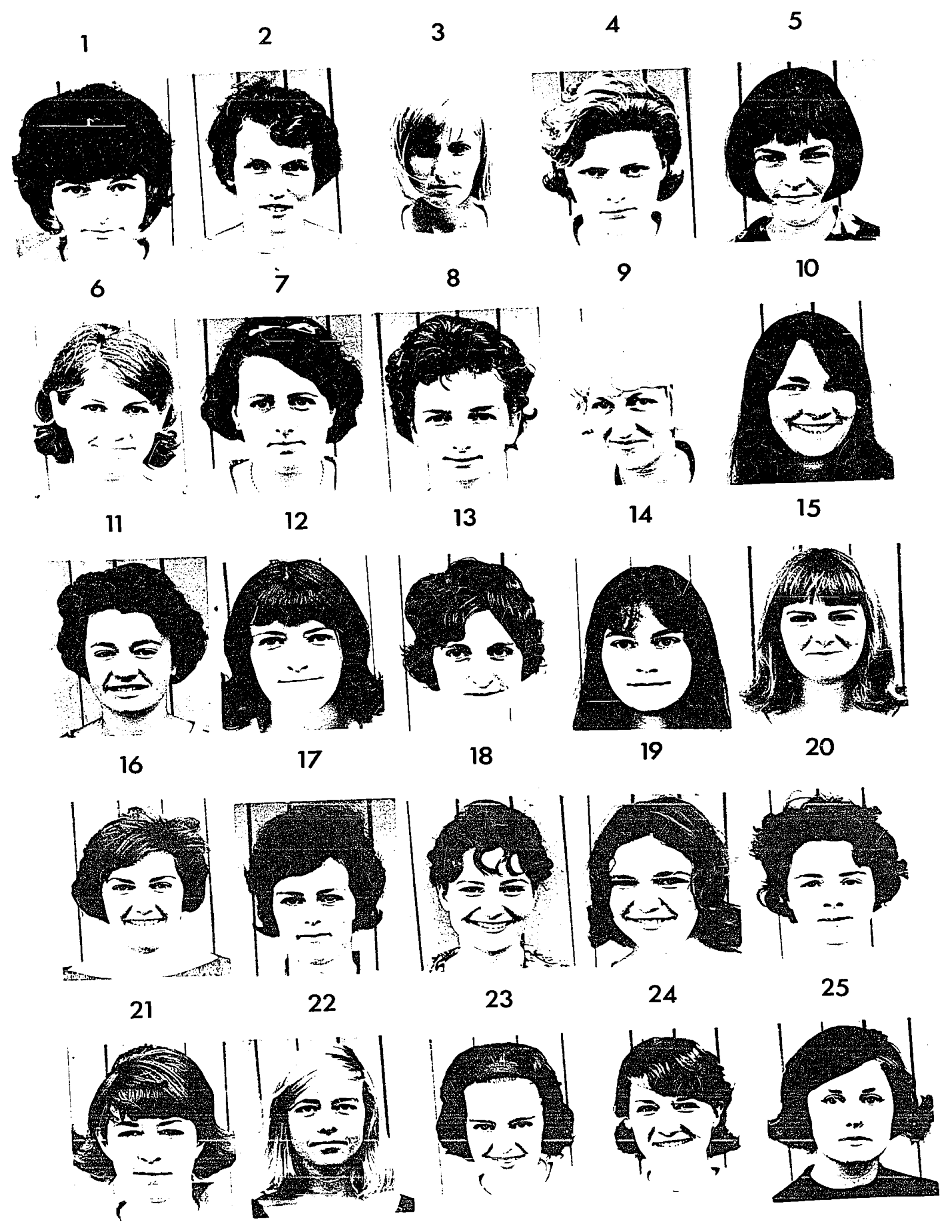




\section{INSPECTION SERIES}
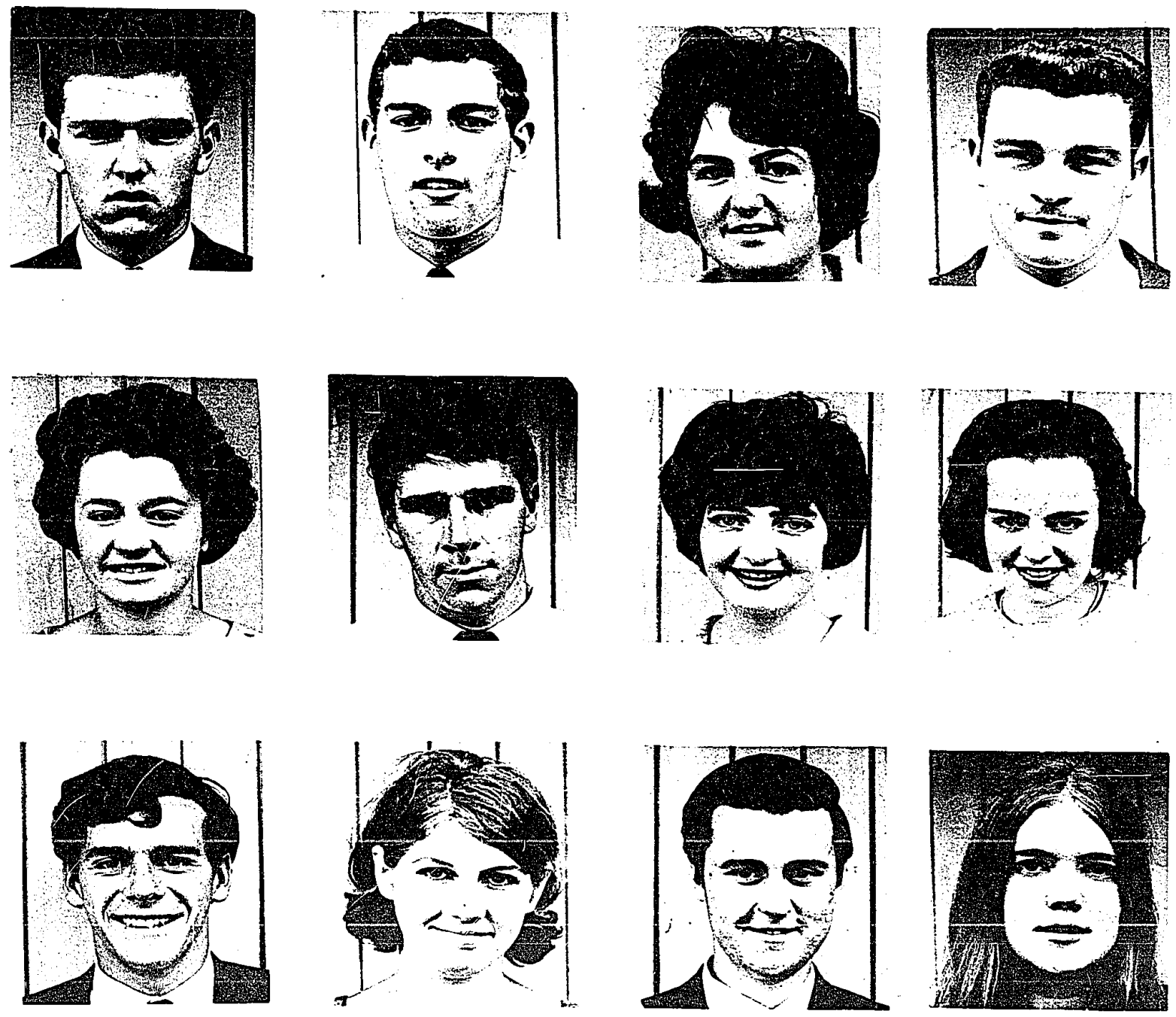


\section{INSPECTION SERIES}
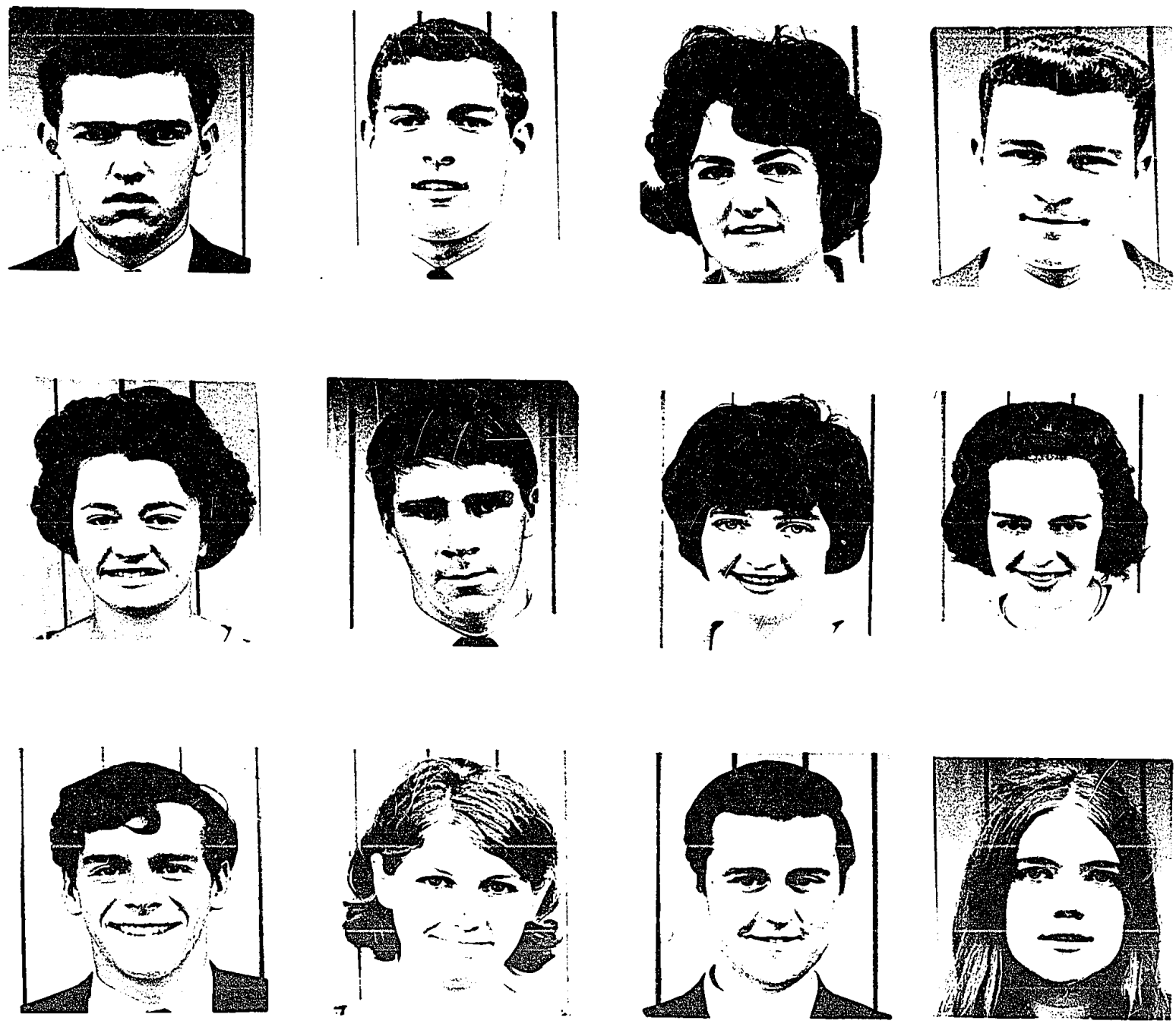

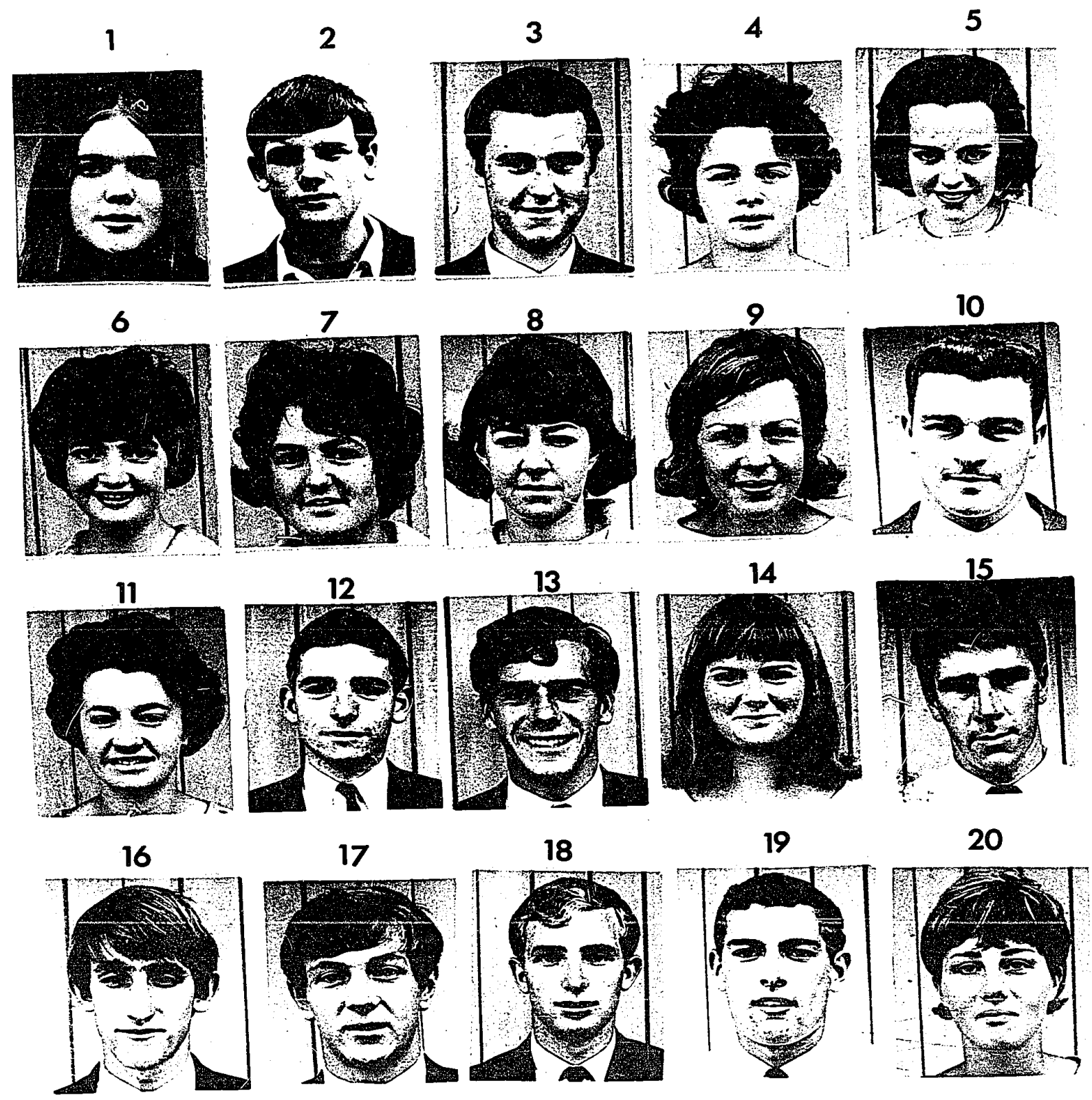

21

22

23

24

25
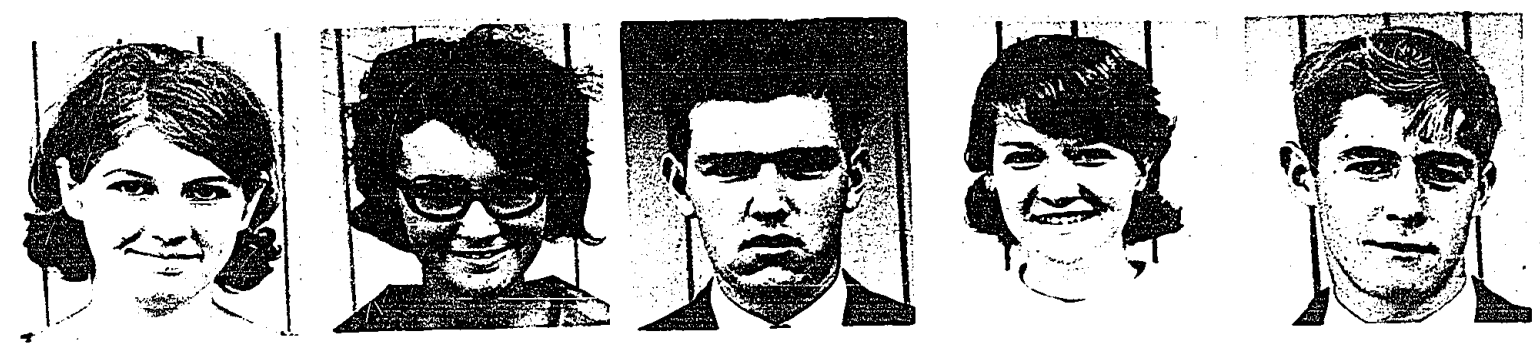


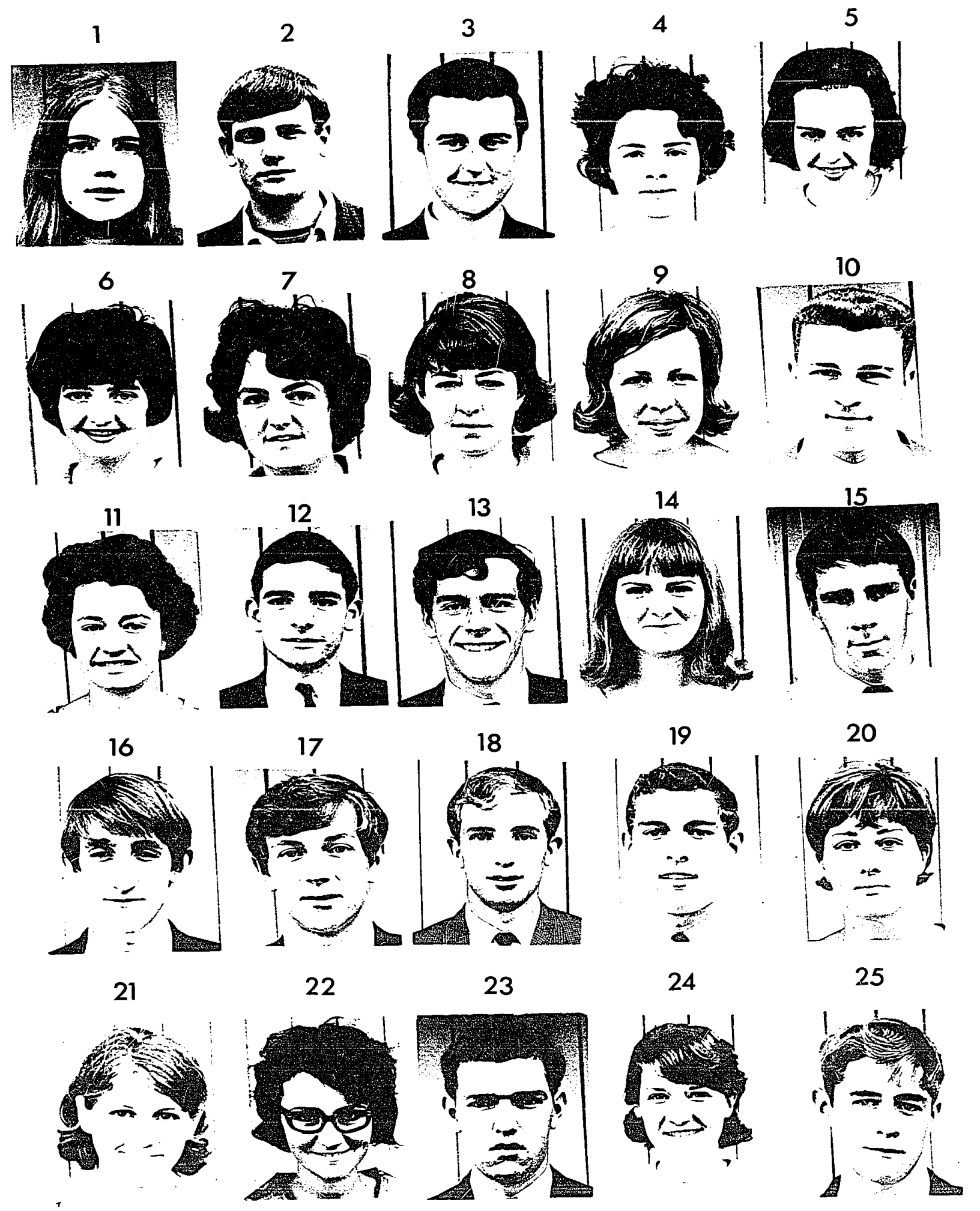


APPENDIX $H$

Summary of Analysis of Variance (Experiment 3) 
Table $H: 1$

\section{Summary of Analysis of Variance \\ for Facial Recognition Task}

\section{Source}

Subjects

Groups

Faces

$S$ (G)

G $\mathbf{X}$

SF (G) df

2

2

27

4

54
Mean Square

10.03

2.33

3.15

2.02

0.42

$$
\begin{aligned}
& * * \mathrm{p}<.01 \\
& \mathrm{~F} \quad 2,27 \mathrm{p}<.05=3.35
\end{aligned}
$$

